\title{
WestVirginiaUniversity
}

THE RESEARCH REPOSITORY @ WVU

Graduate Theses, Dissertations, and Problem Reports

2014

\section{Exploring the Components of Prenatal Anxiety}

\author{
Suzan Walsh Clemens \\ West Virginia University
}

Follow this and additional works at: https://researchrepository.wvu.edu/etd

\section{Recommended Citation}

Clemens, Suzan Walsh, "Exploring the Components of Prenatal Anxiety" (2014). Graduate Theses, Dissertations, and Problem Reports. 245.

https://researchrepository.wvu.edu/etd/245

This Dissertation is protected by copyright and/or related rights. It has been brought to you by the The Research Repository @ WVU with permission from the rights-holder(s). You are free to use this Dissertation in any way that is permitted by the copyright and related rights legislation that applies to your use. For other uses you must obtain permission from the rights-holder(s) directly, unless additional rights are indicated by a Creative Commons license in the record and/ or on the work itself. This Dissertation has been accepted for inclusion in WVU Graduate Theses, Dissertations, and Problem Reports collection by an authorized administrator of The Research Repository @ WVU.

For more information, please contact researchrepository@mail.wvu.edu. 


\title{
Exploring the Components of Prenatal Anxiety
}

Suzan Walsh Clemens, M.S.

\author{
Dissertation submitted \\ to the Eberly College of Arts and Sciences \\ at West Virginia University \\ in partial fulfillment of requirements for the degree of \\ Doctor of Philosophy in \\ Clinical Psychology
}

\author{
Daniel W. McNeil, Ph.D., Chair \\ Ellesa Clay High, Ph.D. \\ Elisa Krackow, Ph.D. \\ Kevin T. Larkin, Ph.D. \\ Aaron Metzger, Ph.D. \\ Department of Psychology
}

Morgantown, West Virginia

2014

Keywords: Prenatal Anxiety, Perinatal Anxiety, Antenatal Anxiety, Childbirth, Pregnancy

Copyright 2014 Suzan Walsh Clemens 


\section{ABSTRACT \\ Exploring the Components of Prenatal Anxiety}

\section{Suzan Walsh Clemens, M.S.}

Anxiety and fear often are associated with pregnancy, and its short- and long-term biological, psychological, and social lifestyle changes that affect both the mother and the child. The primary aim of this study was to differentiate components of prenatal anxiety and fear, to facilitate operational classifications of those components. A better understanding of prenatal anxiety and fear can inform the creation of future measures and facilitate referrals for high levels of such distress. An exploratory descriptive research design was used to examine potential components of prenatal anxiety and fear (i.e., anxiety sensitivity, fear of pain, depression, and childbirth-related self-efficacy). The project involved a cross-sectional data collection from a heterogeneous community sample of pregnant women $(N=102)$ who attended the West Virginia University Healthcare - Obstetric and Gynecology Clinic, Morgantown, WV. The women were scheduled for delivery either by a vaginal $(n=91)$ or an operative (Cesarean, $n=11)$ birth. Data were examined using the cluster analyses techniques of Ward's hierarchical and $k$-means methods. A four-factor solution was chosen as the most parsimonious. Cluster 1 had high emotionality (i.e., anxiety sensitivity, depression), high fear of pain, and low childbirth-related self-efficacy. Cluster 2 was low on emotionality, but had high fear of pain levels, with low selfefficacy. Cluster 3 was low on emotionality, but had low fear of pain and high self-efficacy. Cluster 4 had high emotionality, low fear of pain and high self-efficacy. The clusters significantly differed on six of the seven variables associated with prenatal anxiety. Overall, the clusters were well differentiated, with implications for treatment and referral. Limitations and future directions were discussed. 


\section{Acknowledgements}

The Ph.D. road frequently is filled with potholes and detours, and my road was no exception. The support and mentorship of several people were vital in re-directing me and helping me re-pave my way.

Foremost is my husband, James Hatcher. He has given me his wholehearted support throughout the years needed by the process. In addition, when a health-related detour appeared, he took leave from work to assist me. Regardless of the terrain, he weathered my storms. He champions me when I am down, and extends his help when needed. I treasure him as a fellow life-traveler.

Behind my husband are our children and their spouses. When things would become tough, they would encourage me, always telling me "You are the key. You can do it!" and ready to celebrate when I did. They always believed in me, even when I was not exactly sure of myself.

My advisor, Daniel W. McNeil, has been with me from the beginning. He, also, was there on the detours. Through high and low roads, he has always been a loyal supporter. He is excited about what we do, and he can be counted on for innovative solutions to roadblocks and his friendship.

My clinical director, Kevin T. Larkin, always has his door open. He was receptive to hearing about my frustrations and dilemmas, and willing to problem-solve and assist in any way he could.

The faculty of West Virginia University’s Psychology Department were continually supportive in too many ways to mention, large and small. 
Last, but in no way least, is my contingent of graduate student friends. They welcomed me regardless of the age gap. They supported me when I needed it, and they celebrated me when I met milestones, large or small. They have become a part of my family, and I continue to treasure their friendship. 


\section{Table of Contents}

Introduction: Exploring the Components of Prenatal Anxiety 7

$\begin{array}{ll}\text { Stress, Anxiety, and Fear during Pregnancy and Childbirth } & 7\end{array}$

$\begin{array}{lr}\text { Emotional Issues Surrounding Childbirth } & 12\end{array}$

$\begin{array}{ll}\text { Prenatal anxiety and depression } & 13\end{array}$

$\begin{array}{ll}\text { Prenatal anxiety and fear } & 14\end{array}$

$\begin{array}{ll}\text { Prenatal anxiety and pain } & 21\end{array}$

$\begin{array}{ll}\text { Prenatal anxiety and self-efficacy } & 23\end{array}$

Components of Prenatal Anxiety 25

Preliminary Data for a Comprehensive Model 28

$\begin{array}{ll}\text { Statement of the Problem } & 29\end{array}$

$\begin{array}{ll}\text { Focus of this study } & 30\end{array}$

$\begin{array}{ll}\text { Method } & 31\end{array}$

Research Design and Analysis Plan Overview 31

Stage 1 - Cluster analysis $\quad 31$

Stage 2 - Analyses of variance $\quad 34$

$\begin{array}{ll}\text { Setting and Participants } & 34\end{array}$

$\begin{array}{ll}\text { Measures } & 35\end{array}$

$\begin{array}{ll}\text { Procedure } & 39\end{array}$

$\begin{array}{ll}\text { Variables for Analyses } & 39\end{array}$

$\begin{array}{lr}\text { Results } & 40\end{array}$

Data Reduction and Management $\quad 40$

$\begin{array}{ll}\text { Stage } 1 \text { - Cluster Analysis } & 41\end{array}$ 
Ward's method cluster analysis $\quad 41$

One-way ANOVAs on clustering variables 43

One-way ANOVAS and Kruskal-Wallis algorithms on

demographic variables $\quad 44$

K-means cluster analysis and one-way ANOVAs on

clustering variables

One-way ANOVAs and Kruskal-Wallis tests on

demographic variables

Stage 2 - Analyses of Variance

45

Interpretation of the Cluster Solution

46

Discussion

48

Limitations

53

Future Directions

53

$\begin{array}{ll}\text { Conclusions } & 54\end{array}$

$\begin{array}{ll}\text { References } & 55\end{array}$

$\begin{array}{ll}\text { Appendices } & 75\end{array}$

$\begin{array}{ll}\text { Tables } & 89\end{array}$

$\begin{array}{ll}\text { Figures } & 105\end{array}$ 


\section{Exploring the Components of Prenatal Anxiety}

Childbirth is associated with short- and long-term biological, psychological, and social (e.g., lifestyle) changes for the mother (Austin, Priest, \& Sullivan, 2008). Due to these changes, and anticipation of the birthing process, moderate levels of anxiety are normal during pregnancy; these levels of anxiety typically are congruent with the anticipated stressors of childbirth and parenthood (Wenzel, 2011). Lee et al. (2007) observed the extent of such anxiety in a study in which $54 \%$ of the 357 women who participated reported symptoms of anxiety at least one time during their pregnancy. For some women, anxiety can manifest at high degrees or increase in magnitude until it negatively affects their lives, the lives of their children, and the lives of their families (Austin, Priest, \& Sullivan, 2008; Buist, Ross, \& Steiner, 2006). Because of the negative effects associated with anxiety and other psychological disorders, the American Psychological Association Summit on Women and Depression in 2000 declared the psychological status of a woman during her childbearing years a major public health issue (Mazure, Keita, \& Blehar, 2002).

\section{Stress, Anxiety, and Fear during Pregnancy and Childbirth}

Stress is defined as any emotional or physical demand on the mind or body, such as pregnancy, childbirth, participation in a bicycle race, taking a psychology exam, or disease, that produces an actual or anticipated disruption of an individual's internal balance (i.e., homeostasis) (Selye, 1976; Ulrich-Lai \& Herman, 2009). Homeostasis is the body's way of maintaining a relatively stable condition while adapting to fluctuating internal and external environmental factors (Ulrich-Lai \& Herman, 2009). When a physical or cognitive stress antecedent (i.e., stressor) is perceived or anticipated, a physiological stress response is initiated. The presumed purpose of the response is to handle the stressor and restore homeostasis. The response includes 
the activation of the autonomic nervous system and the hypothalamic-pituitary-adrenal axis (Ulrich-Lai \& Herman, 2009). When the hypothalamic-pituitary-adrenal axis is activated, it produces a cascade of hormones that includes corticotrophin-releasing hormone, adrenocorticotropic hormone, and cortisol (Chrousos, 2009). This change in hormonal balance affects several systems and their functions, including the cardiovascular system, the digestive system, and the reproductive system (e.g., uterine contractions) (Kuo, Chen, Yang, Lo, \& Tsai, 2000). The subsequent bodily changes also may be associated with anxiety and fear. An indepth discussion of stress, anxiety, and fear is beyond the scope of this paper. These topics will be addressed briefly, however, in relation to their association with childbirth.

Many hormone levels vary widely from their normal levels throughout pregnancy. One of those hormones is cortisol. In the stress response, cortisol is a fundamental hormone. Increased levels of cortisol result in greater blood sugar levels and suppression of the activity of the immune system, in addition to aiding in the metabolism of nutrients. Evolutionarily, these changes prepare the body to protect itself by restraining bodily functions that are nonessential in a threat situation and enhancing the availability of glucose for muscle activity. This process has been named the "flight-or-fight response." Cortisol also is important in fetal lung development. Due to placental and fetal production, a woman's cortisol levels are elevated during pregnancy, reaching levels three times higher than normal by labor (Wenzel, 2011).

Progesterone is a hormone that promotes embryogenesis and supports gestation, so it too is elevated during pregnancy. Research shows that progesterone is involved in activity in the amygdala and hippocampus, brain regions that are integral to fear and anxiety responses (Dreher et al., 2007). Work by Felmingham, Fong, and Bryant (2012) revealed that high progesterone 
levels were associated with "higher baseline and stress-evoked cortisol levels" in relation to threat stimuli (p. 1896).

Due to shared hormonal etiology, anxiety and pregnancy have common somatic manifestations. An example of this shared somatic expression is hyperventilation, which is initiated by progesterone. Hyperventilation is a symptom of pregnancy and panic disorder (Bayliss \& Millhorn, 1992; Wenzel, 2011). Wenzel (2011) speculates that the physical sensations associated with the hormonal changes during pregnancy may trigger heightened anxiety in women who have increased sensitivity toward physical stress symptoms, which is one component of anxiety sensitivity (Kemper, Lutz, Bähr, Rüddel, \& Hock, 2012). Unfortunately, there is a lack of human research in relation to how stress hormones interact with other hormones during pregnancy.

Pregnancy and childbirth are physically and emotionally stressful events, and one way to assess such stress is to measure stress hormone levels (Alehaagen, Wijma, Lundbert, Melin, \& Wijma, 2001). Alehagen, Wijma, and Lundberg (2001) found significant changes from early pregnancy to labor in the amount of maternal stress hormones, with levels of adrenaline and cortisol increasing more than 500\% and noradrenaline increasing by 50\%. Catecholamine stress hormones (e.g., adrenaline and noradrenaline) were found negatively to affect uterine contractility during labor, possibly resulting in the need for labor augmentation and other obstetrical interventions (Brand \& Brennan, 2009; Soucasaux, 1993).

As stated earlier, anxiety and fear are part of the stress response repertoire. Both constructs seem to share common antecedents and responses and are associated with threat perception (Barlow, 2002). Due to their perceived common behavioral, psychological, physiological, and cognitive components, the terms anxiety and fear frequently are used 
synonymously. They are, however, distinct states (Barlow, 2002; Carleton, Abrams, Asmundson, Antony, \& McCabe, 2009; Craske, Antony, \& Barlow, 2006; Davis, 1992; Lang \& McTeague, 2009; Leeuw, Goossens, Linton, Crombez, Boersma, \& Vlaeyen, 2007; Marks, 1987; McNeil, Ries, Turk, \& Vargovich, 2010). Commonalities between fear and anxiety include the arousal of the autonomic nervous system and their elicitation either by internal stimuli such as thoughts and increased heart rate or external stimuli such as seeing a snake or hearing a newscast about a possible tornado. The type of stimuli, behavioral responses, and brain activity associated with fear and anxiety, however, may differ.

Fear is related to external, proximal stimuli that are perceived as immediately dangerous. Responses associated with fear are rapid physiological hyperarousal with high visceral activation of defensive behaviors and include withdrawal, submission, aggression, and immobility. Fear is characterized by less cognitive processing, with mental processing having a visual focus. In relation to brain structure, fear is associated primarily with activity in the amygdala and the periaqueductal gray matter (Grillon, 2008; LeDoux, 2002). In contrast, anxiety is more likely elicited by internal stimuli associated with an anticipated and worrisome future event (Barlow, 2002). Anxiety involves sustained low-level physiological arousal, heightened sensory sensitivity (e.g., hypervigilance), high verbally-focused cognitive processing, and preventative/avoidant behaviors. Anatomically, anxiety is linked with the activation of the bed nucleus of the stria terminalis and the hippocampus (Grillon, 2008; LeDoux, 2002).

Although fear and anxiety are separate constructs, they are highly associated; they can act as antecedents for each other (McNeil, Ries, Turk, \& Vargovich, 2010). Acknowledging that anxiety and fear are separate constructs, due to the transposable use of the words anxiety and fear 
in research, the terminology used in this study will reflect the usage of the cited authors. Otherwise, the phrases anxiety or prenatal anxiety will be used to describe both states.

Anxiety is one of the earliest occurring of the psychological mood states, manifesting in childhood (Leonardo \& Hen, 2008). In the USA, the prevalence rates for anxiety disorders are $18.1 \%$ over 12 -months and $35.5 \%$ for lifetime (National Institute of Mental Health, 2011). There also is a sex-related factor with females being $60 \%$ more likely than males to experience an anxiety disorder in their lifetime (Borri et al., 2008). The basis for this difference may be related in part to females being more stress-responsive (e.g., hyperarousal, hypervigilance, distraction) and males being less so, based on work with lower animals by Curtis, Bethea, and Valentino (2006), who showed a sex difference in relation to the corticotrophin-releasing factor regulation of the locus coeruleus-norepinephrine system.

Work with humans and lower animals indicates that genetic and environmental factors during development are involved in the etiology and development of anxiety and fear (Barlow, 2000; Baltes, Lindenberger, \& Staudinger, 2006; Kraszpulski, Dickerson, \& Salm, 2006; Leonardo \& Hen, 2008; LeDoux, 2002). Commonalities among mammalian interspecies behaviors has led to fear and anxiety being perceived as hardwired, having evolutionary behavior components associated with safety in the face of perceived threats (LeDoux, 2002; Leonardo \& Hen, 2008; Marks, 1987). Anxiety sensitivity, the tendency to fear anxiety's somatic symptoms (e.g., sweating, elevated heart rate), is a heritable trait (Brown et al, 2012).

In addition to a genetic component, anxiety is affected by environmental factors. Environmental situations affect the manifestation of genes, and the genetic expression includes changes in neural brain circuitry (Jokić-Begić, 2010; Kolb \& Whishaw, 1998). Factors such as socioeconomic status, isolation, and the loss of a significant other can regulate gene expression 
and cellular behavior. Changes in those regulatory processes can influence mental and physical states (e.g., viruses, anxiety, depression) through central nervous system processes (Cole, 2009). Anxious and fearful behaviors also can be learned and modified using modeling and classical and operant behavioral conditioning (Cole, 2009; Jokić-Begić, 2010; Mazur, 2006; McEwen, Eiland, Hunter, \& Miller, 2011). Depending upon their frequency, behaviors can result in changes in the brain's anatomy and associated functions; the brain's ability to reform itself is referred to as neuroplasticity (Jokić-Begić, 2010).

\section{Emotional Issues Surrounding Childbirth}

The biopsychosocial changes associated with childbirth, while having some universality across pregnant women as a group, manifest individually (Kay, 1982; Melender, 2002; Reynolds, 1988; Saisto \& Halmesmäki, 2003; Wenzel, 2011). These changes include, but are not limited to, bodily alterations (e.g., weight gain, stretch marks, post-operative scars), physical ailments (e.g., insomnia, heartburn, urinary frequency, gingivitis), emergence or increase of psychological concerns (e.g., worries about the well-being of the fetus, apprehension about pain during labor), and social group expectations (e.g., labor behavior, role changes, parenting self-efficacy) (Kay, 1982; Otley, 2011; Samant, Malik, Chabra, \& Devi, 1976; Standley, Soule, \& Copans, 1979). These alterations can be difficult in ordinary circumstances, and the presence of deprivation or dysfunctional lifestyles (e.g., poverty, domestic violence, lack of social support) can compound the challenges. If pathologies such as generalized anxiety disorder, psychoactive substance abuse, major depressive disorder, body dysmorphic disorder, gestational diabetes, and/or morbid obesity are involved, they can increase the intensity and scope of any distress (Austin, 2004). These conditions can result in the childbirth-related events becoming stressful, aversive, anxietyproducing experiences for a woman (Wenzel, 2011). In addition to the numerous lifestyle 
changes, she will have to labor and birth the baby, which typically includes some degree of pain. The anticipation of an upcoming aversive, painful event that cannot be escaped can lead to heightened anxiety and fear (Skevington, 1995).

Prenatal anxiety and depression. Anxiety frequently is comorbid with depression, and some scientists theorize that both constructs have a unifying factor of emotionality (Barlow, 2000). The tripartite model of anxiety, fear, and depression hypothesizes that the three constructs share symptoms, but also have unique elements (Craske et al., 2009). Research has shown that the comorbidity of anxiety and depression also is present during pregnancy and the postnatal periods (Austin \& Priest, 2005; Brand \& Brennan, 2009; Reid, Power, \& Cheshire, 2009; Wenzel, 2011). While these disorders can present together, prenatal depression contributes to negative maternal and fetal outcomes independently of anxiety and fear (Dayan et al., 2006). Maternal depression can result in, or is associated with, dissatisfaction with social support, postpartum parenting stress, infant cognitive developmental delays, and onset of externalized behaviors in the infant later in childhood (Boury, Larkin \& Krummel, 2004; Brand \& Brennan, 2009; Buist et al., 2007; Misri et al., 2010). Studies show a developmental trajectory of depression from the prenatal to postnatal periods, with prenatal anxiety, anxiety sensitivity, and a history of anxiety disorders being more predictive of prenatal and postnatal depression than a prior history of depression (Austin \& Priest, 2005; Fairbrother \& Woody, 2007; Lee et al., 2007; Wenzel, 2011).

Studies show that anxiety disorders during the perinatal period (e.g., from conception through the first year after birth [postpartum]), are more common than depression (Austin et al., 2008; Austin \& Priest, 2005; Brand \& Brennan, 2009; Lee et al., 2007). That disproportion corresponds with the presentation of anxiety and depression outside of pregnancy, and reflects a 
literature review by Alder, Fink, Bitzer, Hösli, and Holzgreve (2007) who found that the course of anxiety and depression throughout the perinatal period is stable (American Psychiatric Association, 2000). In a study of 408 women, Matthey, Barnett, Howie, and Kavanagh (2003) discovered that $65.6 \%$ of those who had a history of an anxiety disorder and $29.4 \%$ of the women who had only a history of a depressive disorder developed an anxiety or depressive disorder postpartum.

Prenatal anxiety and fear. Prenatal (e.g., antenatal) anxiety and fear are the presence of those states during pregnancy (Saisto \& Halmesmäki, 2003). Though prenatal anxiety has unique factors, such as extreme hormonal fluctuations, that set it apart from other anxiety states, it is not independently recognized as an anxiety disorder. The Diagnostic and Statistical Manual of Mental Disorders - Fifth Edition (DSM-5; American Psychiatric Association, 2013) acknowledges prenatal anxiety under the "umbrella" of perinatal anxiety, and this designation is in relation to anxiety's comorbidity with a major depressive episode in the postpartum period (e.g., peripartum-onset) or with an adjustment disorder (e.g., becoming a parent) (Wenzel, 2011).

While prenatal anxiety has distinctive features in comparison to other anxiety states, the psychological, physiological, and behavioral anxiety characteristics of the pregnant and nonpregnant states share mutual attributes. These commonalities include varying levels of arousal, from no or little distress to phobia-like qualities, and following different courses such as continuation throughout the perinatal period and beyond, or termination with childbirth (Austin, Priest, \& Sullivan, 2008; Lang, Sorrell, Rodgers, \& Lebeck, 2006; Leonardo \& Hen, 2008; McNeil, Ries, Turk, \& Vargovich, 2010; Saisto \& Halmesmäki, 2003; Wenzel, 2011). In addition, the prevalence of anxiety disorders during pregnancy appears comparable to its distribution in the general female population (Borri et al., 2008). 
Like other types of anxious and fearful states, prenatal anxiety and fear can consist of multiple stimulus elements. A comparison can be made to dental anxiety and fear, another acute pain situation. Distress about dental care can be elicited by a multitude of factors (e.g., injections, being "enclosed" in a dental chair, criticism by the dentist), singularly or in combination (McNeil \& Berryman, 1989). Similarly, prenatal anxiety can be conceptualized as being triggered by a diversity of stimuli, some of which are labor pain, surgical procedures (e.g., episiotomy), epidural injections, and lack of control of body or environment (Lang, Sorrell, Rodgers, \& Lebeck, 2006; Wenzel, 2011; White, Matthey, Boyd, \& Barnett, 2006).

While pregnancy is a normal health condition, it manifests in physical and physiological changes including weight gain, dizziness, and hormonal fluctuations that are abnormal outside of pregnancy (Kelly, Russo, \& Katon, 2001; Leveno, et al., 2003). These changes can act as antecedents, triggering anxiety responses. As previously mentioned, some pregnancy symptoms such as hyperventilation, fatigue, insomnia, chest tightness, and gastrointestinal problems also are symptomatic of anxiety, and this commonality can lead to false interpretations of anxiety and fear pathology by caregivers and the women themselves (Kuo, Chen, Yang, Lo, \& Tsai, 2000; Leveno, 2003; Wenzel, 2011; Yonkers, Smith, Gotman, \& Belanger, 2009). Studies show that levels of prenatal anxiety fluctuate throughout pregnancy, which indicates that the presence of anxiety should be assessed multiple times across that period (Austin \& Priest, 2005; Lee, Lam, Lau, Chong, Chui, \& Fong, 2007). There are several extant measures to assess prenatal anxiety; many are described and evaluated in Wenzel (2011). As noted previously, many assessments can give false positive scores due to overlap in somatic symptoms associated both with pregnancy and anxiety. 
According to Marks (1987), when a stimulus is novel, the uniqueness may be more threatening than the stimulus itself. As a stressor, the birthing process is unique in that it occurs in approximately a quarter of the population (i.e., women who have birthed), and only during their childbearing years. According to Dye (2008) reporting on the 2006 Census, $45 \%$ of women aged 15 to 44 years who were surveyed were childless; but the percentage who had experienced birth was not clear. In the USA, the average number of birthing experiences per woman over the course of her lifetime is 2.1 (World Bank, 2011). Women who have experienced birth have personal knowledge to draw upon in a later pregnancy, which can aid in alleviating some childbirth-related anxiety. Effects of prior experience can be seen in the differences in the selfreported levels of fear, anxiety, and pain across groups of women associated with their parity status found by Alehagen, Wijma, and Wijma (2001), and Areskog (1983). Nulliparous women, who have not experienced childbirth, reported higher fear levels, and parous women, who have experienced childbirth one or more times, reported lower fear levels. There are a small percentage of parous women, however, who have preexisting anxiety disorders. For these women, their anxiety levels are comparable with the levels of women who are birthing for the first time (Zar, Wijma, \& Wijma, 2002). Nieminen, Stephansson, and Ryding (2009) found that while nulliparous women had higher mean fear scores than parous women, the range of scores for the parous women included more intense fear scores. The higher scores for some parous women might have been associated with previous negative birth experiences.

As described by Barlow (2002), the core of anxiety is "a sense of uncontrollability and unpredictability" (p. 65), which is an apt description of the states of pregnancy and childbirth. Childbirth is predictable in that a woman who is pregnant will have a birth, probably close to the end of a nine-month period (earlier termination of pregnancy notwithstanding). In addition, 
there are factors that a woman can control such as attending prenatal obstetrical visits, choosing a health provider, learning about medications used during labor, and becoming trained in pain control techniques. There are numerous elements, however, that she cannot control or predict, some of which are bodily changes, prolonged labor, forceps delivery, Cesarean section, birth defects, pain levels during labor, and loss of life of self or child (Bakshi et. al., 2008;

Geissbuehler \& Eberhard, 2002; Reynolds, 1988; Saisto \& Halmesmäki, 2003). Many choices relating to childbirth such as using epidural anesthesia, attending a birthing center or childbirth classes, or using a midwife can be dependent on factors such as availability and financial status (Marmor \& Krol, 2002). This lack of certainty can result in increased prenatal anxiety levels. Some elevation in anxiety during pregnancy is normal for the majority of women (Wenzel, 2011). When anxiety levels increase and begin to interfere with day-to-day living, it is deemed abnormal. Intolerance of uncertainty associated with the need to control, which is found in generalized anxiety disorder and obsessive-compulsive disorder, might be a psychological vulnerability factor that predisposes a woman to experience the appearance or elevation of existing anxiety disorders during pregnancy (Wenzel, 2011). In addition, women who have existing psychological disorders do become pregnant, resulting in prenatal anxiety that is comorbid with pre-existing depression, substance abuse, personality disorders, and eating disorders (Austin, 2004; Hofberg \& Ward, 2002).

High levels of prenatal anxiety are associated with numerous negative outcomes for the mother and her child throughout the perinatal period and beyond. Studies show that during pregnancy, women experience a number of negative events that are associated with prenatal anxiety including, but not limited to, sleeplessness, cervical and vaginal problems, and issues common to the presence of anxiety spectrum disorders (e.g., obsessive-compulsive behaviors) 
(Austin, 2008; Wenzel, 2011). Beyond biomedical factors, prenatal anxiety independently contributes to hypertension and preeclampsia (Alder, Fink, Bitzer, Hösli, \& Holzgreve, 2007; Qiu, Williams, Calderon-Margalit, Cripe, \& Sorensen, 2009; Wenzel, 2011).

Prenatal anxiety can persist throughout labor (Alehagen, Wijma, \& Wijma, 2006). When a woman is highly anxious during labor, anxiety levels correspond with increased labor duration and obstetrical interventions such as labor augmentation, intravenous administrations, internal exams, fetal monitoring, and an increased number of instrument-assisted births (Lang, Sorrell, Rodgers, \& Lebeck, 2006; Nerun, Halvorsen, Sørlie, \& Øian, 2006). Dystocia (i.e., slow, abnormal, or difficult birth) and emergency Cesarean sections have been associated with fear of childbirth (Laursen, Johansen, \& Hedegaard, 2009). Avoidance and escape are behavioral responses associated with anxiety and fear (Craske, 2003). These behaviors in relation to childbirth have been found to take the form of high epidural anesthetic usage during labor and on-demand Cesarean sections (Alehagen, Wijma \& Wijma, 2001; Lang, Sorrell, Rodgers \& Lebeck, 2006; Nerun, Halvorsen, Sørlie \& Øian, 2006; Saisto \& Hamesmäki, 2003). Anxietyand fear-related catastrophizing also have been associated with the increased use of both epidural anesthesia and Cesarean delivery (Alehagen, Wijma, \& Wijma, 2001; Bakshi et al., 2008; Nieminen, Stephansson, \& Ryding, 2009; Van Den Bussche, Crombez, Eccleston, \& Sullivan, 2007; Waldenström, Hildingsson, \& Ryding, 2006).

For some women, prenatal anxiety does not resolve after birth. Hildingsson, Nilsson, Karlström, and Lundgren (2011) found that of the 135 women in their study who experienced high prenatal childbirth fear, 55 continued to feel significant fear one year postpartum. Prenatal anxiety has been associated after childbirth with general emotional instability, perceptions of negative birth experiences, and a feeling of personal failure (Cheung, Ip, \& Chan, 2006; Hall, 
Hauck, Carty, Hutton, Fenwick, \& Stoll, 2009; Melender, 2002; Nieminen, Stephansson, \& Ryding, 2009; Nilsson, Lundgren, Karlström, \& Hildingsson, 2012; Ryding, Wijma, Wijma, \& Rydhström, 1998; Waldenström, Hildingsson, \& Ryding, 2006). Maternal postnatal anxiety can effect poor bonding with the infant, and can result in an increased risk of insecure attachment with ensuing cognitive, attentional, and emotional problems (Avant, 2006; Davies, Slade, Wright, \& Stewart, 2008; Ferber \& Feldman, 2005; Wenzel, 2011).

High levels of prenatal anxiety also can affect the fetus. Several periods during pregnancy appear to be critical to the emotional aspects of fetal neurodevelopment. Fetal programming is a theory that addresses this developmental process, and it is based in the fetal origins hypothesis (Barker, 1994). The fetal programming hypothesis theorizes that the uterine environment affects the neurodevelopment of the fetus, and if negative, can result in such issues as the child's subsequent propensity for mood psychopathology and lower mental developmental scores (Brouwers, van Baar, \& Pop, 2001; Kinsella \& Monk, 2009). Animal models have been used to explore the fetal programming hypothesis. Kraszpulski, Dickerson, and Salm (2006) effected prenatal stress in Sprague-Dawley rats using a random schedule of saline injections. They found associations in the development of the amygdalas of the offspring that might ultimately affect adult stress responses. It is theorized that a possible mechanism is maternal stress hormones including, but not limited to, cortisol and norepinephrine, which pass through the placenta to the fetus and can result in changes in the development of the fetus' hypothalamicpituitary-adrenal axis and brain (Kinsella \& Monk, 2009). These developmental changes have been connected with deviations in fetal heart rate that have been associated with anxiety sensitivity in children and adults (Lederman, Lederman, Work, \& McCann, 1985; Monk, Fifer, Myers, Sloan, Trien, \& Hurtado, 2000). 
Human research has shown that high levels of hormones related to maternal prenatal anxiety and stress are associated with negative child outcomes. These outcomes include hyperactivity, inattention, reduced mental processing speed, conduct problems, emotional dysregulation, and self-reported anxiety (Brand \& Brennan, 2009; Davis \& Sandman, 2010; O’Connor, Ben-Shlomo, Heron, Golding, Adams, \& Glover, 2005; O’Conner, Heron, Golding, Beveridge, \& Glover, 2002; O’Connor, Heron, Golding, Glover, \& the ALSPAC Study Team, 2003). The outcomes differ based on the sex of the child and on the developmental period during pregnancy in which maternal anxiety was experienced. Several of the studies cited here have demonstrated positive correlations with high maternal prenatal anxiety levels and increased child behavior problems. In those studies, women who scored in the top levels on anxiety measures had children who exhibited more problem behaviors and who scored more than two standard deviations above the mean on problem behavior and negative emotional measures.

Several researchers have found that negative child outcomes associated with high maternal prenatal anxiety have long-range effects (Brand \& Brennan, 2009; Brouwers, vanBaar, \& Pop, 2001; Kinsella \& Monk, 2009; O’Connor, Ben-Shlomo, Heron, Golding, Adams, \& Glover, 2005; O’Conner, Heron, Golding, Beveridge, \& Glover, 2002). For example, Mennes, van den Bergh, Lagae, and Stiers (2009) found that maternal prenatal anxiety was related to developmental brain alterations in 17-year-old males. Van den Bergh and Marcoen (2004) found that maternal prenatal anxiety accounted for some of the variance in attention deficit hyperactivity disorder symptoms (22\%), externalizing problems (15\%), and self-reported anxiety $(9 \%)$ in 8 - and 9-year-old children after controlling for the children's gender and birth weight, parents' educational level, maternal smoking during pregnancy, and maternal postnatal anxiety. 
Prenatal anxiety and pain. Pain is an inherent part of childbirth, and anxiety and fear in relation to that pain is present in many or even most women (Caton et al., 2002; Caton, Frölich \& Euliano, 2002; Melender, 2002; Reynolds, 1988). Geissbuehler and Eberhard (2002) analyzed questionnaire responses from pregnant women, and found two prominent fears: fetus health and childbirth pain. Anxiety and fear have been associated with increased pain reporting. Women who are highly anxious during pregnancy report that emotion throughout their labor (Alehagen, Wijma, \& Wijma, 2006). This anxiety is associated with subsequent reports of higher levels of anticipated, current, and retrospective labor pain (Alehagen, Wijma, \& Wijma, 2006; Carleton, Abrams, Asmundson, Antony, \& McCabe, 2009; Klusman, 1975). Saisto and Halmesmäki (2003) report that fear of labor pain is associated with fear of pain in general.

Like anxiety and fear, pain is multi-dimensional. It has genetic and environmental etiologies, and the related gene expression is different between males and females, possibly due to differences in the corticotrophin releasing factor receptors (Curtis, Bethea, \& Valentino, 2006; Filippova \& Nozdrachev, 2010; Hadjistavropoulos, Craig, \& Fuchs-Lacelle, 2004; Mogil et al., 2011; Ruau et al., 2012; Vasileiou, Giaginis, Klonaris, \& Theocharis, 2010). These differences are affected by acculturation (Curtis, Bethea, \& Valentino, 2006). While there is a general societal expectation of pain during labor and childbirth, the pain is perceived, interpreted, and responded to in different ways (Callister, Khalaf, Seminic, Kartchner, \& Verbvilainen-Jullkunen, 2003; Kay, 1982). For example, some cultures view birth as a natural and normal process that includes some amount of pain, while other cultures see it as a medical event that must be managed as painlessly as possible (Gaskin, 2002, 2003; Senden et al., 1988). Relating to pain perception, Chang, Chen, and Chen (2002) found that for first-time mothers, childbirth pain was correlated with psychogenic (e.g., pain expectation), not physical factors. Christiaens, 
Yerhaeghe, and Bracke (2010) discovered that the acceptance of labor pain and the perception of personal pain control resulted in less medication usage during labor. In general, when the experience of pain is perceived as aversive, higher pain levels are reported (Vancleef, Peters, Roelofs, \& Asmundson, 2006; Vowles, McNeil, Sorrell, \& Lawrence, 2006). Dennenbring, Stevens, and House (1997) discovered that various experiential, cognitive, and demographic factors (e.g., induced labor, pregnancy desirability) predicted sensory childbirth pain, while other factors (e.g., labor duration, medication-free labor expectancy associated with childbirth education, depression) predicted affective pain.

Catastrophic worry has been associated with generalized anxiety disorder (HazlettStevens \& Craske, 2003; Riskind \& Williams, 1999; Vasey \& Borkovec, 1992). Catastrophic cognitions also are associated with higher levels of pain, possibly due to interactions with genetic factors (George et al., 2008; Sullivan et al., 2001). Research by Sjögren (1997) found that some women experience catastrophic thoughts in relation to their impending childbirth, as evidenced by $44 \%$ of the women in the study reporting the expectation of intolerable physical pain. Bussche, Crombez, Eccleston, and Sullivan (2007) found that catastrophizing was strongly associated with fear of pain (e.g., being overwhelmed by childbirth pain) and the avoidance of the pain experience (e.g., use of epidural anesthesia). Thorn, Ward, Sullivan, and Boothby (2003) postulated, based on Sullivan, Thorn, Haythornthwaite, Keefe, Martin, Bradley, and Lefebvre's (2001) communal coping model, that catastrophizing is part of an individual's personal coping style for distressing situations. In relation to pain, exaggerated responses are a way to maximize social support and the proximity of others. Cano and Williams (2010) proposed that the purpose of a person's vocalizations about pain might be to elicit a partner's empathy, and could serve the function of increasing intimacy between them. 
Social pain is defined as distress due to the perception of actual or perceived psychological distance from others who are deemed important (Eisenberger \& Lieberman, 2004). It is hypothesized that social connectedness is evolutionary in that belonging to a group enhances an individual's safety (Eisenberger \& Lieberman, 2004). This evolutionary theory is bolstered by research showing that social and physical pain share a neural alarm system (e.g., hypothalamic-pituitary-adrenal axis), both being perceived as a threat (Kross, Berman, Mischel, Smith, \& Wager, 2011). Evolutionally, survival depends on successful responses to threat. Taylor et al. (2000) theorize that, especially for women who are pregnant or caring for an infant, neither flight nor fight might be the optimal reaction to threat. An alternative response might be creating a protective social structure, being a friend and befriending others (Cardoso, Linnen, Joober, \& Ellenbogen, 2011). A woman's belief in her ability to involve her spouse in helping her with childcare duties was found by Ozer (1995) to be predictive of her emotional well-being and distress. In a literature review, Otley (2011) found that having poor social networks and dissatisfaction with one's significant other were associated with higher levels of fear concerning childbirth.

Prenatal anxiety and self-efficacy. Self-efficacy is a person's belief in her/his ability to deal with situations containing unpredictable and stressful elements (Bandura, 1977; Bandura \& Schunk, 1981). Sjögren (1997) discovered fear of personal incompetence during labor (65\%) was associated positively with women's childbirth anxiety. When women were questioned during early and active childbirth labor stages, Lowe (1987) found that self-efficacy (e.g., labor coping), in addition to state anxiety and fear of pain, explained a significant amount of variance in relation to childbirth pain. Berentson-Shaw, Scott, and Jose (2009) conducted a longitudinal study that extended from pregnancy through postpartum, involving primiparous women who 
previously had birthed only one child. The researchers found that higher levels of childbirthrelated self-efficacy were associated with decreased labor pain and distress in addition to increased satisfaction with the women's overall birthing experience. Stockman and Altmaier (2001) defined childbirth self-efficacy as a series of tasks or stages to be conquered or successfully completed. Using this concept, they found women who had higher levels of selfefficacy relative to overcoming barriers (e.g., non-supportive labor partner) experienced the emotional and cognitive factors of pain differently (e.g., less painfully) than women who had lower levels of self-efficacy. Melender (2002) found that fear of childbirth was associated with childbirth-related performance anxiety, which was in relation to acting out activities in front of others. Summarizing the literature, Otley (2011) commented that a sense of powerlessness during labor was related to fear of childbirth.

Yet another source of anxiety for women during pregnancy is the impending change of role involved in becoming a parent or becoming a parent of multiple children. Parenting selfefficacy is a person's belief in her/his abilities to discharge parental responsibilities adequately (Coleman \& Karraker, 1997). Studies indicate that high parenting anxiety and lack of parenting self-efficacy can negatively affect parenting abilities. Coleman and Karraker (1997) discussed the importance of a woman's prenatal ability to perceive herself as a competent mother and subsequent positive mother-child interactions. Ozer (1995) found that women's lack of selfefficacy in their ability to juggle responsibilities at home and work with their parental responsibilities was associated with poorer maternal psychological health. Research by Spielman and Taubman-Ben-Ari (2009) found that parental self-efficacy was significantly correlated with positive attachment style, which is a bond of the infant to a caregiver resulting in the development of positive psychological traits in the infant (Waters, Crowell, Elliott, Corcoran, 
\& Treboux, 2002). Otley (2011) described fear of childbirth as a factor associated with parenting self-efficacy.

In summary, becoming a parent typically is a life-changing experience. The events related to pregnancy, childbirth, and/or parenting can result in feelings of anxiety, fear, or depression. Higher levels of these emotions are normal for this transitory stage of life. Elevated anxiety levels associated with the numerous stress antecedents associated with childbirth, in addition to the hormonal fluctuations inherent to pregnancy, can exacerbate existing anxiety or elicit a new anxiety state during pregnancy. Women who are sensitive to the associated physical and cognitive symptoms have a tendency to experience higher elevations of anxiety and fear during pregnancy. When the changes associated with childbirth-related events are perceived to be beyond one's abilities (e.g., lack of self-efficacy), increased anxiety levels can be present. Higher maternal anxiety levels during pregnancy are associated with an increase of short- and long-range negative outcomes for the mother and her child.

Considering the perinatal trajectory of prenatal anxiety, the multiple obstetrical care visits involved in pregnancy and postpartum present an optimal time for assessing anxiety in addition to other psychosocial risk factors (e.g., depression, domestic violence, rape history) (Austin \& Priest, 2005; Austin, Priest, \& Sullivan, 2008; Sieber, Germann, Barbir, \& Ehlert 2006). Obstetrical caregivers can be the gatekeepers in prenatal mental health, assessing and referring women to appropriate resources.

\section{Components of Prenatal Anxiety}

Prenatal anxiety is a multidimensional construct, not a unitary one. Standley, Soule, and Copans (1979) interviewed 73 primiparous American women experiencing uncomplicated pregnancies and suggested prenatal anxiety contains three dimensions: (a) pregnancy and 
childbirth; (b) postnatal baby care; and (c) existing psychological conditions. The pregnancy and childbirth dimensions included concerns about the fetus' well-being, general anxiety about pregnancy including its physical aspects, and worries about upcoming childbirth. The dimension focusing on anxiety in the postpartum period was in relation to the care and feeding of the infant.

Several models have been theorized to capture the construct of prenatal anxiety, as shown in Table 1. Huizink, Mulder, de Medina, Visser, and Buitelaar (2004) posited that pregnancy anxiety (e.g., prenatal anxiety) might be a distinctive syndrome due to its association with outcomes (e.g., infant mental and motor development) that are not associated with general anxiety. Based on their study of 230 nulliparous women, they proposed a model of prenatal anxiety that includes three components: concern about one's appearance, fear of giving birth, and fear of bearing a handicapped child. Concern about one's appearance addresses body shape and physical attractiveness. Concerns about the well-being of the child include worries about physical and mental handicaps, poor health proneness, or fetal/neonate death. The fear of giving birth component, was composed of three items: pain of labor contractions and delivery, lack of previous birth experience, and concern about controlling one's behavior and screaming during labor. While these three issues undoubtedly are involved in the childbirth experience, they might be related to different anxiety dimensions (e.g., fear of pain, fear of novel experiences, obsessive-compulsive behavior).

Sieber, Germann, Barbir and Ehlert (2006) conceptualized prenatal anxiety as birth anxiety, which was defined as feelings of anxiety in relation to any aspect of labor and delivery. A form of prenatal stress, birth anxiety was seen as differentiated from general anxiety. These researchers tested their model in the first part of a longitudinal study of 61 primiparous Swedish women. They found that existing anxiety disorder symptoms (e.g., phobia, obsessive- 
compulsive behavior) were predictors of birth anxiety. They associated prenatal anxiety with a need to control the environment due to an intolerance of uncertainty, concerns about the wellbeing of the fetus and the mother herself, and stressful life events (e.g., their partners' not desiring the pregnancies). They also found a negative correlation between birth anxiety and childbirth-related self-efficacy.

Such anxiety dimensions, in addition to changes in mood experienced by women from conception through one year after birth (e.g., the perinatal period), led Ross, Sellers, Gilbert Evans, and Romach (2004) to create a biopsychosocial perinatal model. The participants in their study were 150 Canadian primiparous and multiparous women who were not experiencing mental or physical pathology. Using structural equation methodology, their model demonstrated that biological risks (e.g., hormones [progesterone], personal history of depression, family psychiatric history of depression or anxiety) had a direct effect on the factors of psychosocial stress (e.g., social support, life stress) and anxiety (e.g., general anxiety, obsessive-compulsive behaviors, phobia). Psychosocial stress was found to have a direct affect on the anxiety and depression factors; anxiety also had a direct affect on depression.

Wenzel (2011) developed a model containing three components: genetic vulnerability -family or personal history of anxiety and/or depression disorders; neurochemical variability -childbirth-related chemical changes (e.g., increased oxytocin in the third trimester) that affect neurotransmitters and mood; and psychological vulnerability -- the cognitive and coping styles associated with specific anxiety disorders. The biological component was divided into genetic and neurochemical factors reflecting the uniqueness of the hormonal changes intrinsic to a normal pregnancy, childbirth, and postpartum period. The genetic component interacts in oneway relationships with the other components. The psychological and neurochemical components 
interact bi-directionally. All of the components interact with life stress, and, directly and indirectly, lead to anxiety through life stress.

While these models of prenatal anxiety are informative and directive, more work is needed. Based on the literature, there is a multitude of biological, psychological, and social factors that intertwine to create prenatal anxiety. The nature of those factors, how those factors relate to each other, and the extent of their influence needs to be determined. Studies are needed to consolidate and verify existing knowledge to affect clarification of the prenatal anxiety construct.

\section{Preliminary Data for a Comprehensive Model}

Clemens (2010) collected data on 92 pregnant women. Post-hoc analyses were performed using cluster analytic techniques to discern groupings between the women in relation to anxiety, depression, and childbirth-related self-efficacy. A hierarchical cluster analysis was executed using Ward's method. The hierarchical analysis was followed by a $k$-means iterative analysis. The variables used in the analyses were the $Z$-scores of the total scores from five assessments displayed in Figure 1 that measures fear of pain, childbirth fear, anxiety sensitivity, depression, and childbirth-related self-efficacy. Findings suggested there were three clusters exhibiting distinct components associated with prenatal anxiety as manifested in the women in the study.

Women in Cluster $1(n=14)$ had high scores on fear of pain, anxiety sensitivity, childbirth anxiety, and depression. They reported feeling able to handle labor. In Cluster $2(n=$ 56), the women scored lower on measures of fear of pain, anxiety sensitivity, childbirth-related anxiety, and depression. They scored higher on childbirth self-efficacy, meaning they also felt competent about handling labor. The scores of the women in Cluster $3(n=22)$ were higher for 
fear of pain, anxiety sensitivity, childbirth anxiety, and depression. In contrast to Cluster 1, these women, however, did not feel competent in relation to their labor coping abilities.

These results are consistent with the literature on prenatal anxiety (Alder, Fink, Bitzer, Hösli, \& Holzgreve, 2007; Austin, 2004; Wenzel, 2011). Cluster 1 and Cluster 3 had comparable scores on anxiety sensitivity, and those scores where higher in comparison to Cluster 2. This clustering indicates that anxiety sensitivity might be a fundamental component in prenatal anxiety (Wenzel, 2011). When fear of pain was at a higher level in Cluster 1 than in Cluster 3, childbirth-related anxiety and depression also were at slightly higher levels. Storksen, Eberhard-Grain, Garthus-Niegel, and Eskild (2011) also found this association. In the 1,642 women in their study, the presence of higher levels of anxiety and depression increased a woman's odds of having fear of childbirth. Yet, the majority of the women in their study who experienced fear of childbirth did not have anxiety or depression. These differences could reflect the work by Carleton and Asmundson (2009), which points to pain-related anxiety and fear as separate constructs. Another outcome was that lower childbirth self-efficacy in Cluster 3 grouped with higher anxiety and fear of pain scores. Storksen, Eberhard-Grain, Garthus-Niegel, and Eskild (2011) also found this grouping, as did Beebe, Lee, Carrieri-Kohlman, and Humphreys (2007). An implication of these analyses is that childbirth anxiety treatment may need to be tailored to fit patient characteristics, as defined by their cluster membership. The current study expanded on the exploration of the components found in the preliminary analyses of existing data.

\section{Statement of the Problem}

Prenatal anxiety has many different facets (i.e., biological, psychological, social) with resulting distinct, interacting components. In addition to being comorbid with other disorders 
(e.g., depression), prenatal anxiety results in numerous, sometimes long-term, negative effects for the mother and her child. Since the use of anti-anxiety medication to lessen the level of anxiety during pregnancy has not been well researched, many women and their obstetrical caregivers choose not to use medication to treat prenatal anxiety (Gentile, 2010). A functional analysis of the prenatal anxiety components can determine which behavioral treatments or referrals to pursue to decrease or eliminate the anxiety symptoms (Austin, 2004; Wenzel, 2011). With lifetime prevalence rates of $31 \%$ within the general population, anxiety disorders are the most common psychological problems after substance abuse, with which it is frequently comorbid (American Psychiatric Association, 2013). Intervening in anxiety development early in pregnancy can lessen fetal exposure to maternal stress hormones, interrupting fetal programming that results in anxious children and, subsequently, anxious adults. Assessing and treating prenatal anxiety is a preventative measure that should be incorporated into regular healthcare. To this end, the nature and extent of perinatal anxiety must be further clarified and comprehended. This study's purpose is to consolidate previous research results and to explore the structural components of prenatal anxiety. Ultimately, the results can inform future research to initiate the creation of future assessment measures facilitating more appropriate and efficacious treatment referrals.

Focus of this study. The primary aim of this study was to provide differentiations among the psychological components of prenatal anxiety and its associated social factors to facilitate an operational classification of the prenatal anxiety construct. Cluster analyses and analyses of variance were employed to determine groupings among the women and to reveal how the groupings associated with individual anxiety-related constructs. Based on Clemens (2010), three cluster groupings were expected. See Table 2. 
The scoring of the variables for childbirth self-efficacy are opposite in the pilot analysis than in the current study. In the pilot analysis, higher levels of childbirth self-efficacy indicate better self-efficacy. In the current study, higher levels of childbirth self-efficacy indicate poorer self-efficacy. This change in the direction was effected to make the scores of the childbirth selfefficacy variable in line with the scores of the other measures, where higher scores point to more problems or pathologies.

\section{Method}

\section{Research Design and Analysis Plan Overview}

In this study, an exploratory, descriptive research design on cross-sectional data was used to differentiate groups of pregnant women in relation to anxiety, depression, and demographic factors. The project involved a collection of original data from a heterogeneous sample of pregnant women. The Institutional Review Board at West Virginia University in Morgantown, WV approved this protocol. Data were analyzed with the PASW Predictive Analytics SoftWare (SPSS 18.0.3) program using cluster analyses in addition to two analyses of variance algorithms using one-way analyses of variance (ANOVA) and Kruskal-Wallis tests.

The analysis involved two stages. The first stage involved cluster analyses to determine groupings within the data. The second stage utilized analyses of variance to determine betweencluster associations and variances with psychological and demographic variables.

Stage 1 - Cluster Analysis. Cluster analysis is used as an exploratory technique for determining internally homogenous and externally heterogeneous groupings of objects (e.g., symptoms, disorders) found among respondents based on a predetermined set of variables. The purpose of this procedure is to explore commonalities of variables to discern patterns within the data objects (e.g., participants) to create an operational categorization (Burns \& Burns, 2008; 
Hair \& Black, 2000). In this study, cluster analysis was used to determine groupings of women in relation to specific psychological construct variables that have been associated with prenatal anxiety.

It is the nature of cluster analysis to construct groups even if there is no meaningful group structure. To optimize the validity of the groupings, the choice of variables in this study was based on the current literature in addition to a post-hoc exploratory cluster analysis of the data from Clemens (2010). Due to the small but adequate sample size, only four variables known to be associated with prenatal anxiety were chosen to prevent overfitting. The four variables were the women's scores on self-report measures of anxiety sensitivity, fear of pain, and depression, in addition to a scale assessing childbirth-related self-efficacy.

A two-step procedure was used based on procedures found in Mooi and Sarstedt (2011) and in Burns and Burns (2008). The sequence began with the use of a hierarchical procedure, the results of which were interpreted to determine the optimal number of clusters extant in the data set. Ward's method, using squared Euclidean distance as its distance measure, was the chosen hierarchical amalgamation algorithm. This study's analysis compared the relative magnitude of each variable (e.g., higher scores equal more symptoms or greater psychopathology based on the means of the difference between the measure scores); Ward's method is a technique commonly used for that purpose (Mooi \& Sarstedt, 2011).

Ward's method is an agglomerative technique that uses a bottom-up progression in which each object (e.g., variable) begins as an individual cluster and all objects end up as part of a single cluster. The method uses an ANOVA approach in which the unit of measure between objects is the sum of squares (e.g., the squared amount of how much each score in the cluster deviates from the cluster mean). It assesses cluster membership by the evaluation of which 
variable's inclusion produces the smallest increase in within-cluster variance based on the error sum of squares, which results in increasingly homogeneous within-cluster and heterogeneous between-cluster distances (Burns \& Burns, 2008; Mooi \& Sarstedt, 2011). The resulting clusters were assessed for stability (Mooi \& Sarstedt, 2011). Stability was determined by rerunning the original analyses after changing the order of the dataset, and assessing if results were comparable. This stability appraisal was followed by running the analysis using different clustering methods and checking for equivalent outcomes. When stability was determined, using the cluster variables as dependent variables and the cluster groupings as the independent variables, one-way ANOVAs were computed to compare the centroids within each cluster solution to determine significant differences in the variables within and between the clusters. Post hoc Tukey tests were conducted to follow up ANOVAs as appropriate.

Using Ward's method results in larger numbers of variables within the clusters as the criteria for similarity is relaxed, so it frequently is paired with a $k$-means cluster analysis. The $k$ means algorithm does not determine the number of clusters, so the number of clusters determined by the Ward's cluster analysis was input as the grouping parameter. The same grouping variables that were used in the Ward's method were used in the $k$-means analysis.

The $k$-means cluster analysis is a non-hierarchical partitioning method that separates the data into a specific number of clusters with the greatest distinction from each other, minimizing within-cluster and maximizing between-cluster variation (Mooi \& Sarstedt, 2011). The $k$-means algorithm initially uses random assignment to place variables into clusters. This placement reduces the sum of squares, resulting in a reduction of within-cluster variation (Mooi \& Sarstedt, 2011). This step is followed by successive reassignment to clusters based on the calculation of the Euclidean distances of each variable's nearness to the mean of the clusters and whether the 
assignment decreases the within-cluster variation. The reassignment continues until a predetermined number of iterations has been achieved or cluster assignments result in no changes (e.g., convergence). Unlike the Ward's method, the $k$-means allows some shifts among clusters.

To inform the individuality of the chosen variables to form the clusters, one-way ANOVAs and Kruskal-Wallis tests were calculated using the demographic variables (i.e., age, education, annual income, annual household income, parity, trimester, traumatic birth, Cesarean section scheduled) as dependent variables and the $k$-means cluster variable as the factor variable. Kruskal-Wallis tests were performed on the four clusters for the binary variables and to verify the one-way ANOVAs since the data did not meet univariate assumptions, as later described.

Stage 2 - Analyses of variance. The second stage of the statistical assessment used ANOVA and Kruskal-Wallis tests to determine relations with the clusters and psychological and social variables that the current literature has associated with prenatal anxiety. Table 3 contains a list of the variables that potentially could be included. Among these possibilities, the seven variables selected, which were input as dependent variables, were chosen based on their association with prenatal anxiety in the current literature. The variables were childbirth-related anxiety, catastrophizing, health concerns about the baby, concerns about the mother's health, parenting self-efficacy, social support during birth, and social support for baby care after birth. The $k$-means clustering variable was input as the factoring variable.

\section{Setting and Participants}

Between March and July 2012, participants were recruited at the West Virginia University Healthcare - Obstetric and Gynecology Clinic, which serves women primarily in north-central West Virginia. The patients in the clinic include a diverse grouping of social 
economic and education levels, and their pregnancies range from normal to high-risk.

Obstetrical caregivers include obstetricians and midwives. Eligibility requirements were that the women were pregnant, 18 years of age or older, English-speaking, and without overt developmental or psychological symptoms that would prevent their understanding of or participation in the study. See Figure 2 for a flow chart describing how participants were included or excluded. Women who were anticipating Cesarean Section delivery were included in the study. See Appendix A for an exploratory analysis of women who were expecting a vaginal versus a Cesarean section delivery.

The required number of participants for the cluster analysis as per the recommendation of Formann (1984), published in German, as quoted in Dolnicar (2002) and in Mooi and Sarstedt (2011), was a minimum of $2^{\mathrm{k}}$, where $\mathrm{k}$ was the number of variables. Dolnicar (2002) recommended $5^{*} 2^{\mathrm{k}}$. In relation to the analyses of variance, the $\mathrm{G}^{*}$ Power program (Erdfelder, Faul \& Buchner, 1996) was used to determine adequate sample size to detect a predicted effect size using an alpha $=.05$ and power of $1-$ beta $=.80$. The larger number $(n=100)$ from the computations was used to determine the minimum number of participants in relation to acceptable statistical power.

\section{Measures}

There were seven measures for a total of 169 items involved in the analyses. The packets were assembled with the demographics form behind the other forms, which were in random order across participants.

Demographic information form. A questionnaire was administered to gather basic information about the participants, including age, race/ethnicity, personal and household income, education, information about prior births (e.g., how many, if traumatic), and information about 
the current birth (e.g., birth due date, planned cesarean delivery, intended pain control methods). Questions about anxiety in relation to the health of the child, childbirth, finances, and parenting were included. Several of the questions on the demographic form were used as factors in the statistical analyses as shown in Table 3. See Appendix B.

Anxiety Sensitivity Index-3. The ASI-3 (Taylor et al., 2007) measures anxiety in relation to physical, cognitive and social factors in addition to providing a total scale score. It is a self-report instrument comprised of 18 Likert-style items (1 - very little, 5 - very much). The psychometric properties of the ASI-3 were examined by Taylor et al. (2007) and the subscale reliabilities were: Physical Concerns subscale $\alpha=.76-86$; Cognitive Concerns subscale $\alpha=.81$ .91; and Social Concerns subscale $\alpha=.73-.86$. Criterion-related validity as well as convergent and discriminant validities have been demonstrated (Taylor et al., 2007). The total score, which ranges from 18 to 90 , was used in this study. The total score discriminates between people who have and people who do not have anxiety disorders (Kemper, Lutz, Bähr, Rüddel, \& Hock, 2012). Higher scores indicate elevated levels of a proneness to experience physical and cognitive symptoms as anxiety-provoking. See Appendix C.

Center for Epidemiological Studies Depression Scale. The CES-D (Radloff, 1977) is a 20 item, self-report instrument using a Likert-style construction with a 4-point scale (0 - rarely or none, 3 - most or all of the time) to measure depressive symptoms in the general population. The scores range from 0 to 60 . A cut-off of 16 or higher has been recommended for indicating depression, though research points to a higher cut-off point for females (Zumbo, Gelin, \& Hubley, 2001). In this study, the clinical cut-offs that were used were 16 to 27 suggesting mild depression, and $>27$ suggesting severe depression (Zich, Attkisson, \& Greenfield, 1990). Using 
Spearman-Brown and split-half statistics, internal consistency is .85 and test-retest reliability is .51. (Radloff 1977). See D.

Childbirth self-efficacy. Valid measures to assess childbirth self-efficacy during pregnancy are lacking. Therefore, a question in the demographic information form was used to assess childbirth self-efficacy: "Right now, rate your ability to handle labor pain? $(1=$ I feel that I can handle labor pain, 5 = I feel that I cannot handle labor pain)." Higher scores suggest poorer self-efficacy, and lower scores suggest better self-efficacy. This scoring is in line with the other measures used, in which higher scores point to more problems or pathologies. While this question has not been statistically validated to measure childbirth self-efficacy, it correlated significantly with the Childbirth Self-efficacy Inventory (Lowe, 1987) in Clemens (2010).

Fear of Pain Questionnaire-III. The FPQ-III (McNeil \& Rainwater 1998) is a Likerttype (1 - not at all, 5 - extreme), self-report instrument consisting of 30 items designed to assess pain-related anxiety or fear with a total score and three subscales scores: Minor Pain, Severe Pain, and Medical/Dental Pain. In this study, the total score was used. The FPQ-III has excellent reliability $(\alpha=.92-.95)$ and convergent validity with similar measures (McNeil \& Rainwater, 1998). The FPQ-III scores range from 30 to 150, with higher levels indicating higher anxiety and fear. As with many anxiety scales, women tend to score higher than males on the FPQ-III, and fear related to upcoming acute pain situations can be seen as normal (Austin, 2004; McNeil \& Rainwater, 1998). See Appendix E.

Health Anxiety Questionnaire. The HAQ (Lucock \& Morley, 1996) is a 21 item, Likert-type scale ( 0 - not at all or rarely, 3 - most of the time) that assesses levels of concern about health. It contains four subscales (i.e., Health Worry and Preoccupation, Fear of Illness and Death, Reassurance-Seeking Behavior, Interference with Life). The total score, which 
ranges from 0 to 63, with higher levels indicating higher anxiety, was used in this study. Splithalf reliability has been demonstrated by Lucock and Morley (1996) to be between $(r=.77)$ and $(r=.94)$ depending upon the research participant group (e.g., lay people, nurses, medical outpatients, psychology outpatients); internal consistency was $(\alpha=.92)$; test-retest reliability for psychological outpatients was $r=.95$ (Lucock \& Morley, 1996). See Appendix F.

Penn State Worry Questionnaire. The PSWQ (Meyer, Miller, Metzger, \& Borkovec, 1990) is a self-report measure that contains 16 Likert-style questions (1 - not at all typical of me, 5 - very typical of me) that assesses generalized anxiety disorder. The scores range from 16 to 80, and a cut score of 57 was suggested to maximize sensitivity (Fresco, Mennin, Heimberg, \& Turk, 2003). The PSWQ has been found to have good internal consistency $(\alpha=.86-.93)$ and test-retest reliability $(r=.74-.93)$ for periods ranging from two to ten weeks (Molina $\&$ Borkovec, 1994). The validity of the PSWQ has been found to be $r=.40-.74$ in comparison to anxiety measures, and $r=.59-.67$ for worry measures (Hazlett-Stevens, Ullman, \& Craske, 2004). See Appendix G.

Wijma Delivery Expectancy/Experience Questionnaire A. The W-DEQ A (Wijma, Wijma, \& Zar, 1998) is a self-report instrument that measures prenatal anxiety and fear of childbirth using a 33-item, Likert-type (0 - never, 5 - very often) format. Internal consistency reliability was $r=0.87$ (Wijma, Wijma, \& Zar, 1998). High scores on the W-DEQ A significantly correlated with the S-R Inventory of Anxiousness $(r=.78)$, the Fear Questionnaire (childbirth, $r=.65$; social, $r=.34$ ), the Spielberger Trait Anxiety Inventory (trait; $r=.54$ ), the Karolinska Scales of Personality $(r=.43)$, and the Neuroticism scale on the Eysenck's Personality Inventory $(r=.38)$, in addition to the Anxiety Symptoms Questionnaire Part One and the Anxiety Disorder Interview Schedule-Revised (Zar, Wijma, \& Wijma, 2002). Scores above 
85 indicate high and above 100 indicate intense childbirth-related fear and anxiety (Ryding, Wijma, \& Wijma, 1998; Zar, Wijma, \& Wijma, 2002). The W-DEQ A is copyrighted, so a copy is not included as an appendix.

\section{Procedure}

The primary researcher $(\mathrm{SWC})$ trained each team member $(n=3)$ prior to his or her involvement in participant recruitment. The training included provision and discussion of an investigator script, role-playing, and an individual, supervised, 4-hour, in vivo recruitment session. Members of the research team recruited participants as they presented for their obstetrical clinic appointments in the waiting area. The prospective participants were advised of the purpose of the study, shown the packet of questionnaires, informed as to what was involved in participation with the study, and given payment information. After any questions were answered, informed consent, including an explanation of the confidentiality of their protected health information, was obtained from each participant. A packet of assessments then was provided to the participant. Upon completion of the packet, the researcher examined each assessment. If missing answers were discovered, the participant was queried to determine whether the question was missed on purpose (noted as "MOP" on the form by the investigator) or was an oversight (which then was corrected by the participant). Each participant was given \$10 USD for her participation.

\section{Variables for Analyses}

The focus of this study was on self-reported psychological, physiological, environmental, and social factors that were representative of the current literature. See Table 3 for variable information, including how the scores were calculated. Since different types of scales (e.g., 1 to 
5, 0 to 3) were used in the assessments, scores on all measures used for the cluster analyses were standardized to make them comparable by using their $z$-score values.

\section{Results}

\section{Data Reduction and Management}

Data were double-entered by the principal investigator (SWC) and one trained research assistant, and the resulting datasets were compared. Discrepancies were resolved by reexamining the raw data. Missing data, notated by an experimenter as Missing On Purpose (MOP) on the questionnaires indicating that the participant intended not to answer the question, was 0.6 percent. The missing responses were examined and appropriate values were entered when the answer could be ascertained. If an appropriate response could not be discerned, mean substitution was utilized; a value was estimated based on the mean value for the question (Tabachnick \& Fidell, 2007). The demographics of the final sample $(N=102)$ are presented in Table 4

Prior to analysis, data were checked for normality and univariate/multivariate outliers. Cell sizes for all variables were uniform at 102. Pearson product-moment correlation coefficients showed significant collinearity between several variables pairs, as shown in Table 5 . This level of correlation was expected for several reasons. One reason was that a number of the variables reflected factors related to anxiety (e.g., anxiety sensitivity, fear of pain), and as demonstrated extensively in the literature, there is an overlap of fear, anxiety, and depression (Barlow, 2002). A second reason was that several of the variables were associated due to factors such as time intervals, with older women having more previous births than younger women, and socioeconomic issues, with women with higher education levels having higher income levels. A third reason was history; for a woman to have a history of traumatic birth or Cesarean section, 
she must have had a previous birthing experience. According to Mooi and Sarstedt (2001), when highly correlated variables are involved in cluster analyses computations, a collinearity less that $r$ $=0.90$ is acceptable. The highest correlation between the variables in this study was $r=0.77$, and it was between social support during birth and social support with childcare. The rest of the correlations were less than or equal to $r=0.67$. Regardless, to control for inflated correlations due to the collinearity affecting weighting in the Ward's and $k$-means cluster analyses, the variables used in those computations were not composite variables (Tabachnick \& Fidell, 2007).

Assumption of normality was violated in 14 of the 19 scales, and homogeneity was not present in 9 of the 19 scales. See Table 5. Using an inverse operation on the data did not normalize the variables. It was deemed critical to retain outliers for external validity in addition to greater power in the analyses. Since cluster analysis does not involve hypothesis testing and the calculation of significance levels are only for descriptive follow-up, using data that does not meet assumptions of independence or normality is acceptable (Norušis, 2012). Therefore, all data for participants were retained, and lack of linearity is noted. Since outliers were retained in the data, Mahalanobis tests were not conducted. The descriptive statistics for the final sample are displayed in Table 4.

\section{Stage 1 - Cluster Analysis}

Ward's method cluster analysis. A Ward's method cluster analysis was performed using four variables: ASI-3, CES-D, FPQ, and CB-SE. The results of the analysis are shown in Table 6. A scree plot was constructed using the agglomeration schedule coefficients. The plot contains a point that denotes each occurrence of a case or cluster being joined together. Bends in the plot indicate natural cutting points for the determination of cluster numbers. The scree plot for this analysis showed no obvious elbows to indicate cluster demarcations. A dendrogram was 
created illustrating the clustering agglomerations. See Figure 3 for the scree plot and dendrogram. Reading from left to right, each participant is joined in a cluster, and the subsequent clusters are joined until only one cluster, that includes all participants, remains. Larger horizontal distances between clusters indicate breaking points for clusters. Examination of the resulting dendrogram indicated either a three- or four-cluster solution. See Figure 4 for a graph of the variables in both solutions.

The cluster analyses for the three- and the four-cluster solutions were assessed for stability (Mooi \& Sarstedt, 2011). First, the order of the dataset was altered randomly. A computerized random number generator was used to determine the order of each participant's responses in the dataset. The Ward's method analysis was recalculated on the randomized data. The result was the same three- and four-cluster solution found in the original configuration. Second, both the original and the randomized data sets were divided in half. Using the same parameter settings as in the original Ward's analyses, all halves were analyzed separately. The results again indicated either three or four viable clusters. Third, other hierarchical methods utilizing the original dataset were calculated (Mooi \& Sarstedt, 2011). One of the alternate methods was average linkage, which uses the average distance from samples in one cluster to the samples in the other clusters as the distance measure to determine heterogeny. The other method was centroid linkage, which uses the Euclidean distance between the centroids of two clusters. These two methods also found three- and four-cluster solutions. Based on the outcomes of all of the calculations to determine the stability of the original Ward's method computation, it was determined that both the three- and four-cluster solutions were stable.

To facilitate a better understanding of which cluster configuration, three or four, was the more reasonable choice, a two-step hierarchical analysis was conducted. This analysis utilizes a 
hierarchical procedure to create pre-clusters, followed by a partitioning procedure that combines the clusters. While this algorithm is usually employed for very large datasets, it can be used in smaller ones, especially when univariate assumptions are not met, which is the case with this dataset (Norušis, 2012). The two-step cluster analysis in SPSS uses the Schwarz Bayesian Criterion as a measure of "goodness" in relation to the clusters' homogeneity and heterogeneity. A silhouette coefficient, which varies from -1 to 1 and is interpreted using Kaufman and Rousseeuw’s (2005) rankings (i.e., poor, fair, good), is utilized as a rating measure to illustrate the quality of the overall clustering. The two-step analysis revealed that both cluster solutions were of comparable quality, in the area of fair, on the border of good.

One-way ANOVAs on clustering variables. One-way analyses of variance (ANOVAs) were computed to better define differences among the clusters in the three- and four-cluster groupings. The ANOVAs compared the centroids of the clusters within each grouping. Ward's cluster analyses were recalculated specifying a three- and a four- cluster solution to obtain cluster grouping variables. The four variables (i.e., ASI-3, FPQ, CES-D, CB-SE) were input as dependent variables and the Ward's cluster grouping variables were entered as the factor variables. The ANOVA results were significant for both the three- and four-cluster solutions, indicating that each of the variables reliably differentiated between the clusters in both of the cluster groupings. See Table 6 for the results.

The graph shown in Figure 4 illustrates both cluster solution groupings. Beginning with the three-cluster solution, the women in Cluster $1(n=25)$ scored higher than the median on ASI3, FPQ, and CES-D, and their CB-SE score was just above the median. The women in Cluster 2 $(n=37)$ scored above the median on FPQ and CB-SE, but their ASI-3 and CES-D scores were below the median. The women in Cluster $3(n=40)$ had scores below the median on all 
measures. In the four-cluster solution, women in Cluster $1(n=13)$ had high scores above the median on all measures. Cluster $2(n=37)$ mirrored Cluster 2 from the three-cluster solution. Cluster $3(n=40)$ had the same configuration as Cluster 3 from the three-cluster solution, with low scores on all measures. Cluster $4(n=12)$ had high scores on ASI-3 and CES-D and scores below the median on FPQ and CB-SE.

One-way ANOVAs and Kruskal-Wallis algorithms on demographic variables. To inform the profiling of the clusters and to determine if non-associated variables were influential in differentiating the women in the clusters, one-way ANOVA and Kruskal-Wallis tests were calculated using the Ward's three- and four-cluster grouping variables as the factor variable and the demographic variables shown in Table 3 as the dependent variables (Burns \& Burns, 2008; Mooi \& Sarstedt, 2011). Age was the only significant variable in the ANOVA and KruskalWallis in the three-cluster solution, and in the ANOVA in the four-cluster solution. Age was not significant, however, in the Kruskal-Wallis test in the four-cluster solution. See Table 6 for the results.

Based on the significant statistical outcomes and the differentiation of the clustering, it was determined that the four-cluster solution was more appropriate than the three-cluster solution in distinguishing among the clusters in a clinically relevant manner. Validity of the four-cluster solution was assessed using criteria from Mooi and Starstedt (2001). Overall, the four-cluster solution's validity was substantial, compact, differentiable, relevant, parsimonious, accessible and actionable with assessment measures that can be administered by obstetrical staff. The criterion validity of the four-cluster solution was good because the variables that were used in the analyses were chosen based on current literature. Reliability was not addressed since the study involved only one point of data collection. 


\section{K-means cluster analysis and one-way ANOVA tests on clustering variables. A $k$ -}

means method cluster analysis was calculated on the entire dataset using the Ward's method four-cluster as the grouping parameter, and the ASI-3, FPQ, CES-D, and CB-SE variables as the dependent variables. See Figure 5 for a graph of the final configuration. One-way ANOVAs revealed all variables to be significant. The results of the $k$-means analysis, in addition to means of the actual measure scores to determine clinical levels of the variables for each cluster, are displayed in Table 7. The data in each of the four clusters found by the $k$-means analysis was compared to the data in the same cluster found by the Ward's method analysis. The data within the cluster components were maintained with matching percentages between the components of Cluster $1=46 \%$, Cluster $2=60 \%$, Cluster $3=62 \%$, and Cluster $4=62 \%$. In a dataset the size of the one used for these analyses, a $60 \%$ change is actually only two to three cases.

One-way ANOVAs and Kruskal-Wallis tests on demographic variables. One-way ANOVA and Kruskal-Wallis tests again were calculated, this time using the $k$-means four-cluster grouping variable as the factor variable and the demographic variables as the dependent variables (Burns \& Burns, 2008; Mooi \& Sarstedt, 2011). As shown in Table 7, there were no significant findings; age was no longer significant. These significant associations of the clusters with variables not included in the analyses and representative of the current literature reinforce the criterion validity of the clusters (Burns \& Burns, 2008).

\section{Stage 2 - Analyses of Variance}

To further explore possible differences among clusters and assist in the profiling of the clusters, seven anxiety-related variables were chosen for additional analyses (Grimm \& Yarnold, 2000). The variables included measures assessing childbirth anxiety, catastrophizing, concerns about the baby's health, concerns for their own (i.e., the mother's) health, parenting self-efficacy, 
social support during the birth, and social support with childcare. Independent one-way ANOVAs and Kruskal-Wallis tests were performed as described above on each of these variables. The results are shown in Table 8 . All but one of the variables, parenting self-efficacy, were different across clusters.

\section{Interpretation of the Cluster Solution}

The cluster configuration involved in the following description is the $k$-means 4 -cluster solution; see Table 9. The cluster centroids composed of the means of the four variables, ASI-3, FPQ, CES-D, and CB-SE, were conceptually distinguishable based on the $z$-scores and actual measure scores (Burns \& Burns, 2008). See Table 7. High and low scores on the ASI-3 and CES-D variables reflected emotionality. The means of Cluster 1 and Cluster 4 exceeded the cutoff for major depression $(>27)$ on the CES-D. None of the four cluster means met the cutoff ( $>$ 85) for high childbirth-related anxiety on the W-DEQ. Parenting self-efficacy was not shown to be significant in the ANOVA calculation, so it was not included in the cluster profile.

Cluster $1(n=9)$ contained women who had the highest scores among the clusters on the ASI-3, FPQ-III, W-DEQ, PSWQ, and HAQ. The women had higher scores on childbirth selfefficacy, indicating poorer self-efficacy. Cluster 1 had the lowest score on concerns about their child's health. In this cluster, $100 \%$ of the women had social support for birth and childcare. The profile of this cluster is high emotionality, high catastrophizing, and high anxiety in relation to their health. This cluster also is characterized by high fear of pain, low childbirth selfefficacy, low anxiety in relation to their child's health, and social support for birth and childcare for $100 \%$ of the women.

Cluster $2(n=23)$ had next to the lowest scores on the anxiety measures: ASI, W-DEQ, PSWQ, and HAQ. The score on the CES-D was the lowest among the clusters. The women in 
this cluster had next to the highest score on the FPQ-III. They had the highest score on childbirth self-efficacy, indicating poorer self-efficacy and matching Cluster 1's score on that variable. They also had the highest score for concerns about their child's health. Ninety-six percent of the women had support for their birth and childcare. The profile of this cluster is low emotionality, low catastrophizing, and low anxiety in relation to their health. Other descriptors of this cluster are high fear of pain with low childbirth self-efficacy. These women had high anxiety concerning their child's health, and the majority of the women had support for birth and childcare.

Cluster $3(n=56)$ had the lowest scores on the ASI, FPQ-III, CES-D, CB-SE, W-DEQ, PSWQ, and HAQ. The women in this cluster had the highest score on concerns about their child's health, matching the score of Cluster 2. In relation to social support, $100 \%$ of the women had support for their birth and $98 \%$ had support for childcare. This cluster's profile is low emotionality, low catastrophizing, and low anxiety for their health. This profile had low fear of pain and low childbirth self-efficacy. The women had high anxiety for their child's health, and $98 \%$ had social support for childcare. All of the women had support for their birth.

Cluster $4(n=13)$ had the highest score on CES-D, matching the score of Cluster 1 . The scores on the ASI, W-DEQ, PSWQ, and HAQ were next to the highest among the clusters. The FPQ-III score was next to the lowest and the childbirth self-efficacy score was the lowest, matching the score in Cluster 3. The score for concerns about their child's health was mid-way between the lowest and highest scores. This cluster was lowest in relation to social support, with $85 \%$ of the women having social support for their birth and $77 \%$ having social support for childcare. This profile reflected high emotionality, depression paramount. The fear of pain 
score was lower and childbirth self-efficacy was better. These women had some worry about their child's heath, and expected some degree of social support for birth and childcare.

\section{Discussion}

Prenatal anxiety can negatively affect the mother, child, and her family (Austin, 2004; Wenzel, 2011). It is theorized that interrupting the progression of maternal anxiety from the preto postnatal periods by treating prenatal anxiety can result in more positive outcomes for the child and the mother (Austin, 2004; Brouwers, van Baar, \& Pop, 2001; Kinsella \& Monk, 2009; Wenzel, 2011). The purpose of this study was to explore the prenatal anxiety construct and to determine clinically relevant groups of women, to create a framework for future studies that would facilitate appropriate assessment and treatment referrals.

Results demonstrated that women can be grouped into clusters based on their scores on assessments of anxiety, fear of pain, depression, and childbirth self-efficacy. The four clusters shown below provided stable, distinct groupings upon which clinical referral for services may be based.

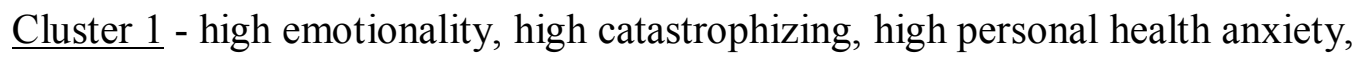
high fear of pain, low childbirth self-efficacy, low anxiety about their child's health. $\underline{\text { Cluster } 2}$ - low emotionality, low personal health anxiety, high fear of pain, low childbirth self-efficacy, high anxiety about their child's health.

Cluster 3 - low emotionality, low personal health anxiety, low fear of pain, high childbirth self-efficacy, high anxiety about their child's health.

$\underline{\text { Cluster } 4}$ - high emotionality, low personal health anxiety, low fear of pain, high childbirth self-efficacy, low anxiety about their child's health. 
In addition to the variables used to create the clusters, women in these groups had both similarities and differences. Overall, expected social support during birth and for childcare was prevalent among the women across the clusters, although it did not differentiate among the clusters. This similarity among clusters is evidenced by comparing the two clusters high in emotionality: Cluster 1, in which $100 \%$ of the women anticipated having support for birth and childcare, with Cluster 4 , in which $85 \%$ of the women anticipated support for the birth and $77 \%$ for childcare. Regardless of high levels of social support in both these clusters, there were other differences between them, suggesting that social support for birth or childcare is not clinically significant in determining cluster membership.

Anxiety sensitivity, as measured by the ASI-3, differentiated the clusters in important ways. For example, in Cluster 1, which had the highest score on anxiety sensitivity, high levels of anxiety encompassed all assessed anxiety areas except the heath of the child. A notable finding for Cluster 1 was that the PSWQ score exceeded the clinical cutoff for generalized anxiety disorder, which was not the case for the other three clusters (Fresco, Mennin, Heimberg, $\&$ Turk, 2003). Women in Cluster 1 may personify the catastrophizing that has been associated with pain in the literature (Bussche, Crombez, Eccleston, \& Sullivan, 2007; Sjögren, 1997).

Women who are in the high emotionality clusters, Cluster 1 and Cluster 4, may be candidates for referral for assessment of anxiety and mood disorders. The women in Cluster 2 and Cluster 3, the low emotionality clusters, had high anxiety scores only in relation to the health of their child. These concerns perhaps could be addressed by the obstetrical staff, possibly by initiating a dialogue and answering questions. If the anxiety remained at high levels and was distressing, these women also might be referred for psychological intervention. 
When higher levels of anxiety were present, such as in Cluster 1 and Cluster 4, so was an elevation in the level of depression. This comorbidity is in line with the tripartite model of anxiety and depression, and it is the basis of the label "emotionality" that was given to all the clusters (Barlow, 2000; Craske et al., 2009). The high emotionality construct present in the clusters also might be predictive of postpartum depression. The two clusters, Cluster 1 and Cluster 4, that presented with high emotionality had clinically significant scores on the anxiety and depression measures and might be referred for psychological treatment, as mentioned previously. In relation to Cluster 3, which was the low emotionality cluster that also had a low score on fear of pain and had high childbirth self-efficacy, prenatal anxiety should continue to be assessed throughout the pregnancy since research indicates that anxiety levels fluctuate throughout that period (Austin \& Priest, 2005; Lee et al., 2007).

High fear of pain uniquely differentiated Cluster 2, and was not associated with anxiety or depression in the women in that cluster. In the two high emotionality clusters, Cluster 1 had the highest fear of pain score while Cluster 4 had a much lower score. In addition, Cluster 2, which had low anxiety and depression scores, had a fear of pain score comparably high with Cluster 1. Childbirth self-efficacy did associate with fear of pain as seen in Cluster 2 and Cluster 4. Cluster 2 indicates that fear of pain can be separate from anxiety in general, which is comparable with work by Carleton and Asmundson (2009). Since the pain-related anxiety in Cluster 2 is focused on the childbirth, women in Cluster 2, who lacked high levels of general anxiety or depression, perhaps should be engaged by their obstetrical caregivers in a discussion of pain management options for childbirth. These women also might be referred to childbirth educators and/or anesthesiologists. Cluster 2, with high levels of anxiety about their child's 
health anxiety and childbirth pain, was consistent with a study by Geissbuehler and Eberhard (2002).

Prenatal anxiety may be uniquely affected by hormonal fluctuations and other biological changes (Wenzel, 2011). The high emotionality clusters, Cluster 1 and Cluster 4, may reflect high sensitivity to hormonally-elicited physical sensations.

Some of the women in the high emotionality clusters may have had anxiety and/or mood disorders prior to pregnancy. Such cases would not represent prenatal anxiety as a unique and separate condition because the elevated emotional distress would have been present prior to pregnancy. Cluster 2, however, might be envisioned as the prototypical prenatal anxiety cluster. The women in that cluster had high fear of pain and low childbirth self-efficacy. This independence of fear of pain has been documented in the current literature, and might be indicative of separate underlying constructs (Carleton \& Asmundson, 2009).

There were no significant findings among clusters in relation to the variables of annual income, household income, education, trimester, previous birth experience, previous traumatic birth, or having a Cesarean section scheduled for the birth. This lack of significance was not in line with the literature, as all of those variables, depending upon the study, have significantly associated with prenatal anxiety. The lack of significance, however, indicated that the clusters differentiated on the clustering variables and were not influenced by extraneous demographic factors. Concerns about parenting self-efficacy were not significantly associated with the clusters. It is possible that, when pregnant, the primary focus of anxiety is the birth. Worries about post-partum issues may well arise after the birth.

Comparing the present analysis with the pilot data (Clemens, 2010) and the current study's $k$-means analysis, both had a cluster that was characterized by low emotionality, low fear 
of pain, and higher childbirth self-efficacy. Both studies had two high emotionality clusters. In the pilot study, the high emotionality clusters had high fear of pain, but differed on childbirth self-efficacy. In the current study, the high emotionality clusters differed on childbirth selfefficacy and fear of pain, with high fear of pain being associated with poorer self-efficacy. The separation of the women into four clusters in the current study seems to have better differentiated the high emotionality clusters based on their fear of pain and childbirth self-efficacy scores.

Even though high prenatal anxiety is a risk factor for numerous negative, long-range outcomes for the mother and her child, estimates are that only $5 \%$ of clinically significant prenatal anxiety in the USA is diagnosed and treated (Borri et al., 2008; Brand \& Brennan, 2009; Buist, Ross, \& Steiner, 2006; Scholle, Haskett, Hanusa, Pincus, \& Kupfer, 2003). Goodman and Tyer-Viola (2010) found that in the 491 women in their study, 113 screened positive for high levels of depression and/or an anxiety disorder during pregnancy. A review of the medical records of those 113 women showed that only $41 \%$ had documentation of any psychological symptoms or diagnoses by their obstetrical caregivers. Woolhouse, Brown, Krastev, Perlen and Gunn (2009) found that $14.7 \%$ of the 1,507 women in their study reported anxiety and depression symptoms postpartum. Of those women, $6.9 \%$ to $15.6 \%$ spoke to no one about it. A retrospective study of 7,081 women in Finland over the years 1996 to 2002 found that mental health problems, including inpatient hospitalizations, were twice as common for women who had previously expressed a fear of childbirth (Rouhe, Salmela-Aro, Gissler, Halmesmäki, \& Saisto, 2011). Schroll, Tabor, and Kjaergaard (2011) found that women who had experienced physical and sexual violence in their lifetime had higher postpartum levels of fear of childbirth. 


\section{Limitations}

The present study had a number of limitations. One issue is that the sample was predominately Caucasian due to the demographics of the geographical area. A second limitation concerns the assessment measures, and this limitation is present overall in the literature. The measures (e.g., ASI-3, CES-D) contained items that might have confounded the results due to overlap between pregnancy and somatic symptoms. A third limitation was that several of the questions used to assess constructs (e.g., childbirth-related self-efficacy), while based in solid and empirically validated theories, have not had their validity and reliability tested. A fourth issue is that the question to assess childbirth self-efficacy related only to the women's abilities in relation to labor pain, not other factors. A fifth limitation is intrinsic to the use of a cluster analysis. A cluster analysis will find clusters regardless of whether or not they truly exist in the data (Hair \& Black, 2000). Finally, these results all are based on one assessment modality, that of self-report.

\section{Future Directions}

This study answered some questions and opened the door for numerous other inquiries. A replication of this study using a newly collected dataset should be performed to determine the reliability of the clusters. A larger dataset providing adequate power for the smaller clusters would boost statistical strength. A larger sample also would provide the opportunity to include other associated variables in the analyses. The social support variable should be further explored. For greater validity and to increase the stability of the clusters, future cluster analyses might use a 2 × 2 table of (general + specific variables) x (observable [directly measurable] + unobservable [inferred]) variables (Wedel \& Kamakura, 2000). Including variables in several 
modalities (e.g., self-report, observations, biological measurements, circumstances, demographics) would add methodological strength.

\section{Conclusions}

In summary, a four-cluster solution using the factors of anxiety sensitivity, fear of pain, depression, and childbirth self-efficacy provides an interesting foundation upon which to build an operational classification of prenatal anxiety. This conceptualization of clusters provides a basis for differentiating appropriate clinical referrals. This solution also can be used for the construction of assessment measures that accommodate pregnancy's somatic symptoms, some of which mirror symptoms of anxiety and depression. Future studies can help refine the clusters and expand associations with other psychological, biological, and social constructs.

Prenatal anxiety is a concern that warrants clinical attention due to the negative outcomes for the mother and her child (Austin, 2003; Austin, Priest, \& Sullivan, 2008; Wenzel, 2011). Levels of prenatal anxiety should be assessed routinely throughout pregnancy. To facilitate diagnosing prenatal anxiety as a clinical condition, work needs to continue on creating and validating parsimonious assessments that accommodate the somatic experiences that pregnancy entails, and that can be easily administered, scored, and interpreted in a clinical setting (Austin, 2003; Lee et al., 2007). 


\section{References}

Alder, J., Fink, N., Bitzer, J., Hösli, I., \& Holzgreve, W. (2007). Depression and anxiety during pregnancy: A risk factor for obstetric, fetal and neonatal outcome? A critical review of the literature. Journal of Maternal-Fetal and Neonatal Medicine, 20, 189-209.

Alehagen, S., Wijma, K., Lundberg, U., Melon, B., \& Wijma, B. (2001). Catecholamine and cortisol reaction to childbirth. Internal Journal of Behavioral Medicine, 8, 50-65.

Alehagen, S., Wijma, B., \& Wijma, K (2006). Fear of childbirth before, during, and after childbirth. Acta Obstetricia et Gynecologica, 85, 56-62.

Alehagen, S., Wijma, K., \& Wijma, B. (2001). Fear during labor. Acta Obstetricia et Gynecologica, 80, 315-320.

American College of Obstetricians and Gynecologists (2004). Labor, delivery and postpartum care: Pain relief during labor and delivery. Danvers, MA:ACOG.

American Psychiatric Association. (2013). Diagnostic and statistical manual of mental disorders (5th ed.). Washington, DC: Author.

Areskog, B., Uddenbert, N., \& Kjessler, B. (1983). Background factors in pregnant women with and without fear of childbirth. Journal of Psychosomatic Obstetrics and Gynaecology, 2, 102-108.

Austin, M-P (2004). Antenatal screening and early intervention for "perinatal" distress, depression and anxiety: Where to from here? Archives of Women's Mental Health, 7, 1-6.

Austin, M-P. (2003). Perinatal mental health: Opportunities and challenges for psychiatry. Australasian Psychiatry, 11, 399-403.

Austin, M-P., Frilingos, M., Lumley, J., Hadzi-Pavlovic, D., Roncolato, W., Acland, S., .. . Parker, G. (2008). Brief antenatal cognitive behavior therapy group intervention for the 
prevention of postnatal depression and anxiety: A randomized controlled trial. Journal of Affective Disorders 105, 35-44.

Austin, M-P., \& Lumley, J. (2003). Antenatal screening for postnatal depression: A systematic review. Acta Psychiatrica Scandinavia, 107, 10-17.

Austin, M-P., \& Priest, S. R. (2005). Clinical issues in perinatal mental health: New developments in the detection and treatment of perinatal mood and anxiety disorders. Acta Psychiatrica Scandinavica, 112, 97-104.

Austin, M-P., Priest, S. R., \& Sullivan, E. A. (2008). Prenatal psychosocial assessment for reducing perinatal mental health morbidity (Review). The Cochrane Library, 4, 1-24.

Avant, K. C. (2006). Anxiety as a potential factor affecting maternal attachment. Journal of Obstetric, Gynecologic, \& Neonatal Nursing, 10, 416-419.

Bakshi, R., Mehta, A., Mehta, A., \& Sharma, B. (2008) Tokophobia, fear of pregnancy and childbirth. Internet Journal of Gynecology \& Obstetrics, 10, 9.

Bandura, A. (1977). Self-efficacy: Toward a unifying theory of behavioral change. Psychological Review, 84, 191-215.

Bandura, A., \& Schunk, D. H. (1981). Cultivating competence, self-efficacy, and intrinsic interest through proximal self-motivation. Journal of Personality and Social Psychology, $41,586-598$.

Barker, D. J. P. (1995). The Welcome Foundation Lecture, 1994. The fetal origins of adult disease. Proceedings of the Royal Society of Biological Sciences, 262, 37-43.

Barlow, D. H. (2002). Anxiety and its disorders: The nature and treatment of anxiety and panic (2nd ed.). New York: The Guildford Press.

Barlow, D. H. (2000). Unraveling the mysteries of anxiety and its disorders from the perspective 
of emotion theory. American Psychologist, 55, 1247-1263.

Beebe, K. R., Lee, K. A., Carrieri-Kohlman, V., \& Humphreys, J. (2007). The effects of childbirth self-efficacy and anxiety during pregnancy on prehospitalization labor. Journal of Obstetric, Gynecologic and Neonatal Nursing, 36, 410-418.

Berentson-Shaw, J. (2009). Do self-efficacy beliefs predict the primiparous labour and birth experience? A longitudinal study. Journal of Reproductive and Infant Psychology, 27, 357-373.

Borri, C., Mauri, M., Oppo, A., Banti, S., Rambelli, C., Ramacciotti, D., . . Cassano, G. B. (2008). Axis I psychopathology and functional impairment at the third month of pregnancy: Results from the perinatal depression-research and screening unit (PNDReScU) Study. Journal of Clinical Psychiatry, 69, 1617-1624.

Boury, J. M., Larkin, K. T., \& Krummel, D. A. (2004). Factors related to postpartum depressive symptoms in low-income women. Women \& Health, 39, 19-34.

Brand, S. R., \& Brennan, P. A. (2009). Impact of antenatal and postpartum maternal mental illness : How are the children? Clinical Obstetrics and Gynecology, 52, 441-455.

Brouwers, E. P. M., van Baar, A. L., \& Pop, V. J. M. (2001). Maternal anxiety during pregnancy and subsequent infant development. Infant Behavior \& Development, 25, 95-106.

Brown, H. M., Trzaskowski, M., Zabos, H. M. S., Rijsdijk, F. V., Gregory, A. M., \& Eley, T. C. (2012). Phenotypic and genetic structure of anxiety sensitivity in adolescence and early adulthood. Journal of Anxiety Disorders, 26, 680-688.

Buist, A., Ross, L. E., \& Steiner, M. (2006). Anxiety and mood disorders in pregnancy and the postpartum period. In D. J. Castle, J. Kulkarni, \& K M. Abel (Eds.) Mood and Anxiety Disorders in Women (pp. 136-162). New York, NY: Cambridge University Press. 
Buist, A., Speelman, C., Hayes, B., Reay, R., Milgrom, J., Meyer, D., \& Condon, J. (2007). Impact of education on women with perinatal depression. Journal of Psychosomatic Obstetrics \& Gynecology, 28, 49-54.

Burns, G. L., Keortge, S. G., Formea, G. J., \& Sternberger, L. G. (1996). Revision of the Padua Inventory of Obsessive Compulsive Disorder Symptoms: Distinctions between worry, obsessions, and compulsions. Behaviour Research and Therapy, 34, 163-173.

Burns, R. \& Burns, R. (2008). Business Research Methods and Statistics Using SPSS. Thousand Oaks, CA: SAGE Publications.

Callister, L. C., Khalaf, I., Kartchner, R., \& Vebvilainen-Julkunen (2003). The pain of childbirth: Perceptions of culturally diverse women. Pain Management Nursing, $4,145-154$.

Cano, A., \& de C. Williams, A. C. (2010). Social interaction in pain: Reinforcing pain behaviours or building intimacy? Psychology Faculty Research Publications, Paper 13, http://digitalcommons.wayne.edu/psychfrp/13.

Cardoso, C., Linnen, A-M., Joober, R., \& Ellenbogen, M. A. (2011). Coping style moderates the effect of intranasal oxytocin on the mood response to interpersonal stress. Experimental and Clinical Psychopharmacology, 20, 84-91.

Carleton, R. N., Abrams, M. P., Asmundson, G. J. G., Antony, M. M., \& McCabe, R. E. (2009). Pain-related anxiety and anxiety sensitivity across anxiety and depressive disorders. Journal of Anxiety Disorders, 23, 791-798.

Carleton, R. N., \& Asmundson, G. J. (2009). The multidimensionality of fear of pain: Construct independence for the Fear of Pain Questionnaire-Short Form and the Pain Anxiety Symptoms Scale 20. Journal of Pain, 10, 29-37. 
Caton, D., Corry, M. P., Frigoletto, F. D., Hopkins, D. P., Lieberman, E., Mayberry, L., .. . Rooks, J. P. (2002). The nature and management of labor pain: Executive Summary. American Journal of Obstetrics and Gynecology, 186, 1-15.

Caton, D., Frölich, M. A., \& Euliano, R. Y. (2002). Anesthesia for childbirth: Controversy and change. American Journal of Obstetrics and Gynecology, 186, 25-30.

Chang, M. Y., Chen, S. H., \& Chen, C. H. (2002). Factors related to perceived labor pain in primiparas. Kaohsiung Journal of Medical Science, 18: 604-609.

Chrousos, G. P. (2009). Stress and disorders of the stress system. National Review of Endocrinology, 5, 374-381.

Cigoli, V., Gilli, G., \& Saita, E. (2006). Relational factors in psychopathological responses to childbirth. Journal of Psychosomatic Obstetrics \& Gynecology, 27, 91-97.

Clemens, S. W. (2010). Assessing the psychometric properties of the Childbirth Stages of Readiness Questionnaire (CSORQ). Unpublished master's thesis, West Virginia University, Morgantown, WV.

Cole, S. W. (2009). Social regulation of gene expression. Current Directions in Psychological Science, 18, 132-137.

Coleman, P. K., \& Karraker, K. H. (1997). Self-efficacy and parenting quality: Findings and future applications. Developmental Review, 18, 47-85.

Craske, M. G. (2003). Origins of phobias and anxiety disorders: Why more women than men? Oxford, UK: Elsevier.

Craske, M. G., Antony, M. M., \& Barlow, D. H. (2006). Mastering your fears and phobias $\left(2^{\text {nd }}\right.$ ed.). New York, NY: Oxford University Press, Inc.

Craske, M. G., Rauch, S. L., Ursano, R., Prenoveau, J., Pine, D. S., \& Zinbarg, R. E. (2009). 
What is an anxiety disorder? Depression and Anxiety, 26, 1006-1085.

Cyna, A. M., \& Dodd, J. (2007). Clinical update: Obstetric anaesthesia. The Lancet, 370, 640642.

Dannenbring, D., Stevens, M. J., \& House, A. E. (1997). Predictors of childbirth pain and maternal satisfaction. Journal of Behavioral Medicine, 20, 127-142.

Davies, J., Slade, P., Wright, I., \& Stewart, P. (2008). Postraumatic stress symptoms following childbirth and mothers' perception of their infants. Infant Mental Health Journal, 29, $537-554$.

Davis, E. P., \& Sandman, C. A. (2010). The timing of prenatal exposure to maternal cortisol and psychosocial stress is associated with human infant cognitive development. Child Development, 81, 131-148.

Davis, M. (1992). The role of the amygdala in fear and anxiety. Annual Review of Neuroscience, $15,353-375$.

Dayan, J., Creveuil, C., Marks, M. N., Conroy, S., Herlicoviez, M., Dreyfus, M., \& Tordjman, S. (2006). Prenatal depression, prenatal anxiety, and spontaneous preterm birth: A

Dolnicar, S. (2002). A review of unquestioned standards in using cluster analysis for datadriven market segmentation. Retrieved September 19, 2011, from http://ro.uow.edu.au/cgi/viewcontent.

Dreher, J-C., Schmidt, P. J., Kohn, P., Furman, D., Rubinow, D., \& Berman, K. F. (2007). Menstrual cycle phase modulates reward-related neural function in women. Proceedings of the National Academy of Science of the United States of America, 104, 2465-2470.

Eisenberger, N. I., \& Lieberman, M. D. (2004). Why rejection hurts: A common neural alarm system for physical and social pain. TRENDS in Cognitive Sciences, 8, 295-300. 
Erdfelder, E., Faul, F., \& Buchner, A. (1996). GPOWER: A general power analysis program. Behavior Research Methods, Instruments, \& Computers, 28, 1-11.

Fairbrother, N., \& Woody, S. R. (2007). Fear of childbirth and obstetrical events as predictors of postnatal symptoms of depression and post-traumatic stress disorder. Journal of Psychosomatic Obstetrics \& Gynecology, 28, 239-242.

Felmingham, K. L., Fong, W. C., \& Bryant, R. A. (2012). The impact of progesterone on memory consolidation of threatening images in women. Psychoneuroendocrinology, 37, 1896-1900.

Ferber, S. G., \& Feldman, R. (2005). Delivery pain and the development of mother-infant interaction. Infancy, 8, 43-62.

Filippova, L. V., \& Nozdrachev, A. D. (2010). Modern concepts on the mechanisms of encoding visceral nociceptive stimuli. Human Physiology, 36, 107-117.

Fresco, D. M., Mennin, D. S., Heimberg., R. G., \& Turk, C. L. (2003). Using the Penn State Worry Questionnaire to identify individuals with generalized anxiety disorder: A receiver operating characteristic analysis. Behavior Therapy and Experimental Psychiatry, 34, 283-291.

Gaskin, I. M. (2002). Spiritual midwifery ( $4^{\text {th }}$ ed). Summertown, TN: Book Publishing Company.

Gaskin, I. M. (2003). Ina May's guide to childbirth. New York, NY: Random House.

Geissbuehler, V., \& Eberhard, J. (2002). Fear of childbirth during pregnancy: A study of more than 8000 pregnant women. Journal of Psychosomatic Obstetrics \& Gynecology, 23, $229-235$.

Gentile, S. (2010). Neurodevelopmental effects of prenatal exposure to psychotropic 
medications. Depression and Anxiety, 27, 675-686.

George, S. Z., Wallace, M. R., Wright, T. W., Moser, M. W., Greenfield III, W. H., Sack, B. K., . . Fillingim, R. B. (2008). Evidence for a biopsychosocial influence on shoulder pain. Pain catastrophizing and catechol- $O$-methyltransferase (COMT) diplotype predict clinical pain ratings. Pain, 136, 53-61.

Goodman, J. H., \& Tyer-Viola, L. (2010). Detection, treatment, and referral of perinatal depression and anxiety by obstetrical providers. Journal of Women's Health, 19, 477490.

Grillon, C. (2008). Models and mechanisms of anxiety: Evidence from startle studies. Psychopharmacology, 199, 421-437.

Hadjistavropoulos, T., Craig, K. D., \& Fuchs-Lacelle, S. (2004). Social influences and the communication of pain. In T. Hadjistavropoulos \& K. D. Craig (Eds.), Pain: Psychological perspectives (pp. 87-112). Mahwah, NJ: Lawrence Erlbaum Associates.

Hahn, S. R., Feiner, J. S., \& Bellin, E. H. (1988). The doctor-patient-family relationship: A compensatory alliance. Annals of Internal Medicine, 109, 884-889.

Hair, J. F., Jr., \& Black, W. C. (2000). Cluster analysis. In L. G. Grimm \& P. R. Yarnold (Eds.), Reading and understanding more multivariate statistics (pp. 147-205). Washington, DC: American Psychological Association.

Hazlett-Stevens, H. \& Craske, M. G. (2003). The catastrophizing worry process in generalized anxiety disorder: A preliminary investigation of an analog population. British Association for Behavioural and Cognitive Psychotherapies. Retrieved March 21, 2013, from http://dx.doi.org/10.1017/S1352465803004016.

Hazlett-Stevens, H., Ullman, J. B., \& Craske, M. G. (2004). Factor structure of the Penn State 
Worry Questionnaire: Examination of a method factor. Assessment, 11, 361-370.

Hildingsson, I., Nilsson, C., Karlström, A., \& Lundgren, I. (2011). A longitudinal survey of childbirth-related fear and associated factors. Journal of Obstetric, Gynecologic, \& Neonatal Nursing, 40, 532-543.

Hofberg, K. \& Ward, M. R. (2002). Fear of pregnancy and childbirth. Postgraduate Medical Journal, 79, 505-510.

International Association for the Study of Pain. In IASP pain terminology. Retrieved March 6, 2009, from http://www.iasp-pain.org.

Jokić-Begić, N (2010). Cognitive-behavioral therapy and neuroscience: Towards closer integration. Psychological Topics, 19, 235-254.

Kay, M. A. (1982). Anthropology of human birth. Philadelphia, PA: F. A. Davis Company. Kaufman, L., \& Rousseeuw, P. J. (2005). Finding groups in data: An introduction to cluster analysis. Hoboken, NJ: John Wiley \& Sons, Inc.

Kelly, R. H., Russo, J., \& Katon, W. (2001). Somatic complaints among pregnant women cared for in obstetrics: Normal pregnancy or depressive and anxiety symptom amplification revisited? General Hospital Psychiatry, 23, 107-113.

Kemper, C. H., Lutz, J., Bähr, T., Rüddel, H., \& Hock, M. (2012). Construct validity of the Anxiety Sensitivity Index-3 in clinical samples. Assessment, 19, 89-100.

Kinsella, M. T., \& Monk, C. (2009). Impact of maternal stress, depression and anxiety on fetal neurobehavioral development. Clinical Obstetrics and Gynecology, 52, 425-440.

Klusman, L. E. (1975). Reduction of pain in childbirth by the alleviation of anxiety during pregnancy. Journal of Consulting and Clinical Psychology, 43, 162-165.

Kolb, B., \& Whishaw, I. Q. (1998). Brain plasticity and behavior. Annual Review of 
Psychology, 49, 43-64.

Kraszpulski, M., Dickerson, P. A., \& Salm, A. K. (2006). Prenatal stress affects the developmental trajectory of the rat amygdala. Stress, 9, 85-95.

Kross, E., Berman, M. S., Mischel, W., Smith E. E., \& Wager, T. D. (2011). Social rejection shares somatosensory representations with physical pain. Proceedings of the National Academy of Sciences Early Edition, 108, 6270-6275.

Kuo, D.-D, Chen, G.-Y., Yang, M.-J., Lo, H.-M., \& Tsai, Y.-S. (2000). Biphasic changes in autonomic nervous activity during pregnancy. British Journal of Anesthesia, 84, 323329.

Lang, P. J., \& McTeague, L. M. (2009). The anxiety disorder spectrum: Fear imagery, physiological reactivity and differential diagnosis. Anxiety, Stress \& Coping, 22, 5-25.

Lang, A. J., Sorrell, J. T., Rodgers, C. S., \& Lebeck, M. M. (2006). Anxiety sensitivity as a predictor of labor pain. European Journal of Pain, 10, 263-270.

Lederman, R. P., Lederman, E., Work, Jr., B., \& McCann, D. (1985). Anxiety and epinephrine in multiparous women in labor: Relationship to duration of labor and fetal heart rate pattern. American Journal of Obstetrics and Gynecology, 153, 870-877.

LeDoux, J. E. (2002). Synaptic self. New York: Penguin Books.

Lee., A. M., Lam, S. K., Lau, S. M. S. M., Chong, C. S. Y., Chui, H. W., \& Fong, D. Y. T. (2007). Prevalence, course, and risk factors for antenatal anxiety and depression. Obstetrical Gynecology, 110, 1102-1112.

Leeuw, M., Goossens, M. E. J. B., Linton, S. J., Crombez, G., Boersma, K., \& Vlaeyen, J. W. S. (2007). The fear-avoidance model of musculoskeletal pain: Current state of scientific evidence. Journal of Behavioral Medicine, 30, 77-94. 
Leonardo, E. D., \& Hen, R. (2008). Anxiety as a developmental disorder. Neuropsychopharmacology, 33 134-140.

Leveno, K. J., Cunningham, F. G., Gant, N. F., Alexander, J. M., Bloom, S. L., Casey, B. M., . . Yost, N. P. (2003). Williams manual of obstetrics. New York: McGraw-Hill.

Lowe, N. K. (1987). Individual variation in childbirth pain. Journal of Psychosomatic Obstetrics and Gynaecology, 7, 183-192.

Lucock, M. P. \& Morley, S. (1996). The Health Anxiety Questionnaire. British Journal of Health Psychology, 1, 137-150.

Marks, I. M. (1987). Fears, phobias, and rituals: Panic, anxiety, and their disorders. New York, NY: Oxford University Press.

Marmor, T. R., \& Krol, D. M. (2002). Labor pain management in the Unites States: Understanding patterns and the issue of choice. American Journal of Obstetrics and Gynecology, 186, 173-180.

Matthew, S., Barnet, B., Howie, P., \& Kavanagh, D. J. (2003). Diagnosing postpartum depression in mothers and fathers: Whatever happened to anxiety? Journal of Affective Disorders, 74, 139-147.

Mazur, J. E. (2006). Learning and behavior (6 $6^{\text {th }}$ ed.). Upper Saddle River, NJ: Pearson Education Inc.

Mazure, C. M., Keita, G. P., \& Blehar, M. C. (2002), Summit on women and depression: Proceedings and recommendations. Washington, DC: American Psychological Association.

McEwen, B. S., Eiland, L., Hunter, R. G., \& Miller, M. M. (2012). Stress and anxiety: Structural plasticity and epigenetic regulation as a consequence of stress. Neuropharmacology, 62, 
3-12.

McNeil, D. W., \& Berryman, M. L. (1989). Components of dental fear in adults? Behaviour Research and Therapy, 27, 233-236.

McNeil, D. W. \& Rainwater, A. (1998). Development of the Fear of Pain Questionnaire - III. Journal of Behavioral Medicine, 21, 389-1349

McNeil, D. W., Ries, B. J., Turk, C. L., \& Vargovich, A. (in press). Anxiety and fear. In V. S. Ramachandran (Ed.), Encyclopedia of human behavior, $2^{\text {nd }}$ ed. San Diego: Academic Press.

Melender, H. (2002). Experiences of fears associated with pregnancy and childbirth: A study of 329 pregnant women. Birth, 29, 101-111.

Melzack, R., \& Katz, J. (2004). The gate control theory: Reaching for the brain. In T. Hadjistavropoulos \& K. D. Craig (Eds.), Pain: Psychological perspectives (pp. 87-112). Mahwah, NJ: Lawrence Erlbaum Associates.

Mennes, M., Van Den Bergh, B., Lagae, L., \& Stiers, P. (2009). Developmental brain alternations in 17 year old boys are related to antenatal maternal anxiety. Clinical Neurophysiology, 120, 1116-1122.

Meyer, T. J., Miller, M. L., Metzger, R. L., \& Borkovec, T. D. (1990). Development and validation of the Penn State Worry Questionnaire. Behaviour Research and Therapy, 28, 487-495.

Misri, S., Kendrick, K.., Oberlander, T. F., Norris, S., Tomfohr, L., Zhang, H., \& Grunau, R. E. (2010). Antenatal depression and anxiety affect postpartum parenting stress: A longitudinal, prospective study. Canadian Journal of Psychiatry, 55, 222-228.

Mogil, J. S., Sorge, R. E., LaCroix-Fralish, M. L., Smith, S. B., Fortin, A., Sotocinal, S. G., . . 
Fillingim, R. B. (2011). Pain sensitivity and vasopressin analgesia are mediated by a gene-sex-environment interaction. Nature Neuroscience, 14, 1569-1573.

Molina, S., \& Borkovec, T. D. (1994). The Penn State Worry Questionnaire: Psychometric properties and associated characteristics. In G. Davey \& F. Tallis (Eds.), Worrying: Perspectives on theory, assessment and treatment (pp. 265-283). New York, NY: Wiley

Monk, C., Fifer, W. P., Myers, M. M., Sloan, R. P. Trien, L., \& Hurtado, A. (2000). Maternal stress responses and anxiety during pregnancy: Effects on fetal heart rate. Developmental Psychobiology, 36, 67-77.

Mooi, E., \& Sarstedt, M. (2001). A concise guide to market research, DOI 10.1007/978-3-64212541-6 9, Springer-Verlag Berlin Heidelberg, 2011.

National Institute of Mental Health (2011). Any anxiety disorder among adults. Retrieved October 11, 2011, from http://nimh.nih.gov/statistics/1ANYANX_ADULT.shtml.

Nerun, H., Halvorsen, L., Sørlie, T., \& Øian, P. (2006). Maternal request for cesarean section due to fear of birth: Can it be changed through crisis-oriented counseling? Birth, 33: 221228.

Nieminen, K., Stephansson, O., \& Ryding, E. L. (2009). Women's fear of childbirth and preference for cesarean section - a cross-sectional study at various stages of pregnancy in Sweden. Acta Obstetricia et Gynecologica, 88, 807-813.

Norušis, M. J. (2012). IBM SPSS Statistics 19: Statistical Procedures Companion. Upper Saddle River, New Jersey: Prentice Hall.

O’Connor, T. G., Ben-Shlomo, Y., Heron, J., Golding, J., Adams, D., \& Glover, V. (2005). Prenatal anxiety predicts individual differences in cortisol in pre-adolescent children. Biological Psychiatry, 58, 211-217. 
O’Connor, T. G., Heron, J., Golding, J., Beveridge, M., \& Glover, V. (2003). Maternal antenatal anxiety and children's behavioral/emotional problems at 4 years: Report for the Avon Longitudinal Study of Parents and Children. British Journal of Psychiatry, 180, 502-508.

O’Connor, T. G., Heron, J., Golding, J., Glover, V., and the ALSPAC Study Team (2003). Maternal antenatal anxiety and behavioural/emotional problems in children: A test of a programming hypothesis. Journal of Child Psychology and Psychiatry, 44, 1025-1036.

Otley, H. (2011). Fear of childbirth: Understanding the causes, impact and treatment. British Journal of Midwifery, 19, 215-220.

Osman, A., Gutierrez, P. M., Smith, K., Fang, Q., Lozano, G., \& Devine, A. (2010). The Anxiety Sensitivity Index-3: Analyses of dimensions, reliability estimates, and correlates in nonclinical samples. Journal of Personality Assessment, 92, 45-52.

Ozer, E. M. (1995). The impact of childcare responsibility and self0efficacy on the psychological health of professional working mothers. Psychology of Women Quarterly, $19,315-335$.

Qiu, C., Wililams, M. A., Calderon-Margalit, R., Cripe, S. M., \& Sorensen, R. K. (2009). Preeclampsia risk in relation to maternal mood and anxiety disorders diagnosed before or during early pregnancy. American Journal of Hypertension, 22, 397-402.

Radloff, L. S. (1977). The CES-D Scale: A self-report depression scale for research in the general population. Applied Psychological Measurement, 1, 385-401.

Reynolds, J. L. (1988). Anxiety and childbirth. Canadian Family Physician, 34, 1831-1832.

Reid, H., Power, M., \& Cheshire, K. (2009). Factors influencing antenatal depression, anxiety and stress. British Journal of Midwifery, 17, 501-508.

Riskind, J. H. \& Williams, N. L. (1999). Specific cognitive content of anxiety and 
catastrophizing: Looming vulnerability and the looming maladaptive style. Journal of Cognitive Psychotherapy, 13, 41-45

Ross, L. E., Sellers, E. J., Evans, G., and Romach, M. K. (2004). Mood changes during pregnancy and the postpartum period: Development of a biopsychosocial model. Acta Psychiatrica Scandinavica, 109, 457-466.

Rouhe, H., Salmela-Aaro, K., Gissler, M., Halmesmäki, E., \& Saisto, T. (2011). Mental health problems common in women with fear of childbirth. BJOG: An International Journal of Obstetrics and Gynaecology, 118, 1104-1111.

Ruau, D., Dudley, J. T., Chen, R., Phillips, N. G., Swan, G. E., Lazzeroni, L. C., . . Angst, M. S. (2012). Integrative approach to pain genetics indentifies pain sensitivity loci across diseases. PLOS Computational Biology, 8, 1-12.

Ruggiero, K. J., Del Ben, K., Scotti, J. R., \& Rabalais, A. E. (2003). Psychometric properties of the PTSD Checklist - Civilian Version. Journal of Traumatic Stress, 16, 295-502.

Ryding, E. L., Wijma, K., \& Wijma, B. (1998). Psychological impact of emergency caesarean section in comparison with elective caesarean, instrumental, and normal vaginal delivery. Journal of Psychosomatic Obstetrics and Gynecology, 19, 133-144.

Saisto, T., \& Halmesmaki, E. (2003). Fear of childbirth: A neglected dilemma. Acta Obstetricia et Gynecologica Scandinavica, 82, 201-208.

Samant, A., Malik, C. P., Chabra, S. K., \& Devi, P. K. (1976). Gingivitis and periodontal disease in pregnancy. Journal of Periodontology, 47, 415-418.

Scholle, S. H., Haskett, R. F., Hanusa, B. H., Pincus, H. A., \& Kupfer, D. J. (2003). Addressing depression in obstetrics/gynecology practice. General Hospital Psychiatry, 25, 83-90.

Schroll, A-M., Tabor, A., \& Kjaergaard, H. (2011). Physical and sexual lifetime violence: 
prevalence and influence on fear of childbirth before, during and after delivery. Journal of Psychosomatic Obstetrics \& Gynecology, 32, 19-26.

Selye, H. (1976). Forty years of stress research: Principal remaining problems and misconceptions. Canadian Medical Association Journal, 115, 53-56.

Senden, I. P. M., vd Wetering, M. D., Eskes, A. B., Bierkens, P. B., Laube, D. W., \& Pitkin, R. M. (1998). Labor pain. A comparison of paturients in a Dutch and an American Teaching Hospital. Obstetrical Gynecology, 71, 541-543.

Serçekuş, P., \& Okumuş, H. (2009). Fears associated with childbirth among nulliparous women in Turkey. Widwifery, 25, 155-162.

Sieber, S., Germann, N., Barbir, A., \& Ehlert, U. (2006). Emotional well-being and predictors of birth-anxiety, self-efficacy, and psychosocial adaptation in healthy pregnant women. Acta Obstetricia et Gynecologica, 85, 1200-1207.

Sjögren, B. (1997). Reasons for anxiety about childbirth in 100 pregnant women. Journal of Psychosomatic Obstetrics and Gynecology, 18, 266-272.

Soucasaux, N. (1993). Uterine contractility in the female sexual organs: Shape, function, symbol and archetype. Rio de Janeiro: Imago Editora.

Spielman, V., \& Taubman-Ben-Ari, O. (2009). Parental self-efficacy and stress-related growth in the transition to parenthood: A comparison between parents of pre- and full-term babies. Health \& Social Work, 34, 201-212.

Standley, K., Soule, B., \& Copans, S. A. (1979). Stressful events related to pregnancy and postpartum. American Journal of Obstetrics and Gynecology, 135, 22-26.

Stockman, A. F., \& Altmaier, E. M. (2001). Relation of self-efficacy to reported pain and pain medication usage during labor. Journal of Clinical Psychology in Medical Settings, 8, 
161-166.

Storksen, H. T., Eberhard-Gran, M., Garthus-Niegel, S., \& Eskild, A. (2011). Fear of childbirth; the relation to anxiety and depression. Acta Obstetricia et Gynecologica, 91, 237-242.

Sullivan, M. J. L., Thorn, B., Haythornthwaite, J., Keefe, F., Martin, M., Bradley, L., \& Lefebvre, J. C. (2001). Theoretical perspectives on the relation between catastrophizing and pain. The Clinical Journal of Pain, 17, 52-64.

Tabachnick, B. G. \& Fidell, L. S. (2007). Using multivariate statistics ( $^{\text {th }}$ ed.). New York, NY: Pearson Education, Inc.

Taylor, S. E., Klein, L. C., Lewis, B. P., Gruenewald, T L., Gurung, R. A. R., \& Updegraff, J. A. (2000). Biobehavioral responses to stress in females: Tend-and-befriend, not fight-orflight. Psychological Review, 107, 411-429.

Taylor, S., Zvolensky, M. J., Cox, B. J., Deacon, B., Heimberg, R. G., Ledley, D. R. . . Cardenas, S. J. (2007). Robust dimensions of anxiety sensitivity: Development and initial validation of the Anxiety Sensitivity Index-3. Psychological Assessment, 19, 176-188.

Thorn, B. E., Ward, L. C., Sullivan, M. J. L., \& Boothby, J. L. (2003). Communal coping model of catastrophizing: conceptual model building: Pain, 106, 1-2.

Ulrich-Lai, Y. M., \& Herman, J. P. (2009). HPA axis and autonomic nervous system responses to stress. Nature Reviews Neuroscience, 10, 387-409.

Van Den Bergh, B. R. H., \& Marcoen, A. (2004). High antenatal maternal anxiety is related to ADHD symptoms, externalized problems, and anxiety in 8- and 9-year olds. Child Development, 75, 1085-1097.

Vancleef, L. M. G., \& Peters, M. L. (2006). Pain catastrophizing, but not injury/illness sensitivity or anxiety sensitivity, enhances attentional interference by pain. Journal of 
Pain, 7, 23-30.

Vancleef, L. M. G., Peters, M. L., Roelofs, J., \& Asmundson, G. J. (2006). Do fundamental fears differentially contribute to pain-related fear and pain catastrophizing? An evaluation of the sensitivity index. Journal of Pain, 10, 527-536.

Van den Bussche, E., Crombez, G., Eccleston, C., \& Sullivan, M. J. L. ((2007). Why women prefer epidural analgesia during childbirth: The role of beliefs about epidural analgesia and pain catastrophizing. European Journal of Pain, 11, 275-282.

Vasey, M., W. \& Borkovec, T. D. (1992). A catastrophizing assessment of worrisome thoughts. Cognitive Therapy and Research, 16, 505-520.

Vowles, K. E., McNeil, D. W., Sorrell, J. T., \& Lawrence, S. M. (2006). Fear and pain: Investigating the interaction between aversive states. Journal of Abnormal Psychology, 115, 821-833.

Waldenström, U., Hildingsson, I., \& Ryding, E. L. (2006). Antenatal fear of childbirth and its association with subsequent caesarean section and experience of childbirth. An International Journal of Obstetrics and Gynaecology (BJOG), 113, 638-646.

Waters, E., Crowell, J., Elliott, M., Corcoran, D., \& Trevoux, D. (2002). Bowlby’s secure base theory and the social/personality psychology of attachment styles: Work(s) in progress. Attachment and Human Development, 4, 230-242.

Weathers, F. W., Ruscio, A. M., \& Keane, T. M. (1999). Psychometric properties of nine scoring rules for the Clinician-Administered Posttraumatic Stress Disorder Scale. Psychological Assessment, 11, 124-133.

Wenzel, A. (2011). Anxiety in childbearing women: Diagnosis and treatment. Washington, DC:American Psychological Association. 
Wenzel, A., Haugen, E. N., Jackson, L. C., \& Brendle, J. R. (2005). Anxiety symptoms and disorders at eight weeks postpartum. Anxiety Disorders, 19, 295-311.

White, T., Matthey, S., Boyd, K., \& Barnett, B. (2006). Postnatal depression and post-traumatic stress after childbirth: Prevalence, course and co-occurrence. Journal of Reproductive and Infant Psychology, 24, 107-120.

Wijma, K., Wijma, B. \& Zar, M. (1998). Psychometric aspects of the W-DEQ: A new questionnaire for the measurement of fear of childbirth. Journal of Psychosomatic Obstetrics and Gynecology, 19, 84-97.

Woolhouse, H., Brown, S., Krastev, A., Perlen, S, \& Gunn, J. (2009). Seeking help for anxiety and depression after childbirth: Results of the Maternal Health Study. Archives of Women's Mental Health, 12, 75-83.

World Bank, Fertility rate, total (births per woman). Retrieved October 12, 2011, from http://data.worldbank.org/indicator/SP.DYN.TFRT.IN.

World Health Organization. (1996). Safe motherhood. Care in normal birth: A practical guide. Geneva, Switzerland: World Health Organization.

Yonkers, K. A., Smith, M. V., Gotman, N., \& Belanger, K. (2009). Typical somatic symptoms of pregnancy and their impact on a diagnosis of major depressive disorder. General Hospital Psychiatry, 31, 327-333.

Zar, M., Wijma, K., \& Wijma, B. (2002). Relations between anxiety disorders and fear of childbirth during late pregnancy. Clinical Psychology and Psychotherapy, 9, 122130.

Zich, J. M., Attkisson, C. C., \& Greenfield, T. K. (1990). Screening for depression in primary care clinics: The CES-D and the BDI. International Journal of psychiatry in Medicine, 
3, 259-275.

Zumbo, B. D., Gelin, M. N., \& Hubley, A. M. (2001, February). Psychometric study of the CED-D: Factor analysis and DIF. Paper presented at the International Neuropsychological Society's $29^{\text {th }}$ Annual Meeting, Chicago, IL. 


\section{Appendix A}

\section{Exploring Cesarean Section Findings}

Across the four clusters identified by Ward's method, there were no differences in type of birth, Cesarean or vaginal. It was noted, however, that Cluster 1 and Cluster 4 had no women scheduled for Cesarean birth. These two clusters also had in common high scores on the ASI-3 and CESD variables. See Table 5. To explore the differences between the clusters, the entire original dataset was divided by the variable C-Section Scheduled; and a Ward's hierarchical analysis was computed on each of the resulting dataset sections. See Figure 5 for the scree plot and dendrogram. The women scheduled for Cesarean delivery clustered into a three- or fourcluster solution. The women who were not scheduled for Cesarean delivery, however, clustered in either a four- or five-cluster solution.

ANOVAs were calculated on the dataset split on the" C-Section Scheduled" variable using the three-, four-, and five-cluster grouping variables as factors. The dependent variables were: a) the ASI-3, FPQ, CESD, and CB-SE variables and b) the demographics variables (see Table 6). The resulting clusters were: three-cluster/yes, three-cluster/no; four-cluster/yes, fourcluster/no; and five-cluster/yes, five-cluster/no. Comparing the clusters across the clustering groups, for the women scheduled for Cesarean delivery, ASI-3 was not significant in the fourand five-cluster groupings and CESD was not significant in the three-cluster grouping. All other of the clustering groupings relating to the ASI-3, FPQ, CESD, and CB-SE variables were significant at either alpha $=.05$ or lower. None of the demographics variables varied across clusters except FPQ. Across each of the groupings, when women were scheduled for Cesarean delivery, one cluster had elevated FPQ scores without associated elevations in ASI-3 or CESD. The balance of the cluster groupings were variations on the overall dataset. While the findings 
were of interest, the purpose of this study was to examine prenatal anxiety in all women, not to differentiate between women who were scheduled for Cesarean birth. Since the original ANOVA found no significance between clusters concerning the Cesarean section variable and since the inclusion of women scheduled for Cesarean section was deemed integral for external validity, the data for these women were retained.

Table: ANOVA Results for Ward's Method 3-, 4-, 5-Clusters - Split File on CsecScheduled $(Y / N)$

\begin{tabular}{|c|c|c|c|c|}
\hline & Variable & C-Sec & $\boldsymbol{F}$ & $p$ value \\
\hline \multicolumn{5}{|l|}{ 3-Cluster $F(2)$} \\
\hline & Age & Yes & .13 & .88 \\
\hline 3-Cluster/Yes: & & No & 1.43 & .24 \\
\hline $1: n=5$ & Trimester & Yes & .34 & .72 \\
\hline $2: n=2$ & & No & .67 & .52 \\
\hline \multirow{2}{*}{$3: n=4$} & Annual Income & Yes & 2.57 & .14 \\
\hline & & No & 2.36 & .10 \\
\hline 3-Cluster/No: & Household Income & Yes & .19 & .83 \\
\hline $1: n=12$ & & No & 1.13 & .33 \\
\hline $2: n=65$ & Education Level & Yes & .86 & .46 \\
\hline \multirow[t]{5}{*}{$3: n=13$} & & No & 1.00 & .38 \\
\hline & \# Prev. Births & Yes & .36 & .71 \\
\hline & & No & .31 & .73 \\
\hline & Other Births & Yes & .16 & .86 \\
\hline & & No & .56 & .58 \\
\hline \multicolumn{5}{|l|}{ 4-Cluster $F(3)$} \\
\hline & Age & Yes & .18 & .91 \\
\hline 4-Cluster/Yes: & & No & 1.00 & .40 \\
\hline $1: n=3$ & Trimester & Yes & .21 & .89 \\
\hline $2: n=2$ & & No & .58 & .63 \\
\hline $3: n=4$ & Annual Income & Yes & 2.62 & .13 \\
\hline \multirow[t]{2}{*}{$4: n=2$} & & No & 1.72 & .17 \\
\hline & Household Income & Yes & .39 & .76 \\
\hline 4-Cluster/No: & & No & 2.02 & .12 \\
\hline $1: n=12$ & Education Level & Yes & .67 & .60 \\
\hline $2: n=56$ & & No & .74 & .53 \\
\hline $3: n=10$ & \# Prev. Births & Yes & .21 & .90 \\
\hline $4: n=13$ & & No & .23 & .88 \\
\hline
\end{tabular}




\begin{tabular}{rllll}
\hline & Other Births & Yes & .12 & .94 \\
\hline \multicolumn{7}{r}{} & & No & .37 & .78 \\
\hline 5-Cluster $\boldsymbol{F ( 4 )}$ & & & & .13 \\
\hline 5-Cluster/Yes: & & Yes & .75 & .56 \\
\hline $1: n=3$ & Trimester & No & .30 & .87 \\
\hline $2: n=1$ & & Yes & .67 & .62 \\
\hline $3: n=1$ & Annual Income & No & 1.68 & .27 \\
\hline $4: n=4$ & & Yes & 1.28 & .29 \\
\hline $5: n=2$ & Household Income & No & .51 & .80 \\
\hline & & Yes & 1.51 & .21 \\
\hline 5-Cluster/No: & Education Level & No & 1.00 & .48 \\
\hline $1: n=12$ & & Yes & .60 & .63 \\
\hline $2: n=22$ & \# Prev. Births & No & .35 & .92 \\
\hline $3: n=10$ & & Yes & .34 & .74 \\
\hline $4: n=13$ & Other Births & Yes & .49 & .90 \\
\hline $5: n=34$ & & No & .27 &
\end{tabular}

\begin{tabular}{ccccc}
\hline & C-Section & 3-Cluster & 4-Cluster & 5-Cluster \\
\hline ASI & Yes & $\mathrm{F}(2) 5.20$ & $\mathrm{~F}(3) 3.04$ & $\mathrm{~F}(4) 2.53$ \\
& & $\mathrm{P}=.04$ & $\mathrm{p}=.10$ & $\mathrm{p}=.149$ \\
\hline & $\mathrm{No}$ & $\mathrm{F}(2) 68.18$ & $\mathrm{~F}(3) 46.21$ & $\mathrm{~F}(4) 34.55$ \\
& & $\mathrm{p}=.000$ & $\mathrm{p}=.000$ & $\mathrm{p}=.000$ \\
\hline FPQ-III & Yes & $\mathrm{F}(2) 15.76$ & $\mathrm{~F}(3) 23.04$ & $\mathrm{~F}(4) 29.41$ \\
& & $\mathrm{p}=.002$ & $\mathrm{p}=.001$ & $\mathrm{p}=.000$ \\
\hline & No & $\mathrm{F}(2) 28.77$ & $\mathrm{~F}(3) 19.10$ & $\mathrm{~F}(4) 44.91$ \\
& & $\mathrm{p}=.000$ & $\mathrm{p}=.000$ & $\mathrm{p}=.000$ \\
\hline CES-D & Yes & $\mathrm{F}(2) 2.29$ & $\mathrm{~F}(3) 7.06$ & $\mathrm{~F}(4) 15.77$ \\
& & $\mathrm{p}=.16$ & $\mathrm{p}=.02$ & $\mathrm{p}=.002$ \\
\hline & No & $\mathrm{F}(2) 69.91$ & $\mathrm{~F}(3) 46.50$ & $\mathrm{~F}(4) 34.77$ \\
& & $\mathrm{p}=.000$ & $\mathrm{p}=.000$ & $\mathrm{p}=.000$ \\
\hline CB-SE & Yes & $\mathrm{F}(2) 8.66$ & $\mathrm{~F}(3) 5.14$ & $\mathrm{~F}(4) 4.42$ \\
& & $\mathrm{p}=.01$ & $\mathrm{p}=.03$ & $\mathrm{p}=.053$ \\
\hline & No & $\mathrm{F}(2) 6.90$ & $\mathrm{~F}(3) 27.37$ & $\mathrm{~F}(4) 20.36$ \\
& & $\mathrm{p}=.002$ & $\mathrm{p}=.000$ & $\mathrm{p}=.000$ \\
\hline
\end{tabular}


Appendix B

Staff Use Only

ID

Demographic Information Form

1) Age:

2) Ethnicity:
A) American Indian or Alaska Native
B) Asian
C) Black or African American
D) _ Hispanic or Latino
E) Native Hawaiian or Other Pacific Islander
F) White
G) __ Other (Describe:

3) What is your usual occupation or type of work?

4) Are you currently employed? Yes No
A. If yes,
Full Time
Part Time

5) A. What is your current annual income?

(Please check only one)

B. What is your current household annual income? (Please check only one)
A) $\quad \$ 0-10,000$
A) _ $\$ 0-10,000$
B) $\$ \$ 10,001-20,000$
B) _— $\$ 10,001-20,000$
C) — $\$ 20,001-35,000$.
C) — $\$ 20,001-35,000$.
D) $\$ 35,001-50,000$.
D) _ $\$ 35,001-50,000$.
E) $\$ \$ 50,001-75,000$.
E) _ $\$ 50,001-75,000$.
F) $\$ \$ 75,001-100,000$.
F) _ $\$ 75,001-100,000$.
G) _ $\$ 100,001+$
G) ___ $\$ 100,001+$

6) What is your highest level of education/school? (Please check only one)
A) __ Grades 1 through grade 12 (did not graduate)
B) __ Graduated high school
C) - GED
D) _ Some college (enter how many years
E) _ Graduated college
F) _ Post graduate years (enter how many years
G) __ Master's Degree
H) __ Doctoral Degree

7) Is your religion (Please circle one):
A) No religion
B) Buddhist 

C) Christian
D) Jewish
E) Muslim
F) Other (please list

8) When is your due date?
A) Trimester (Circle one):
First
Second
Third

9) Who will be delivering your baby?
A) Midwife
B) Obstetrician
C) __ Other (Please describe

10) Do you have a spouse or significant other like a boyfriend or a friend or a family member who is planning to help you:
A) during the birth? Yes No
B) care for your baby after you bring your baby home? Yes No

11) Do you have concerns about the health of your baby? Yes No

If yes:
Has a doctor said that there is a problem with your baby?
Has your doctor said that your pregnancy is "high risk"?
Yes No
Do you think about the concerns every day? Yes No

Yes No
Does thinking about the concerns interfere your daily life? Yes No

12) Do you have concerns about your ability to be a good mother your baby? Yes No

If yes:

Do you think about the concerns every day? Yes No

Does thinking about the concerns interfere your daily life? Yes No

13) Do you have concerns about your partner's (spouse, boyfriend) ability to be a good parent to your baby? Yes No

If yes:

Do you think about the concerns every day? Yes No

Does thinking about the concerns interfere your daily life? Yes No

14) Do you have concerns about your finances? Yes No

If yes:

Do you think about the concerns every day? Yes No

Does thinking about the concerns interfere your daily life? Yes No 
15) Do you have fears about your childbirth? Yes No

If yes:

Has your doctor/midwife told you that there might be a problem? Yes No

Do you think about the concerns every day? Yes No

Does thinking about the concerns interfere your daily life? Yes No

16) Please list any significant mental condition(s) such as depression, panic attacks:

A) you have had in the past:

B) you have now:

17) Are you scheduled to have a cesarean section? Yes No

18) Right now, do you feel that you can handle labor pain? Yes No

19) Right now, rate your ability to handle labor pain? (Please circle a number on the scale below.)

I feel that

I can handle

labor pain
I feel that I can not handle labor pain

\begin{tabular}{lllll}
\hline 1 & 2 & 3 & 4 & 5
\end{tabular}

20) Right now, do you think that you will use medication to handle labor pain? Yes No

21) Right now, rate your need of using medication. (Please circle a number on the scale below.)

I think I

will need

medication
I think I

will not need medication

\begin{tabular}{lllll}
\hline 1 & 2 & 3 & 4 & 5
\end{tabular}

22) Do you plan to use epidural medication during your labor?
A) $\quad$ Yes
B) - No
C) __ Not applicable (Why? 
23) If you choose to use an epidural anesthetic for labor, what is your reason? (Check as many as apply.)
A) I do not feel that I need to suffer pain during labor and delivery.
B) I am afraid that I can not stand the pain.
C) I do not have other ways to control pain.
D) Other:

24) Have you had other births? Yes No

25) If yes: How many births have you had?

26) Have you experienced a traumatic birth? Yes No

27) Has someone close to you had or have you witnessed a traumatic birth? Yes No

28) Looking at the scale below, how do you rate the most intense pain you think that you will experience during your labor? Please enter a number from 0-100.

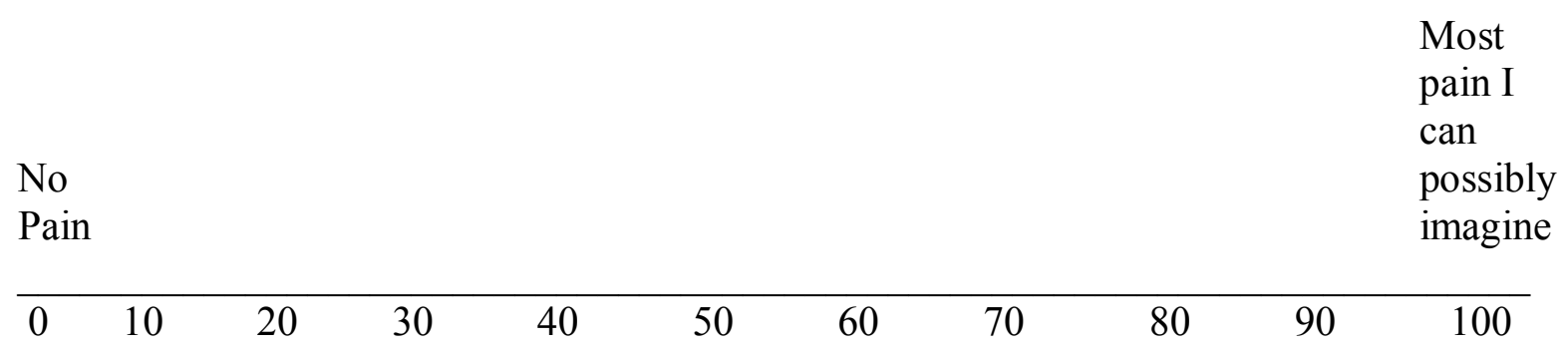

29) Looking at the scale below, how do you rate the most intense fear or anxiety you think that you will experience during your labor? Please enter a number from 0-100.

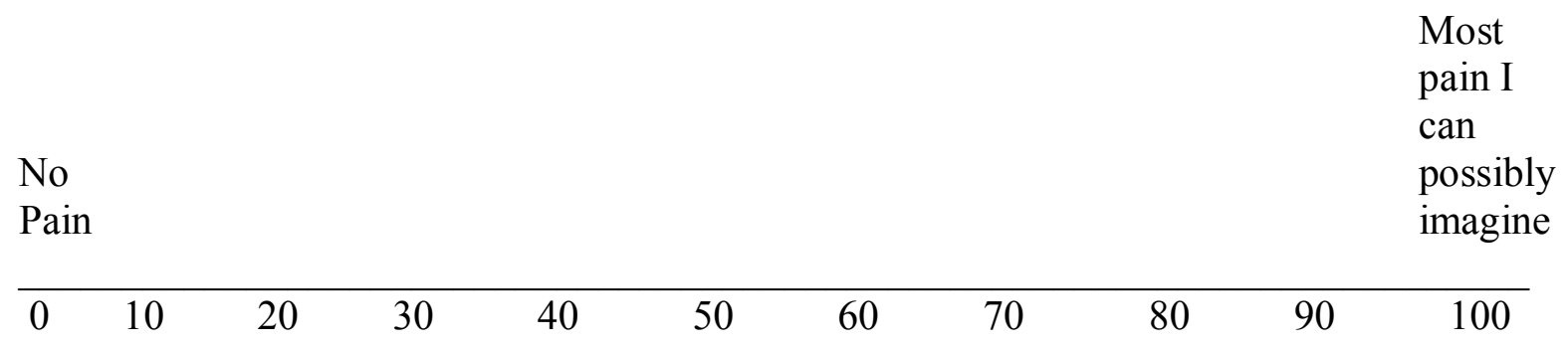


INSTRUCTIONS: Circle the one number that best represents the extent to which you agree with the item. If any of the items concern something that is not part of your experience, answer on the basis of how you might feel if you had such an experience. Otherwise, answer all the items on the basis of your own experience.

\begin{tabular}{|c|c|c|c|c|c|c|}
\hline & & $\begin{array}{l}\text { Very } \\
\text { Little }\end{array}$ & A Little & Some & Much & $\begin{array}{l}\text { Very } \\
\text { Much }\end{array}$ \\
\hline 1. & It is important for me not to appear nervous. & 1 & 2 & 3 & 4 & 5 \\
\hline 2. & $\begin{array}{l}\text { When I cannot keep my mind on a task, I worry } \\
\text { that I might be going crazy. }\end{array}$ & 1 & 2 & 3 & 4 & 5 \\
\hline 3. & It scares me when my heart beats rapidly. & 1 & 2 & 3 & 4 & 5 \\
\hline 4. & $\begin{array}{l}\text { When my stomach is upset, I worry that I might } \\
\text { be seriously ill. }\end{array}$ & 1 & 2 & 3 & 4 & 5 \\
\hline 5. & $\begin{array}{l}\text { It scares me when I am unable to keep my mind } \\
\text { on a task. }\end{array}$ & 1 & 2 & 3 & 4 & 5 \\
\hline 6. & $\begin{array}{l}\text { When I tremble in the presence of others, I fear } \\
\text { what people might think of me. }\end{array}$ & 1 & 2 & 3 & 4 & 5 \\
\hline 7. & $\begin{array}{l}\text { When my chest feels tight, I get scared that I } \\
\text { won't be able to breathe properly. }\end{array}$ & 1 & 2 & 3 & 4 & 5 \\
\hline 8. & $\begin{array}{l}\text { When I feel pain in my chest, I worry that I'm } \\
\text { going to have a heart attack. }\end{array}$ & 1 & 2 & 3 & 4 & 5 \\
\hline 9. & I worry that other people will notice my anxiety. & 1 & 2 & 3 & 4 & 5 \\
\hline 10. & $\begin{array}{l}\text { When I feel "spacey" or spaced out, I worry that I } \\
\text { may be mentally ill. }\end{array}$ & 1 & 2 & 3 & 4 & 5 \\
\hline 11. & It scares me when I blush in front of people. & 1 & 2 & 3 & 4 & 5 \\
\hline 12. & $\begin{array}{l}\text { When I notice my heart skipping a beat, I worry } \\
\text { that there is something seriously wrong with me. }\end{array}$ & 1 & 2 & 3 & 4 & 5 \\
\hline 13. & $\begin{array}{l}\text { When I begin to sweat in a social situation, I fear } \\
\text { people will think negatively of me. }\end{array}$ & 1 & 2 & 3 & 4 & 5 \\
\hline 14. & $\begin{array}{l}\text { When my thoughts seem to speed up, I worry that } \\
\text { I might be going crazy. }\end{array}$ & 1 & 2 & 3 & 4 & 5 \\
\hline 15. & $\begin{array}{l}\text { When my throat feels tight, I worry that I could } \\
\text { choke to death. }\end{array}$ & 1 & 2 & 3 & 4 & 5 \\
\hline 16. & $\begin{array}{l}\text { When I have trouble thinking clearly, I worry that } \\
\text { there is something wrong with me. }\end{array}$ & 1 & 2 & 3 & 4 & 5 \\
\hline 17. & $\begin{array}{l}\text { I think it would be horrible for me to faint in } \\
\text { public. }\end{array}$ & 1 & 2 & 3 & 4 & 5 \\
\hline 18. & $\begin{array}{l}\text { When my mind goes blank, I worry there is } \\
\text { something terribly wrong with me. }\end{array}$ & 1 & 2 & 3 & 4 & 5 \\
\hline
\end{tabular}


Center for Epidemiological Studies Depression Scale (CES-D)

Below is a list of some of the ways you may have felt or behaved. Please indicate how often you have felt this way during the past week by checking the appropriate space.

\section{USE THE FOLLOWING RESPONSE ITEMS:}

1. Rarely or none of the time (Less than 1 day)

2. Some or Little of the time (1-2 days)

3. Occasionally or a Moderate Amount of the Time (3-4 days)

4. Most or All of the Time (5-7 days)

\begin{tabular}{llcccc} 
& & Rarely & Some & Moderate & Most \\
\hline 1. & I was bothered by things that usually don't bother me. & 1 & 2 & 3 & 4 \\
2. & I did not feel like eating; my appetite was poor. & 1 & 2 & 3 & 4 \\
\hline $\begin{array}{l}\text { 3. } \\
\text { from my family or friends. }\end{array}$ & 1 & 2 & 3 & 4 \\
4. & I felt that I was just as good as other people. & 1 & 2 & 3 & 4 \\
\hline 5. & I had trouble keeping my mind on what I was doing. & 1 & 2 & 3 & 4 \\
\hline 6. & I felt depressed. & 1 & 2 & 3 & 4 \\
\hline 7. & I felt that everything I did was an effort. & 1 & 2 & 3 & 4 \\
\hline 8. & I felt hopeful about the future. & 1 & 2 & 3 & 4 \\
\hline 9. & I thought my life had been a failure. & 1 & 2 & 3 & 4 \\
\hline 10 & I felt fearful. & 1 & 2 & 3 & 4 \\
\hline 11. & My sleep was restless. & 1 & 2 & 3 & 4 \\
\hline 12. I was happy. & 1 & 2 & 3 & 4 \\
\hline 13. I talked less than usual. & 1 & 2 & 3 & 4 \\
\hline 14. I felt lonely. & 1 & 2 & 3 & 4 \\
\hline 15. & People were unfriendly. & 1 & 2 & 3 & 4 \\
16. I enjoyed life. & 1 & 2 & 3 & 4 \\
\hline 17. I had crying spells. & 1 & 2 & 3 & 4 \\
\hline 18. I felt sad. & 1 & 2 & 3 & 4 \\
\hline 19. I felt that people disliked me. & 1 & 2 & 3 & 4 \\
\hline 20. I could not get "going." & 1 & 2 & 3 & 4
\end{tabular}




\section{Appendix E}

Fear of Pain Questionnaire

INSTRUCTIONS: The items listed below describe painful experiences. Please look at each item and think about how FEARFUL you are of experiencing the PAIN associated with each item. If you have never experienced the PAIN of a particular item, please answer on the basis of how FEARFUL you expect you would be if you had such an experience. Circle the number for each item below to rate your FEAR OF PAIN in relation to each event.

\begin{tabular}{|c|c|c|c|c|c|c|}
\hline & & Not At All & A Little & $\begin{array}{l}\text { A Fair } \\
\text { Amount }\end{array}$ & $\begin{array}{l}\text { Very } \\
\text { Much }\end{array}$ & Extremely \\
\hline 1. & Being in an automobile accident. & 1 & 2 & 3 & 4 & 5 \\
\hline 2. & Biting your tongue while eating. & 1 & 2 & 3 & 4 & 5 \\
\hline 3. & Breaking your arm. & 1 & 2 & 3 & 4 & 5 \\
\hline 4. & $\begin{array}{l}\text { Cutting your tongue licking an } \\
\text { envelope. }\end{array}$ & 1 & 2 & 3 & 4 & 5 \\
\hline 5. & $\begin{array}{l}\text { Having a heavy object hit you in the } \\
\text { head. }\end{array}$ & 1 & 2 & 3 & 4 & 5 \\
\hline 6. & Breaking your leg. & 1 & 2 & 3 & 4 & 5 \\
\hline 7. & $\begin{array}{l}\text { Hitting a sensitive bone in your elbow } \\
\text { - your "funny bone." }\end{array}$ & 1 & 2 & 3 & 4 & 5 \\
\hline 8. & $\begin{array}{l}\text { Having a blood sample drawn with a } \\
\text { hypodermic needle. }\end{array}$ & 1 & 2 & 3 & 4 & 5 \\
\hline 9. & $\begin{array}{l}\text { Having someone slam a heavy car } \\
\text { door on your hand. }\end{array}$ & 1 & 2 & 3 & 4 & 5 \\
\hline 10. & $\begin{array}{l}\text { Falling down a flight of concrete } \\
\text { stairs. }\end{array}$ & 1 & 2 & 3 & 4 & 5 \\
\hline 11. & Receiving an injection in your arm. & 1 & 2 & 3 & 4 & 5 \\
\hline 12. & Burning your fingers with a match. & 1 & 2 & 3 & 4 & 5 \\
\hline 13. & Breaking your neck. & 1 & 2 & 3 & 4 & 5 \\
\hline 14. & $\begin{array}{l}\text { Receiving an injection in your } \\
\text { hip/buttocks. }\end{array}$ & 1 & 2 & 3 & 4 & 5 \\
\hline 15. & $\begin{array}{l}\text { Having a deep splinter in the sole of } \\
\text { your foot probed and removed with } \\
\text { tweezers. }\end{array}$ & 1 & 2 & 3 & 4 & 5 \\
\hline 16. & $\begin{array}{l}\text { Having an eye doctor remove a } \\
\text { foreign particle stuck in your eye. }\end{array}$ & 1 & 2 & 3 & 4 & 5 \\
\hline 17. & Receiving an injection in your mouth. & 1 & 2 & 3 & 4 & 5 \\
\hline
\end{tabular}




\begin{tabular}{|c|c|c|c|c|c|c|}
\hline \multirow[b]{2}{*}{18.} & \multirow[b]{2}{*}{$\begin{array}{l}\text { Being burned on your face by a lit } \\
\text { cigarette. }\end{array}$} & \multirow{2}{*}{$\begin{array}{c}\text { Not At All } \\
1\end{array}$} & \multirow{2}{*}{$\begin{array}{l}\text { A Little } \\
2\end{array}$} & \multirow{2}{*}{$\begin{array}{c}\text { A Fair } \\
\text { Amount } \\
3\end{array}$} & \multirow{2}{*}{$\begin{array}{c}\text { Very } \\
\text { Much } \\
4\end{array}$} & \multirow{2}{*}{$\begin{array}{c}\text { Extremely } \\
5\end{array}$} \\
\hline & & & & & & \\
\hline 19. & Getting a paper-cut on your finger. & 1 & 2 & 3 & 4 & 5 \\
\hline 20. & Receiving stitches in your lip. & 1 & 2 & 3 & 4 & 5 \\
\hline 21. & $\begin{array}{l}\text { Having a foot doctor remove a wart } \\
\text { from your foot with a sharp } \\
\text { instrument. }\end{array}$ & 1 & 2 & 3 & 4 & 5 \\
\hline 22. & $\begin{array}{l}\text { Cutting yourself while shaving with a } \\
\text { sharp razor. }\end{array}$ & 1 & 2 & 3 & 4 & 5 \\
\hline 23. & $\begin{array}{l}\text { Gulping a hot drink before it has } \\
\text { cooled. }\end{array}$ & 1 & 2 & 3 & 4 & 5 \\
\hline 24. & $\begin{array}{l}\text { Getting strong soap in both your eye } \\
\text { while bathing or showering. }\end{array}$ & 1 & 2 & 3 & 4 & 5 \\
\hline 25. & $\begin{array}{l}\text { Having a terminal illness that causes } \\
\text { you daily pain. }\end{array}$ & 1 & 2 & 3 & 4 & 5 \\
\hline 26. & Having a tooth pulled. & 1 & 2 & 3 & 4 & 5 \\
\hline 27. & $\begin{array}{l}\text { Vomiting repeatedly because of food } \\
\text { poisoning. }\end{array}$ & 1 & 2 & 3 & 4 & 5 \\
\hline 28. & $\begin{array}{l}\text { Having sand or dust blow into your } \\
\text { eyes. }\end{array}$ & 1 & 2 & 3 & 4 & 5 \\
\hline 29. & Having one of your teeth drilled. & 1 & 2 & 3 & 4 & 5 \\
\hline 30. & Having a muscle cramp. & 1 & 2 & 3 & 4 & 5 \\
\hline
\end{tabular}




\section{Appendix F}

Health Anxiety Questionnaire (HAQ)

Below is a list of questions about health anxiety. Please carefully read each item on the list. Indicate how often you have been bothered in this way during the past week, including today, by circling the number in the appropriate space in the columns to the right of each question.

\begin{tabular}{|c|c|c|c|c|c|}
\hline & & $\begin{array}{l}\text { not at all } \\
\text { or rarely }\end{array}$ & sometimes & often & $\begin{array}{l}\text { most of } \\
\text { the time }\end{array}$ \\
\hline 1. & Do you ever worry about your health? & 0 & 1 & 2 & 3 \\
\hline 2. & $\begin{array}{l}\text { Are you ever worried that you may get a } \\
\text { serious illness in the future? }\end{array}$ & 0 & 1 & 2 & 3 \\
\hline 3. & $\begin{array}{l}\text { Does the thought of a serious illness ever } \\
\text { scare you? }\end{array}$ & 0 & 1 & 2 & 3 \\
\hline 4. & $\begin{array}{l}\text { When you notice an unpleasant feeling in } \\
\text { your body, do you tend to find it difficult to } \\
\text { think of anything else? }\end{array}$ & 0 & 1 & 2 & 3 \\
\hline 5. & $\begin{array}{l}\text { Do you ever examine your body to find } \\
\text { whether there is something wrong? }\end{array}$ & 0 & 1 & 2 & 3 \\
\hline 6. & $\begin{array}{l}\text { If you have an ache or pain, do you worry } \\
\text { that it may be caused by a serious illness? }\end{array}$ & 0 & 1 & 2 & 3 \\
\hline 7. & $\begin{array}{l}\text { Do you ever find it difficult to keep worries } \\
\text { about your health out of your mind? }\end{array}$ & 0 & 1 & 2 & 3 \\
\hline 8. & $\begin{array}{l}\text { When you notice an unpleasant feeling in } \\
\text { your body, do you ever worry about it? }\end{array}$ & 0 & 1 & 2 & 3 \\
\hline 9. & $\begin{array}{l}\text { When you wake up in the morning, do you } \\
\text { find you very soon begin to worry about } \\
\text { your health? }\end{array}$ & 0 & 1 & 2 & 3 \\
\hline 10. & $\begin{array}{l}\text { When you hear of a serious illness or death } \\
\text { of someone you know, does it ever make } \\
\text { you more concerned about your own health? }\end{array}$ & 0 & 1 & 2 & 3 \\
\hline 11. & $\begin{array}{l}\text { When you read or hear about an illness on } \\
\text { TV or radio, does it every made you think } \\
\text { you may be suffering from that illness? }\end{array}$ & 0 & 1 & 2 & 3 \\
\hline 12. & $\begin{array}{l}\text { When you experience unpleasant feeling in } \\
\text { your body, do you tend to ask friends or } \\
\text { family about them? }\end{array}$ & 0 & 1 & 2 & 3 \\
\hline
\end{tabular}




\begin{tabular}{|c|c|c|c|c|c|}
\hline & & $\begin{array}{l}\text { not at all } \\
\text { or rarely }\end{array}$ & sometimes & often & $\begin{array}{l}\text { most of } \\
\text { the time }\end{array}$ \\
\hline 13. & $\begin{array}{l}\text { Do you tend to read up about illness and } \\
\text { diseases to see if you may be suffering from } \\
\text { one? }\end{array}$ & 0 & 1 & 2 & 3 \\
\hline 14. & $\begin{array}{l}\text { Do you ever feel afraid of news that reminds } \\
\text { you of death (such as funerals, obituary } \\
\text { notices)? }\end{array}$ & 0 & 1 & 2 & 3 \\
\hline 15. & $\begin{array}{l}\text { Do you ever feel afraid that you may die } \\
\text { soon? }\end{array}$ & 0 & 1 & 2 & 3 \\
\hline 16. & $\begin{array}{l}\text { Do you ever feel afraid that you may have } \\
\text { cancer? }\end{array}$ & 0 & 1 & 2 & 3 \\
\hline 17. & $\begin{array}{l}\text { Do you ever feel afraid that you might have } \\
\text { heart disease? }\end{array}$ & 0 & 1 & 2 & 3 \\
\hline 18. & $\begin{array}{l}\text { Do you ever feel afraid that you may have } \\
\text { any other serious illness? Which illness? }\end{array}$ & 0 & 1 & 2 & 3 \\
\hline 19. & $\begin{array}{l}\text { Have your bodily symptoms stopped you } \\
\text { from working during the past six months or } \\
\text { so? }\end{array}$ & 0 & 1 & 2 & 3 \\
\hline 20. & $\begin{array}{l}\text { Do your bodily symptoms stop you from } \\
\text { concentrating on what you are doing? }\end{array}$ & 0 & 1 & 2 & 3 \\
\hline 21. & $\begin{array}{l}\text { Do your bodily symptoms stop you from } \\
\text { enjoying yourself? }\end{array}$ & 0 & 1 & 2 & 3 \\
\hline 22. & $\begin{array}{l}\text { Do you worry about the health of the baby } \\
\text { you are carrying now, during pregnancy? }\end{array}$ & 0 & 1 & 2 & 3 \\
\hline 23. & $\begin{array}{l}\text { Do you worry about the future health of the } \\
\text { child with whom you are now pregnant? }\end{array}$ & 0 & 1 & 2 & 3 \\
\hline
\end{tabular}


ID

\section{Penn State Worry Questionnaire (PSWQ)}

Instructions: Rate each of the following statements on a scale of 1 ("not at all typical of me") to 5 ("very typical of me") by circling only one number.

1. If I do not have enough time to do everything, I do not worry about it.

Not at all typical

of me
Very typical of me

2. My worries overwhelm me.

2

1

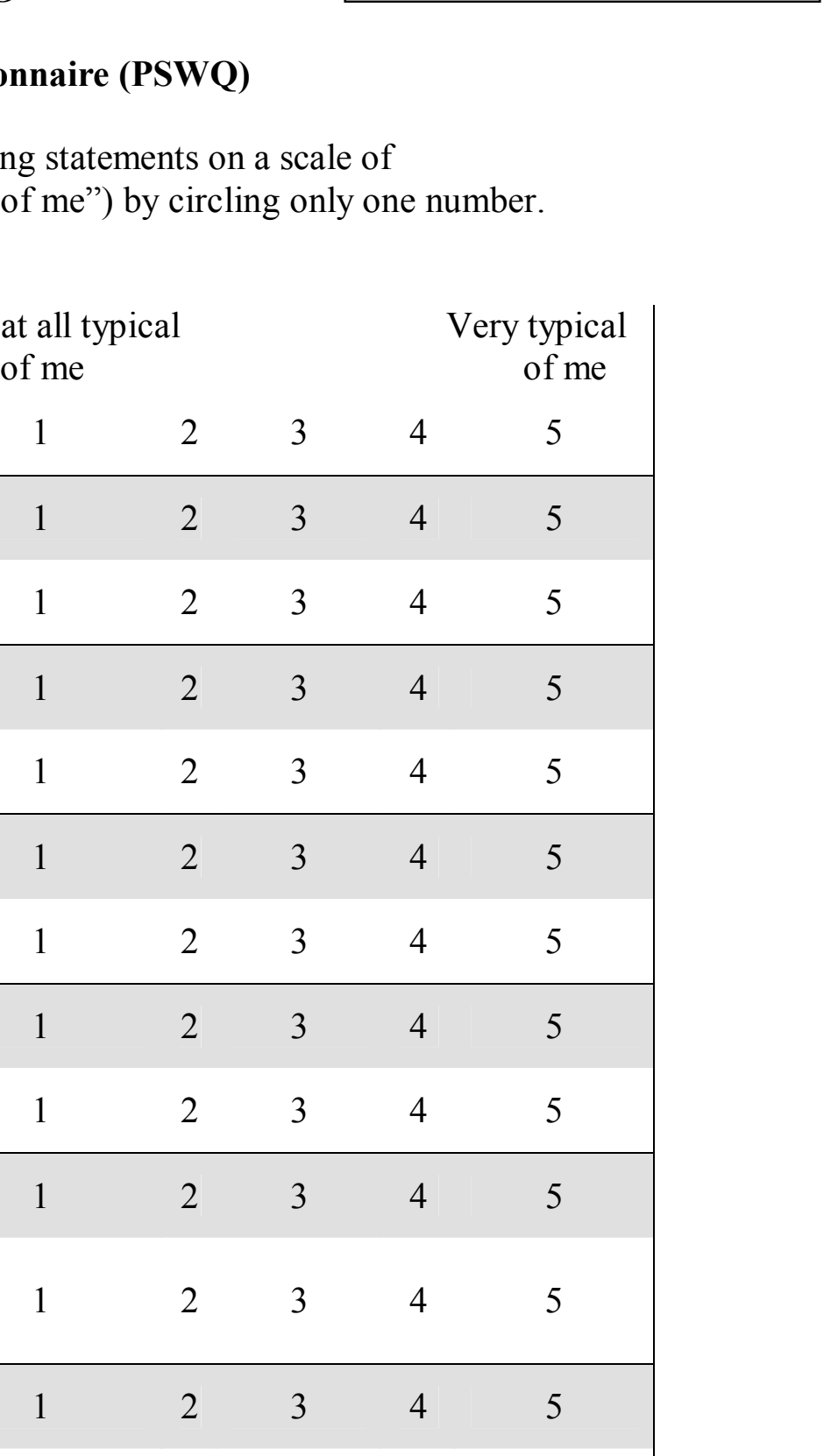

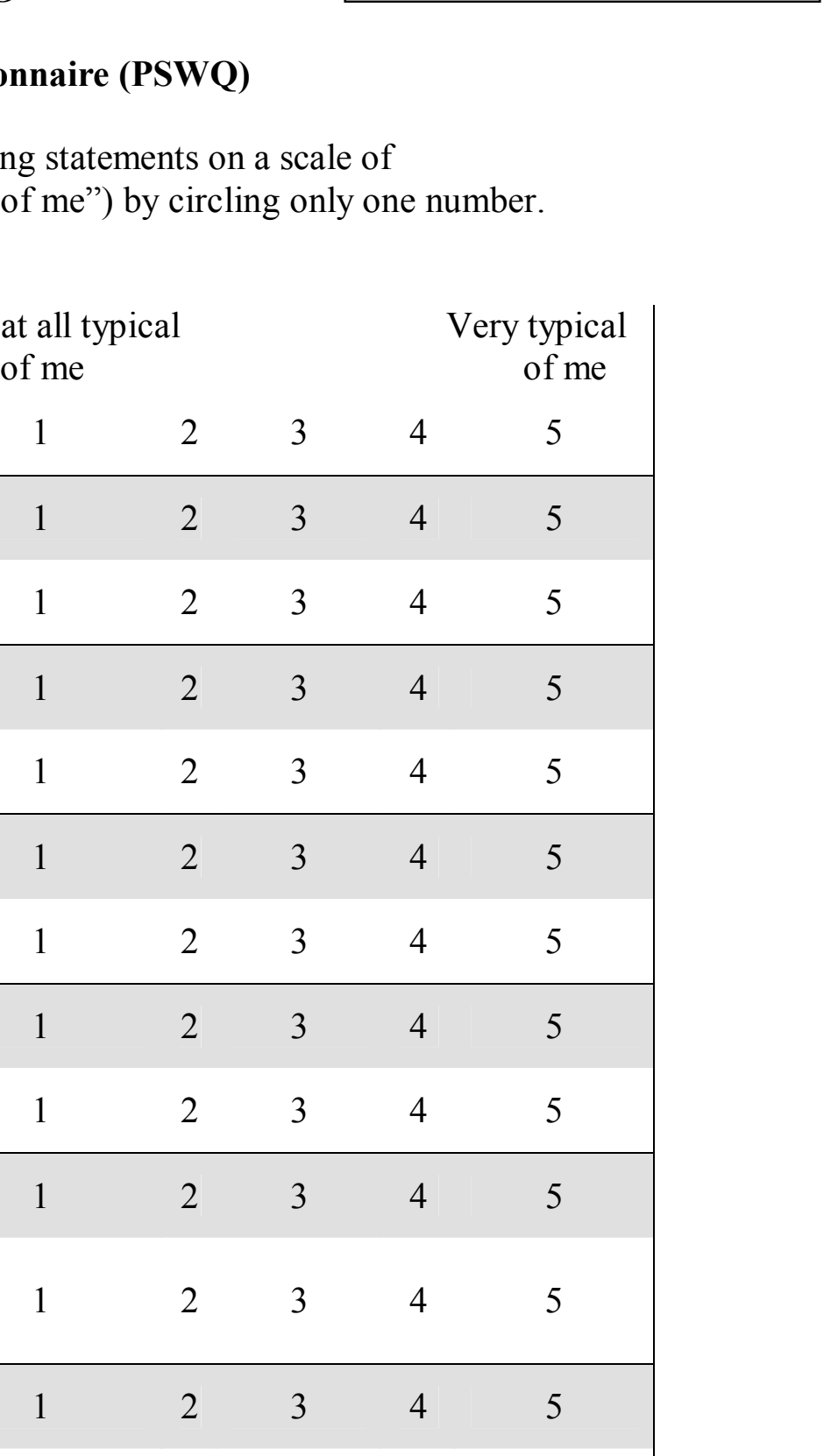

4

5

3. I do not tend to worry about things.

4. Many situations make me worry.

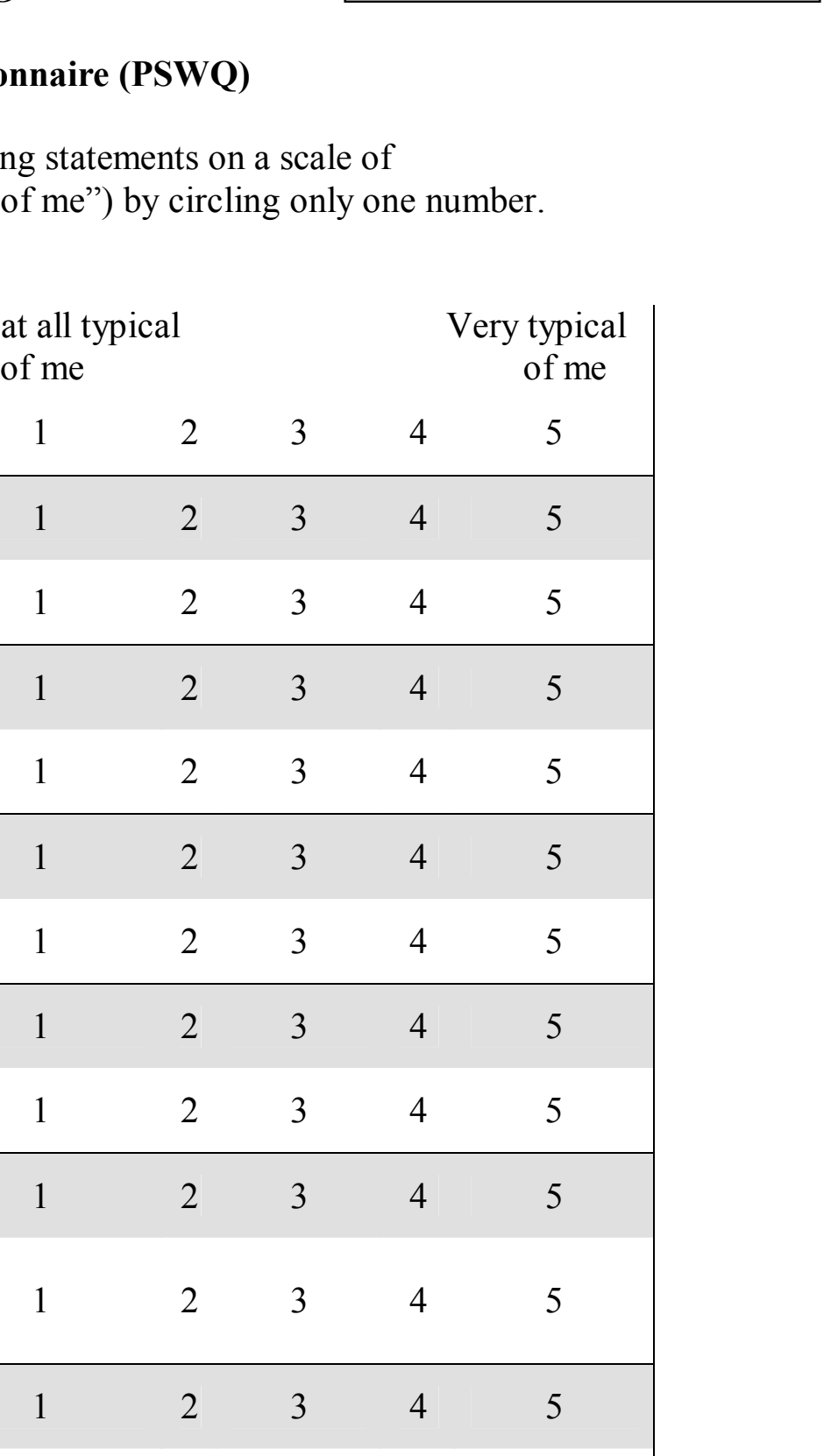

5. I know I should not worry about things, but I just cannot help it.

6. When I am under pressure I worry a lot.

1

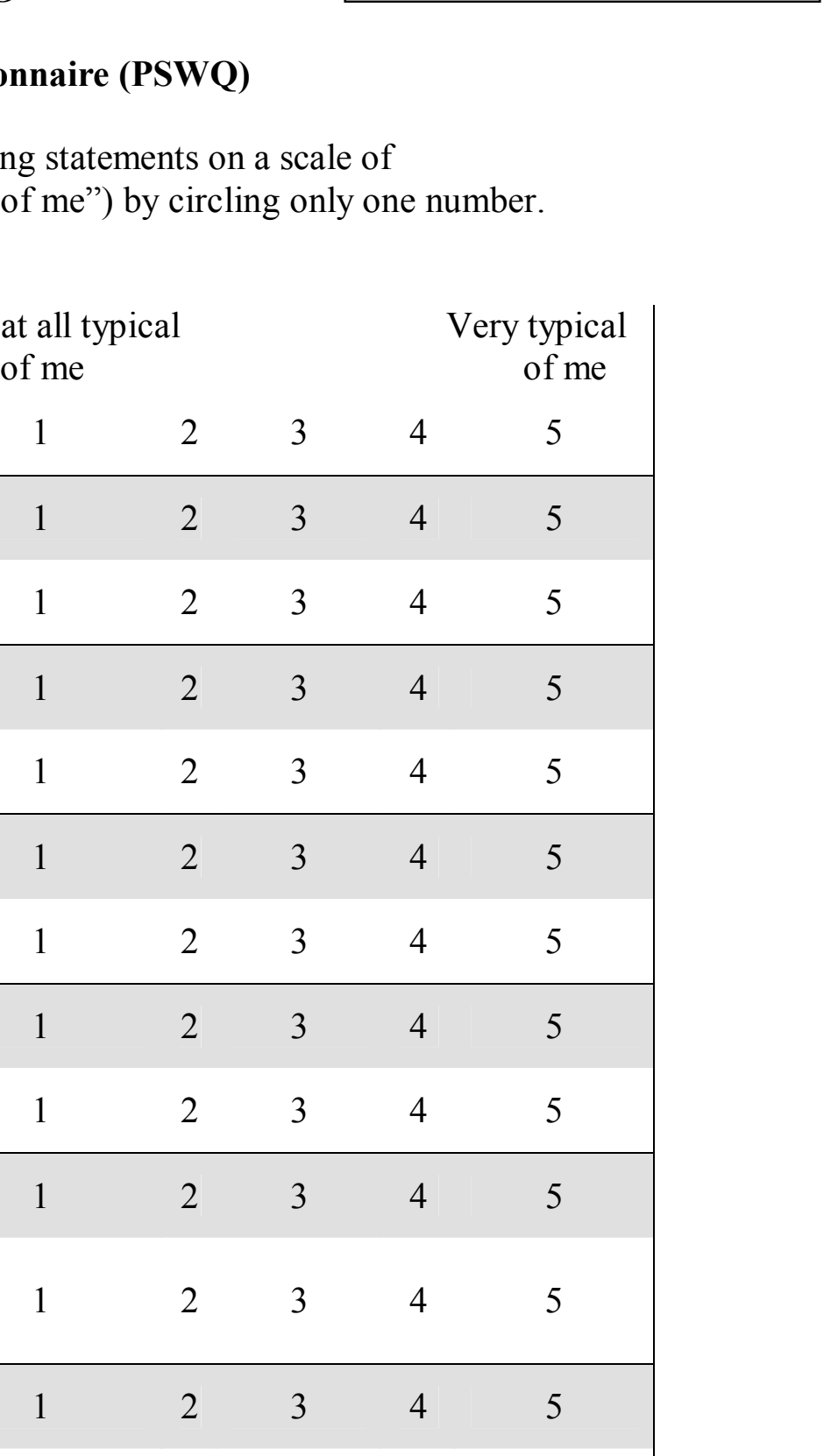

4

5

7. I am always worrying about something.

8. I find it easy to dismiss worrisome thoughts.

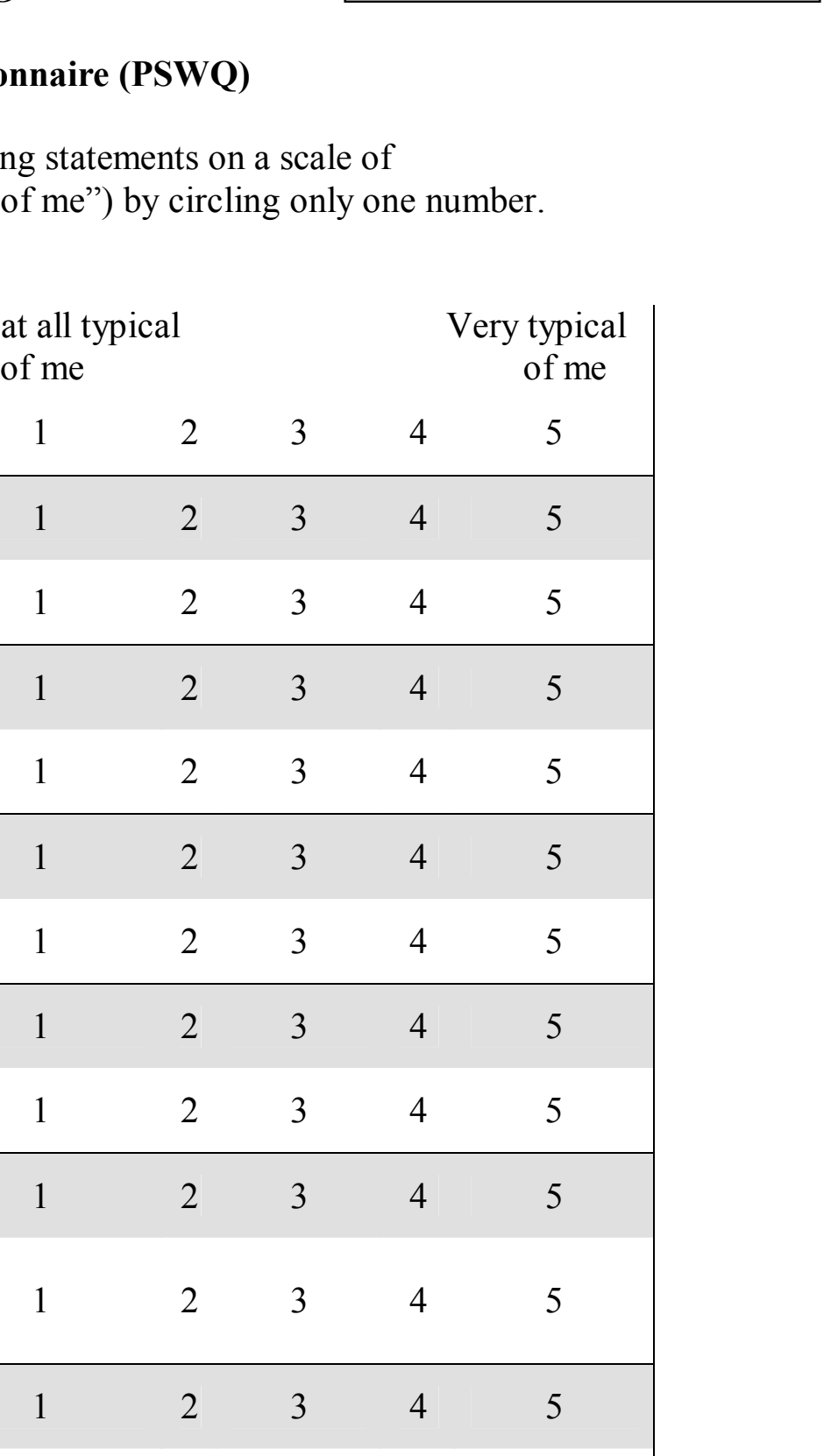

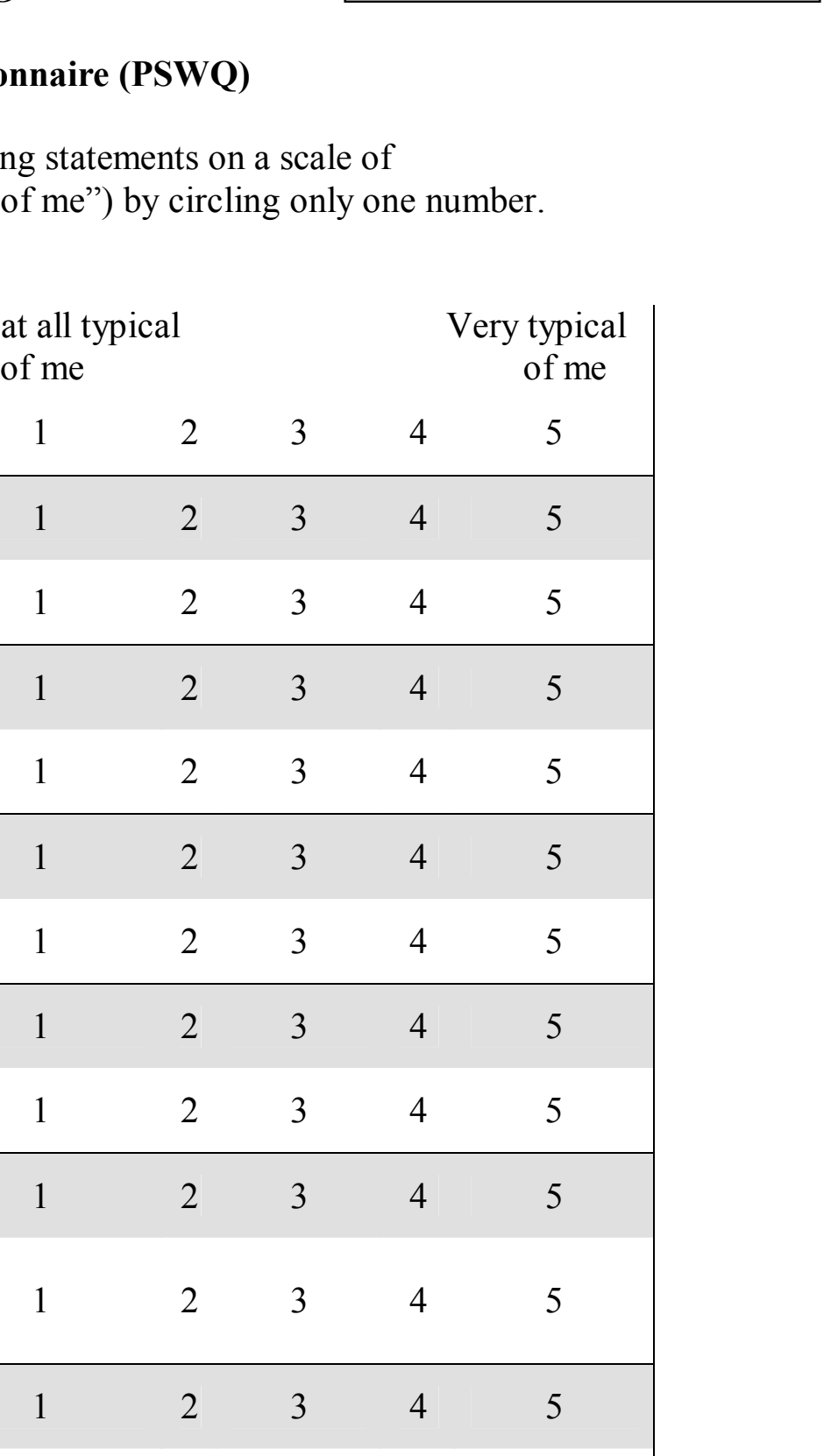

4

5

9. As soon as I finish one task, I start to worry about everything else I have to do.

10. I never worry about anything.

1

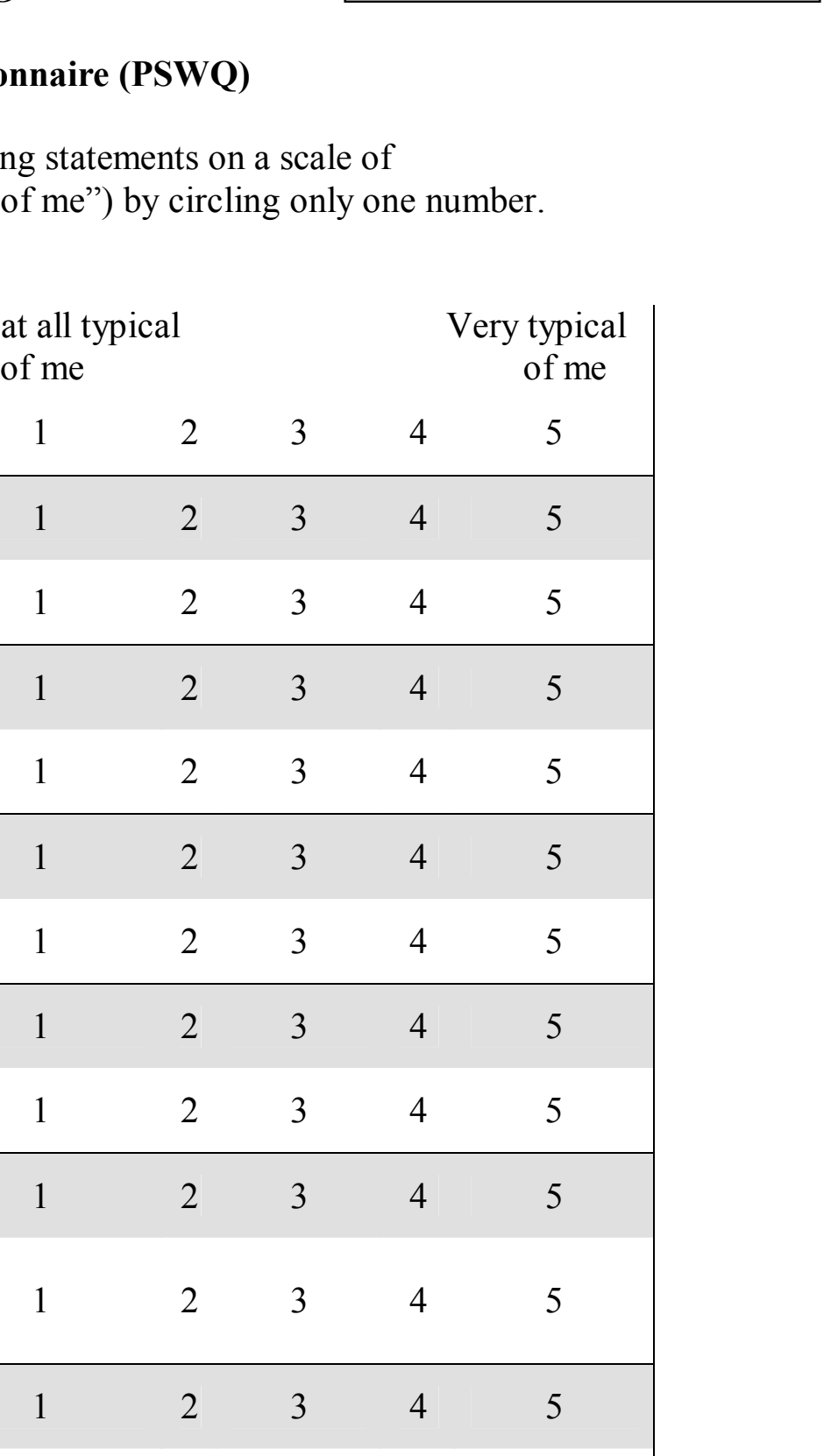

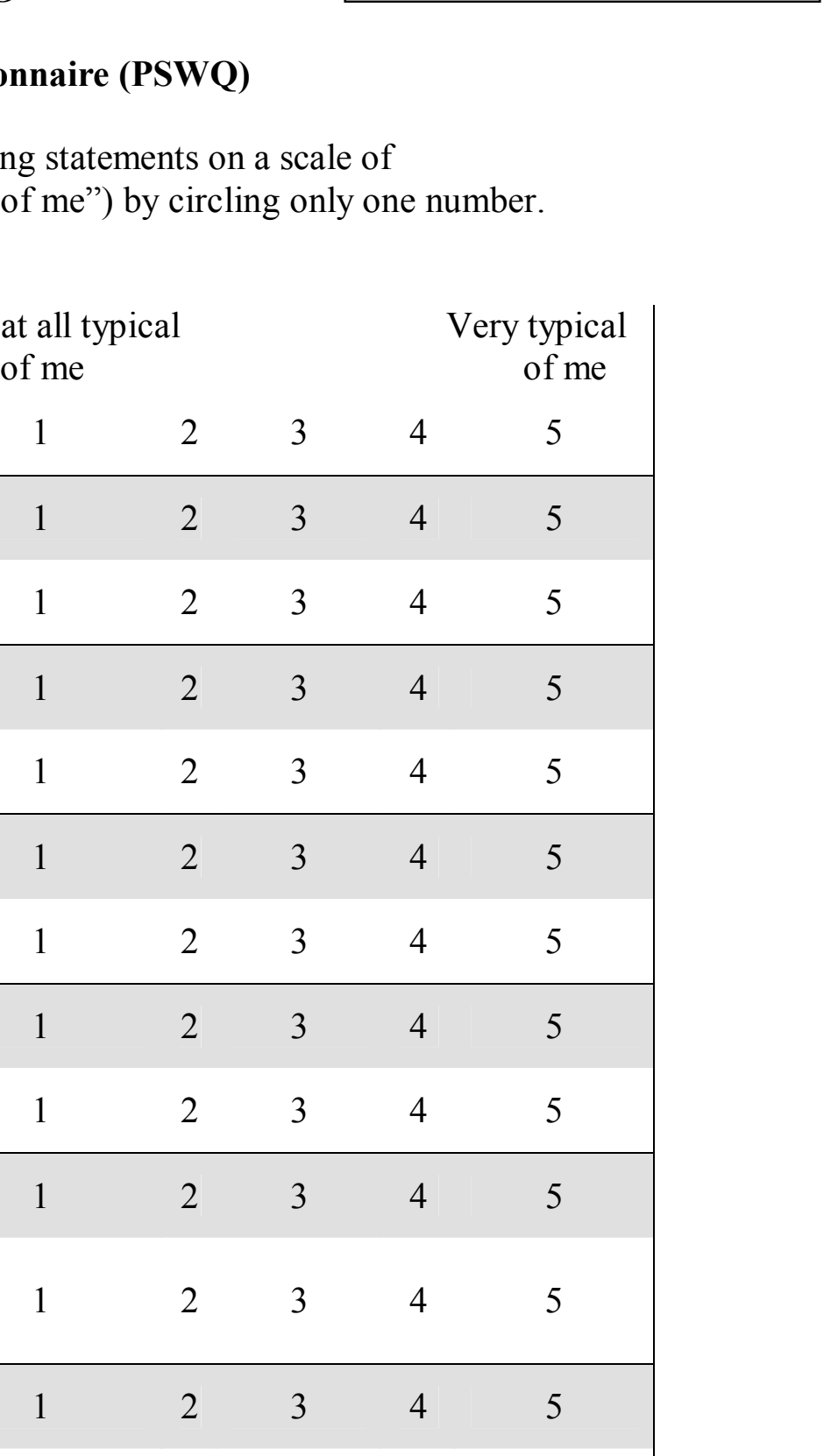

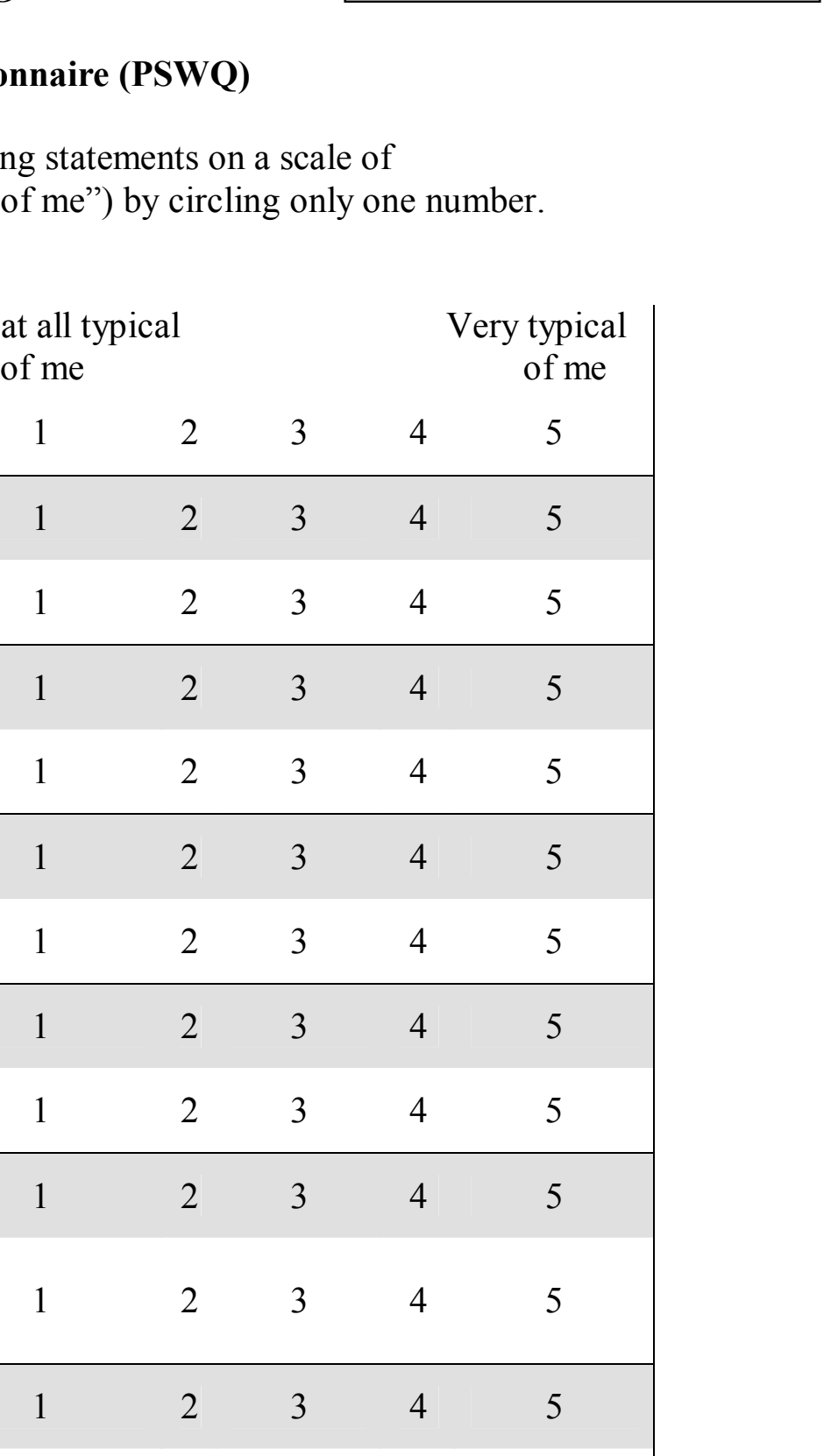

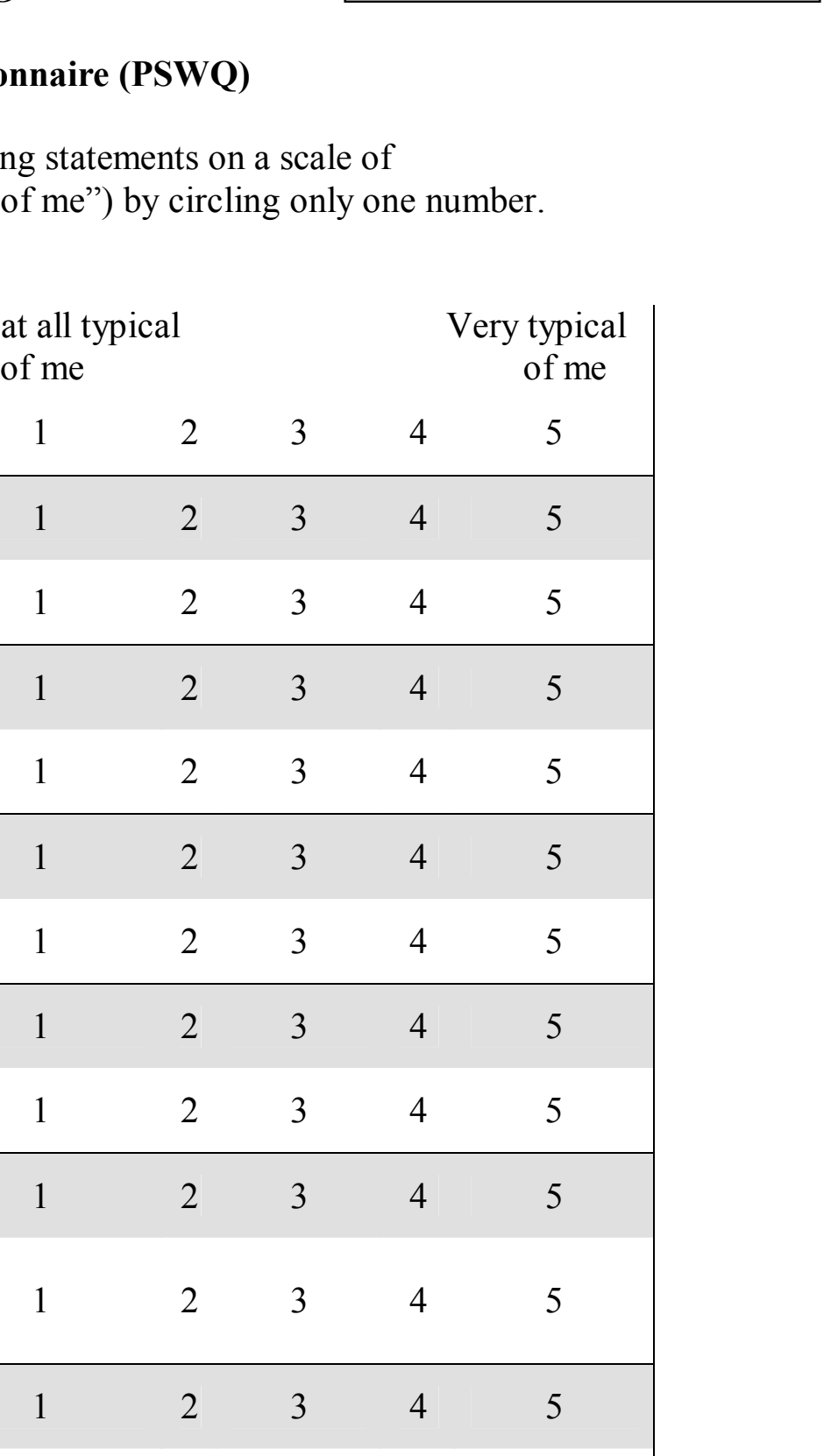

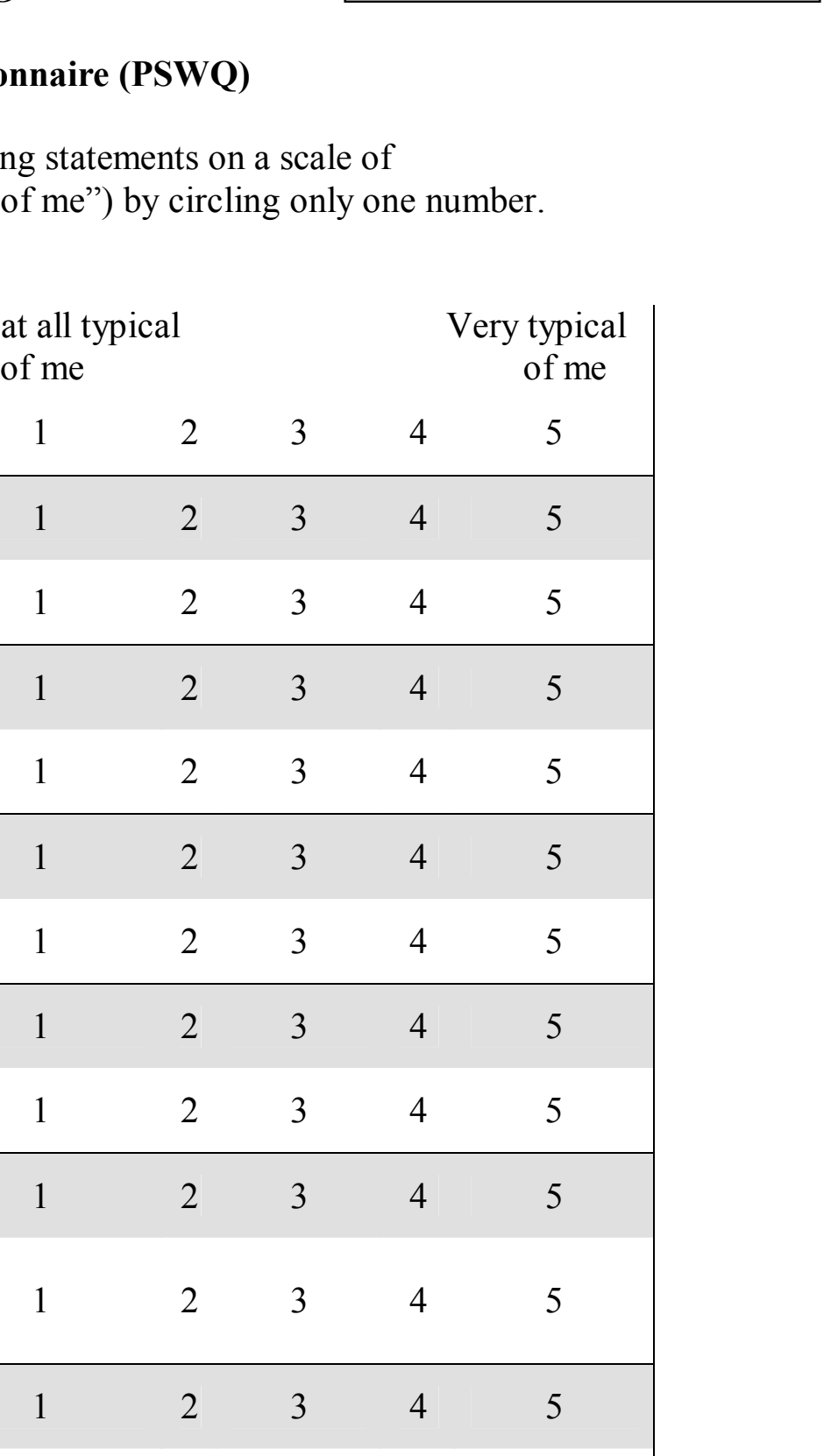

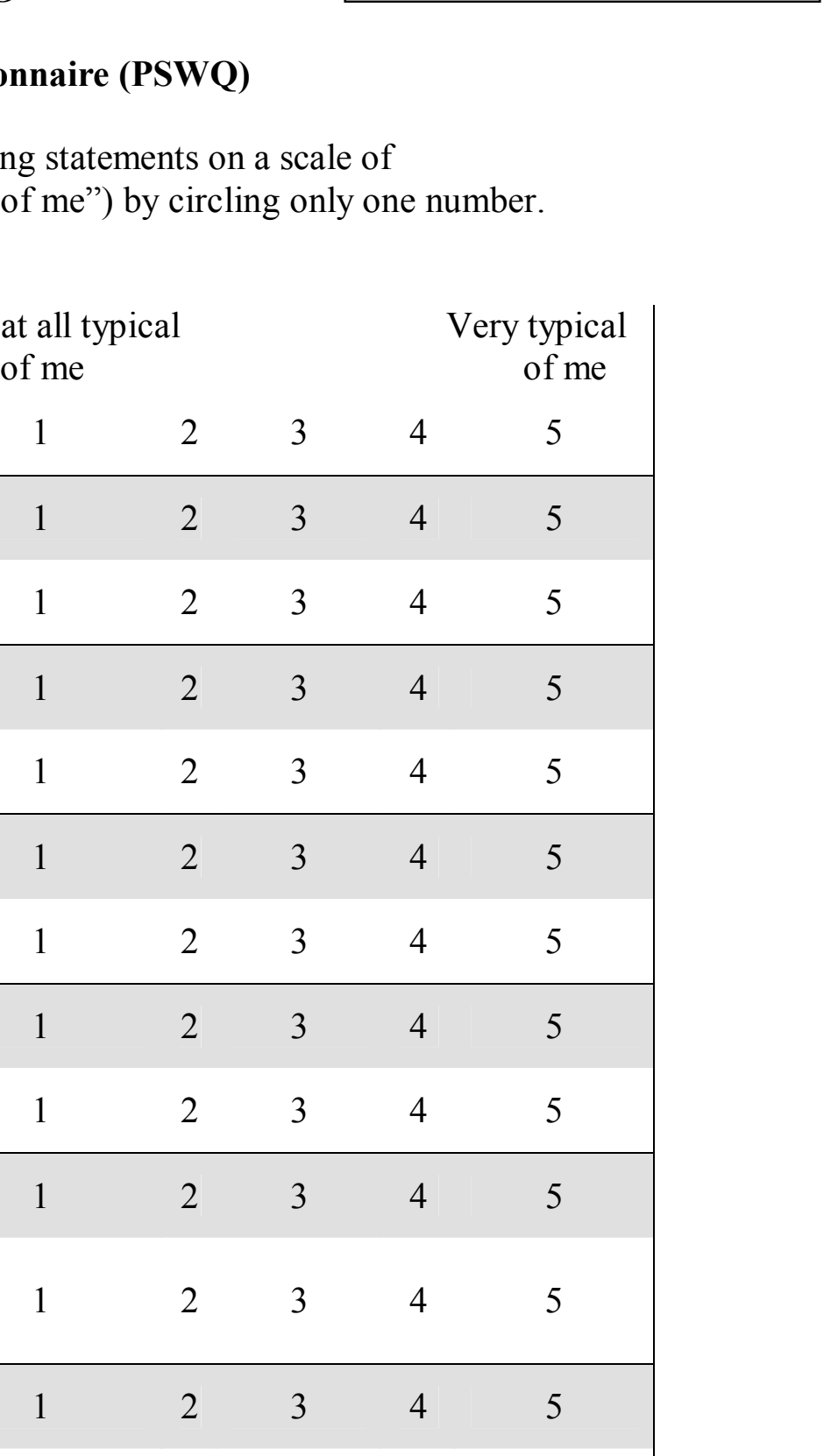

4

5

11. When there is nothing more I can do about a concern, I do not worry about it any more.

12. I have been a worrier all my life.

13. I notice that I have been worrying about things.

14. Once I start worrying, I cannot stop.

15. I worry all the time.

16. I worry about projects until they are all done.

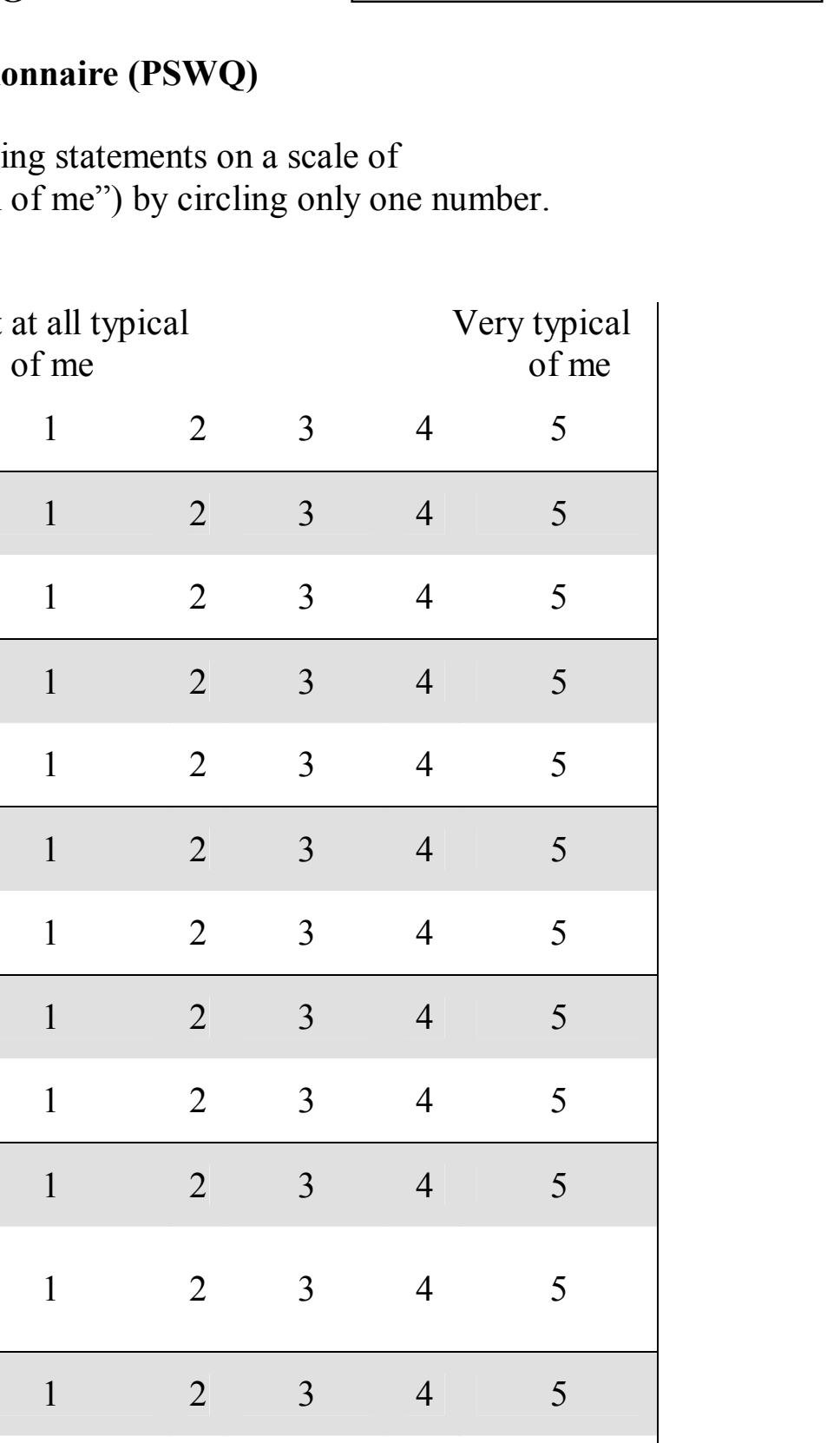

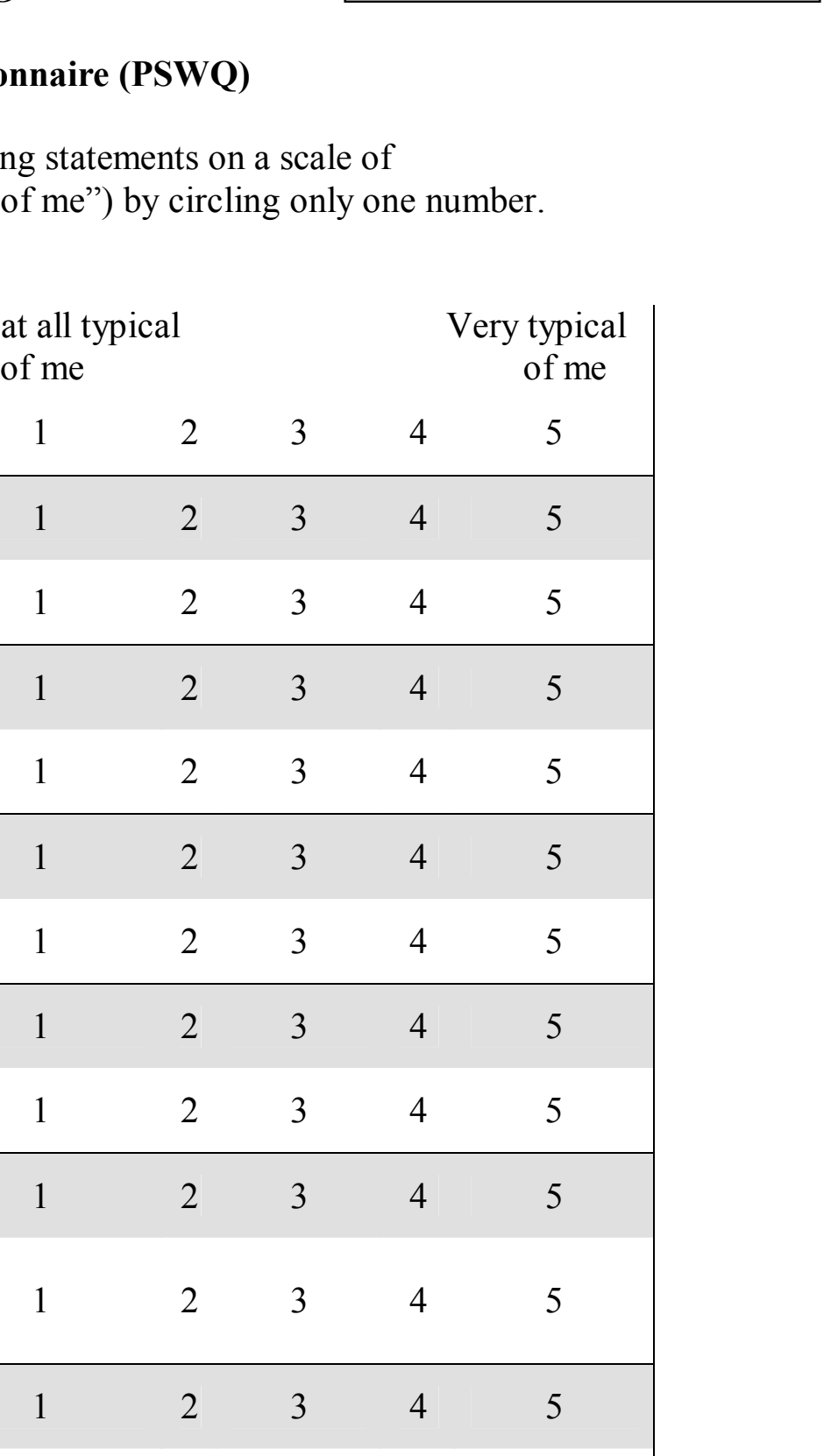

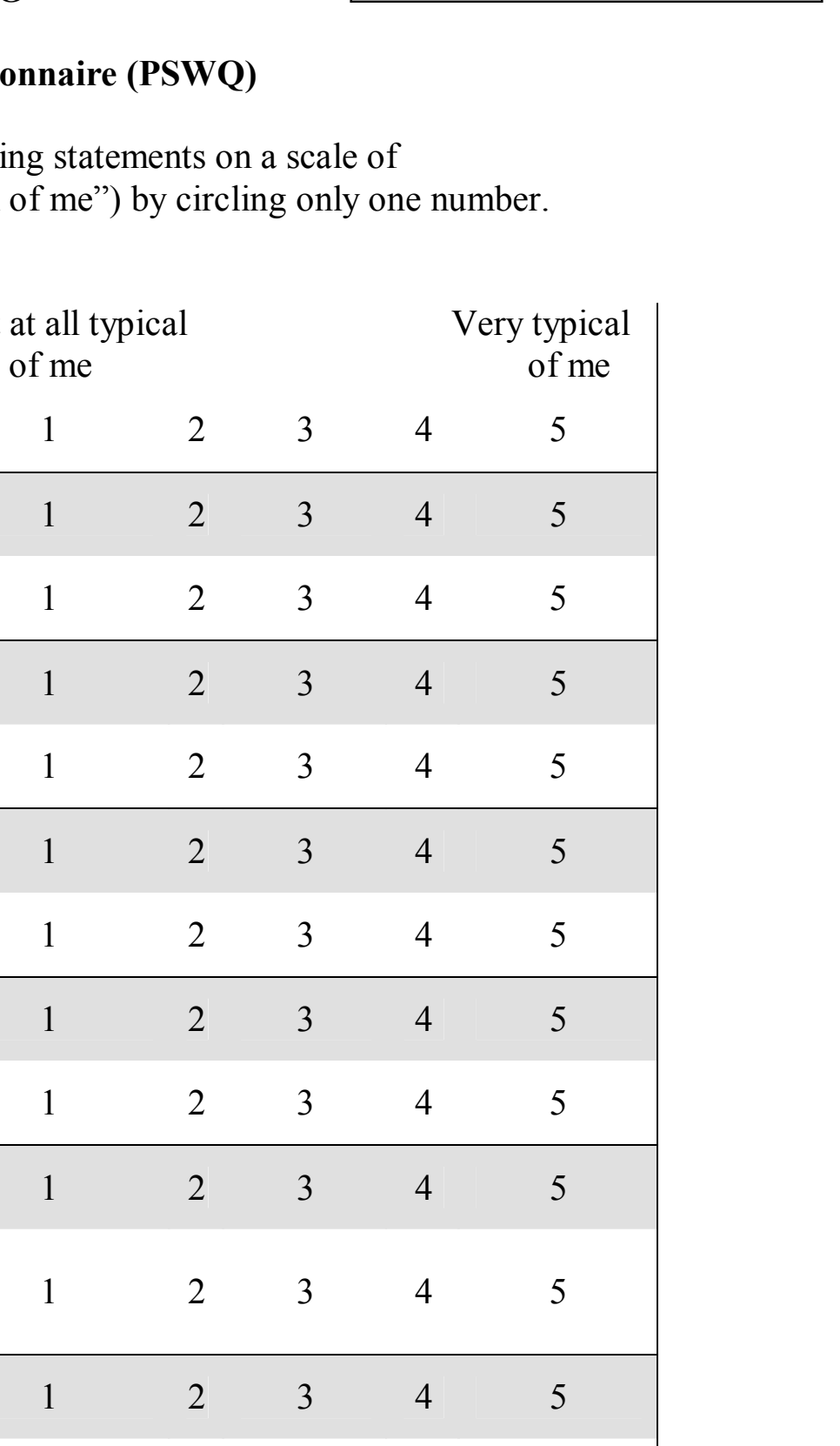

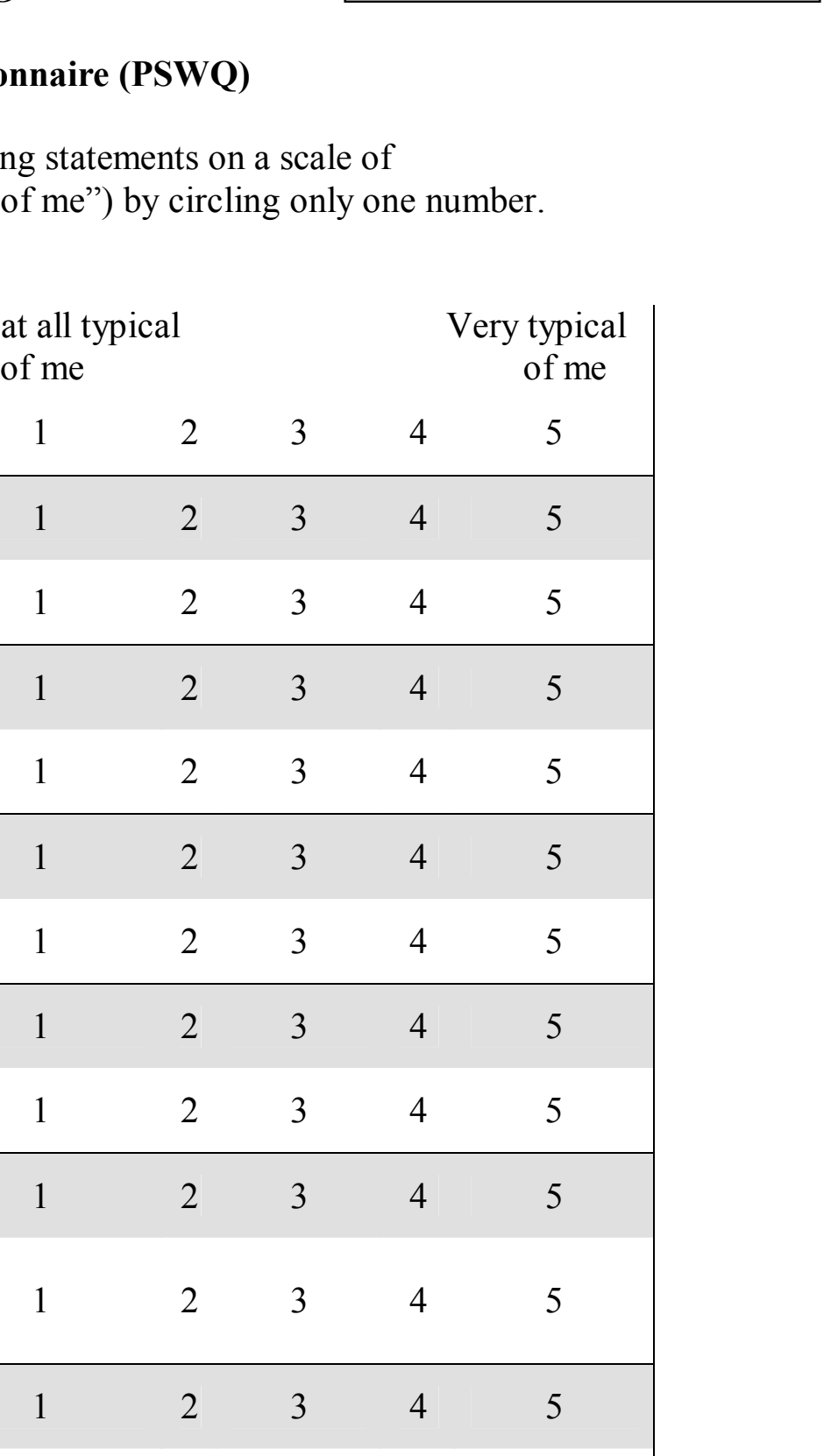

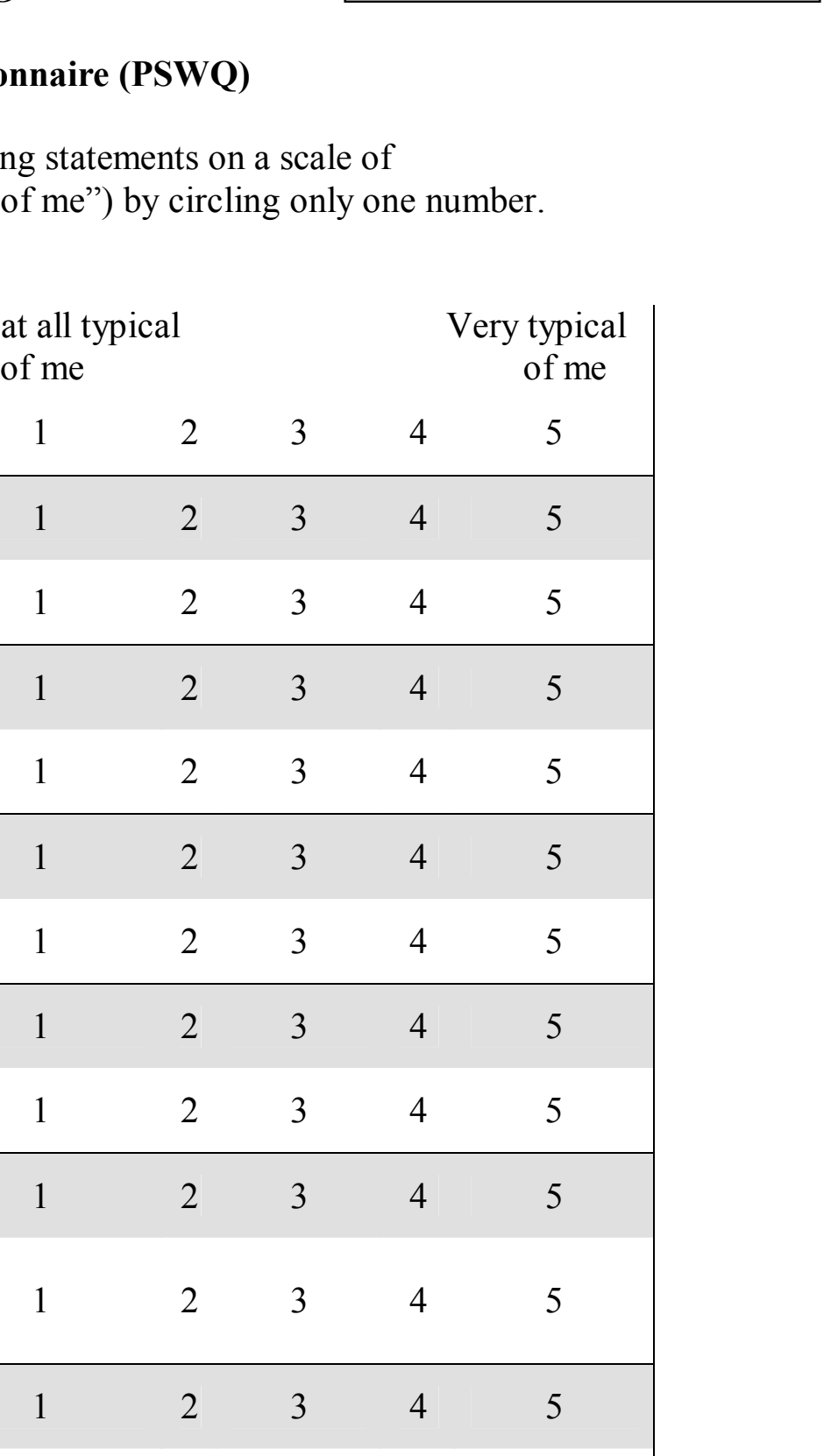

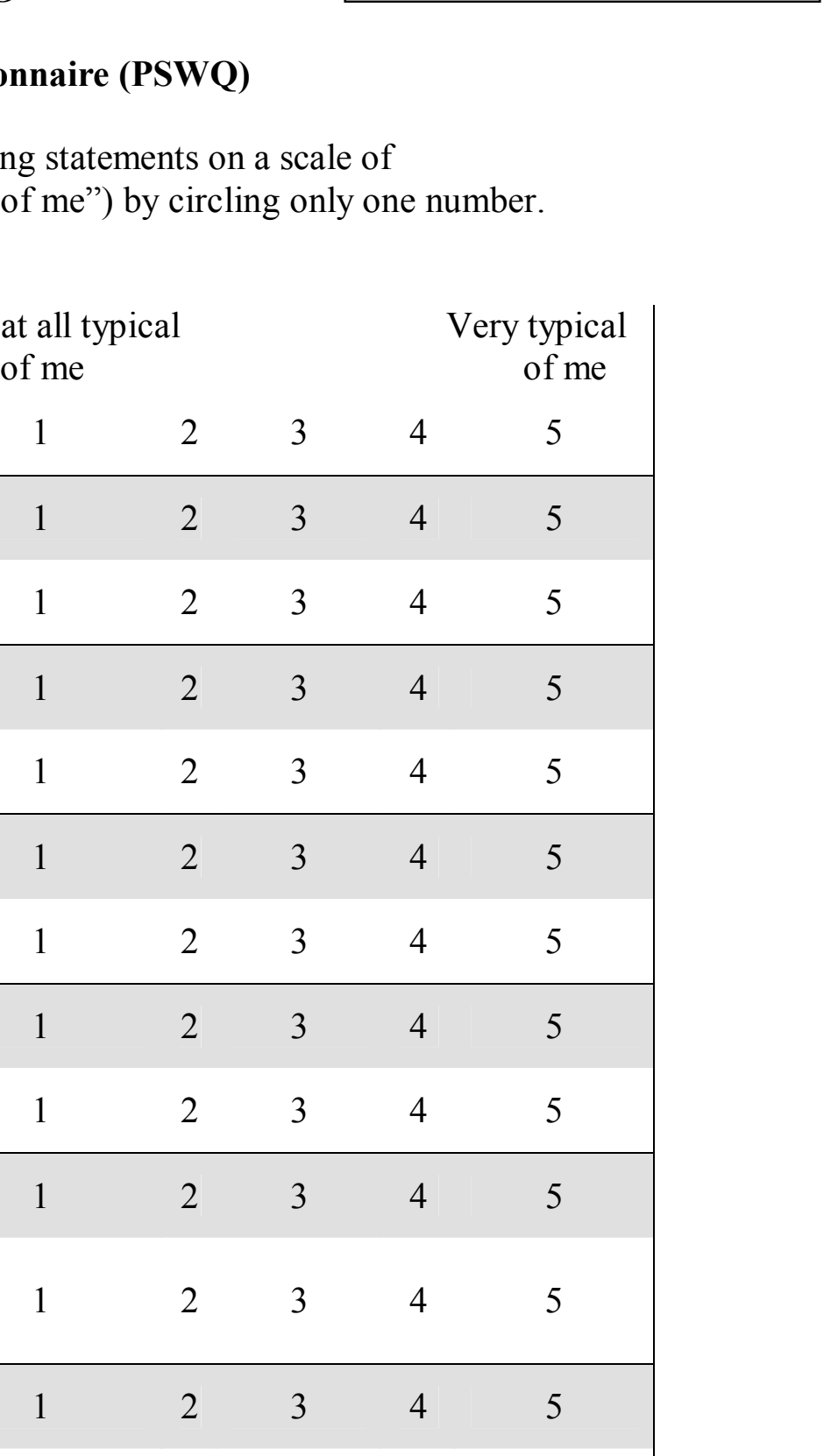

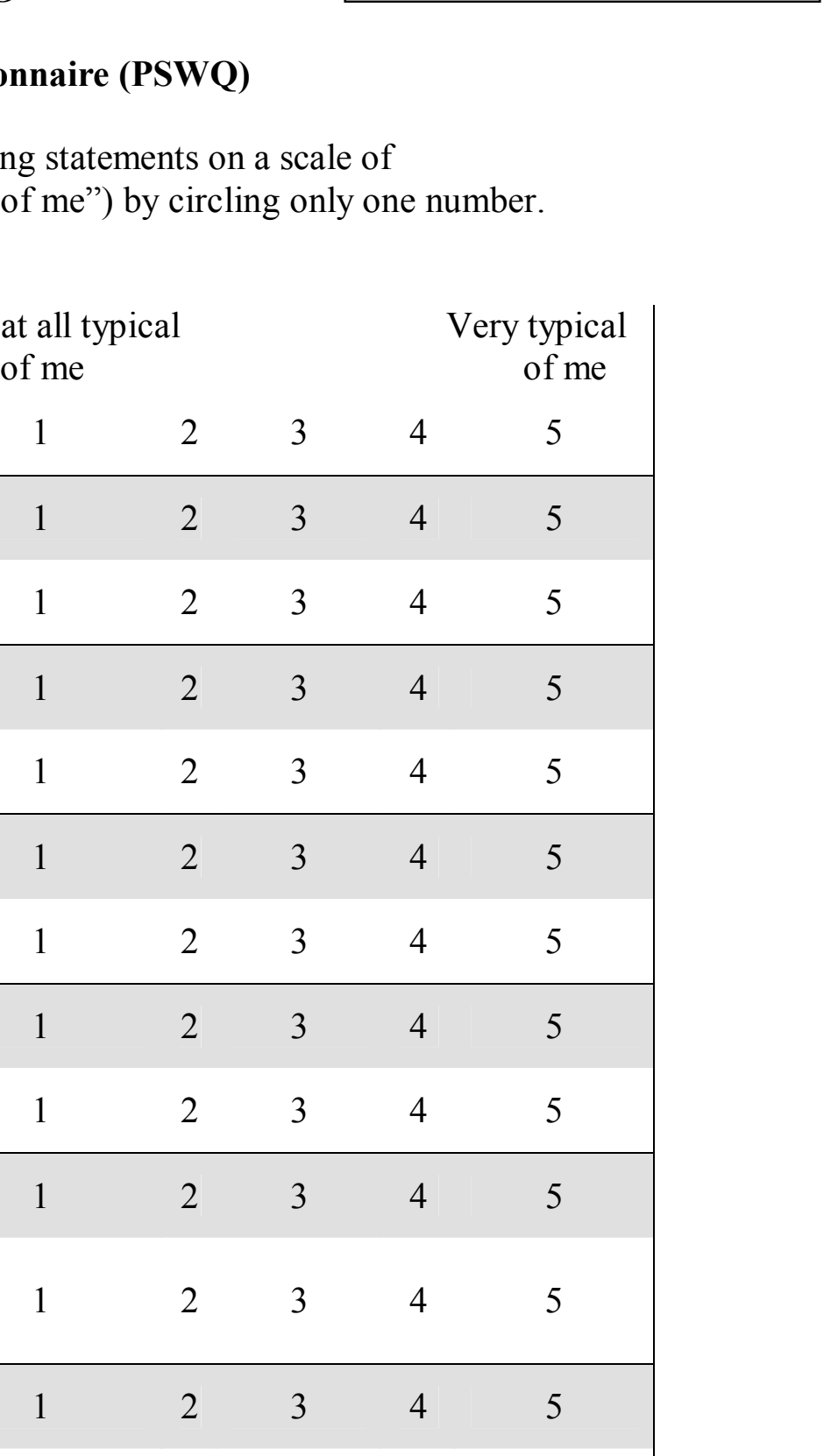

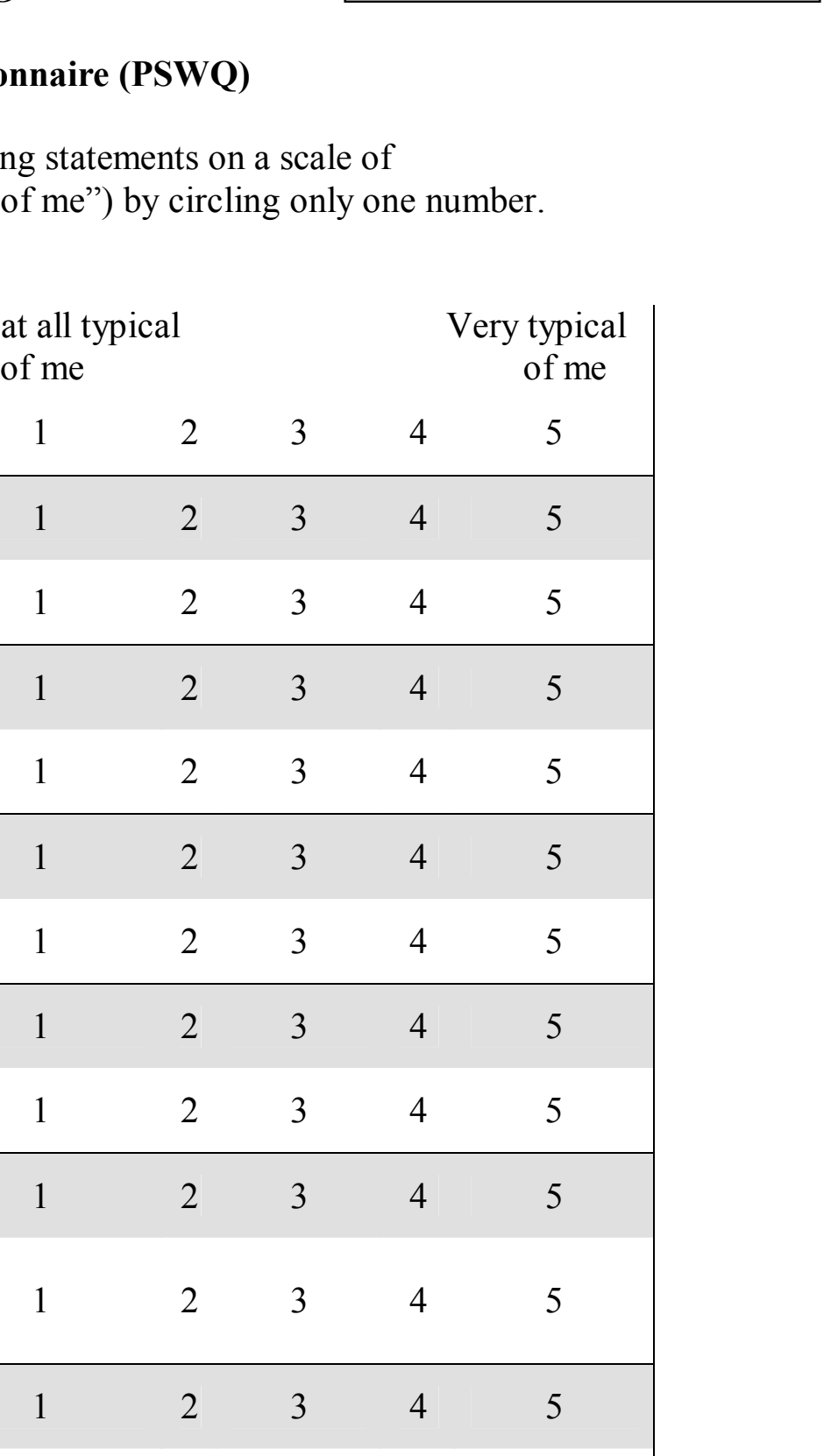

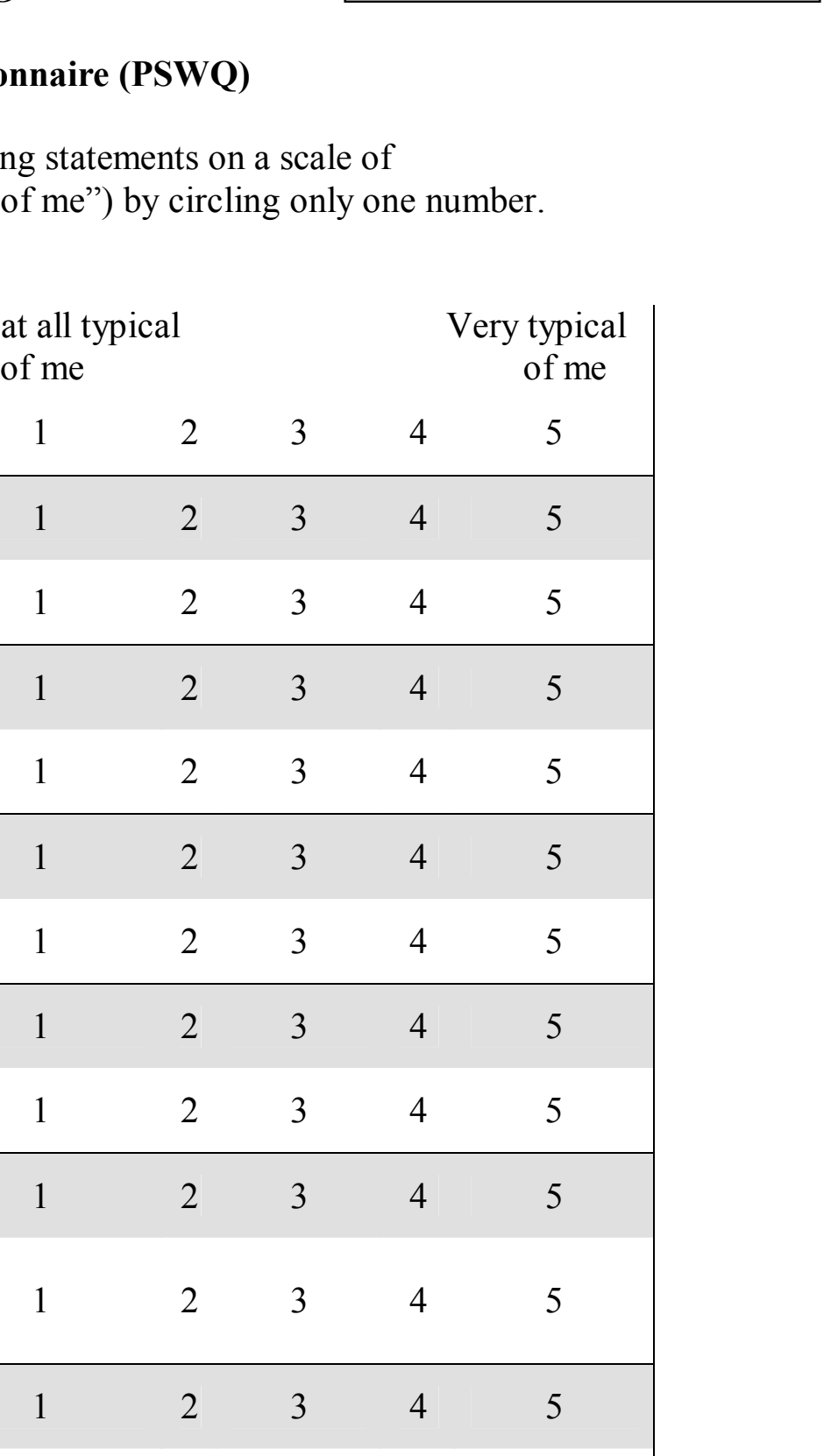

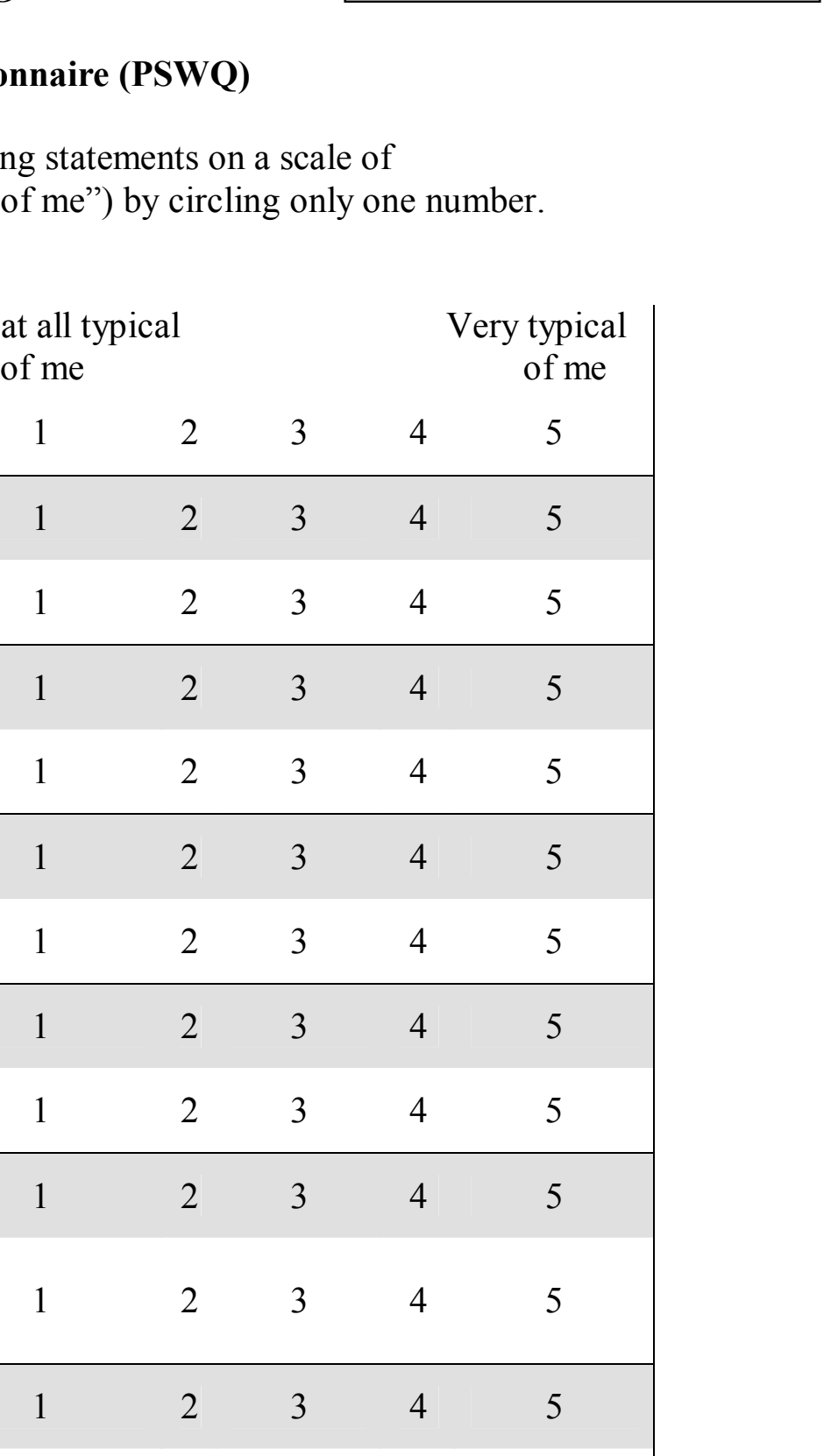


Table 1

Possible Components of Prenatal Anxiety

\begin{tabular}{|c|c|c|c|c|c|c|c|}
\hline & & \multicolumn{6}{|c|}{ Study/Model } \\
\hline & & $\begin{array}{c}\text { Standley, } \\
\text { Soule, \& } \\
\text { Copans } \\
(1979)\end{array}$ & $\begin{array}{l}\text { Huizink, } \\
\text { Mulder, de } \\
\text { Medina, } \\
\text { Visser, \& } \\
\text { Buitelaar } \\
\text { (2004) }\end{array}$ & $\begin{array}{c}\text { Ross, } \\
\text { Sellers, } \\
\text { Gilbert } \\
\text { Evans, \& } \\
\text { Romach } \\
(2004)\end{array}$ & $\begin{array}{c}\text { Seiber, } \\
\text { Germann, } \\
\text { Barbir, \& } \\
\text { Ehlert } \\
(2006)\end{array}$ & $\begin{array}{c}\text { Clemens } \\
(2010)\end{array}$ & $\begin{array}{l}\text { Wenzel } \\
(2011)\end{array}$ \\
\hline Physiological & Hormonal & & & $\mathrm{X}$ & & & $\mathrm{X}$ \\
\hline Psychological & $\begin{array}{l}\text { Personal History of Psychiatric Issues } \\
\text { Family History of Psychiatric Issues } \\
\text { Existing Psychological Symptoms: } \\
\text { Anxiety - General } \\
\text { Anxiety - Sensitivity } \\
\text { Anxiety - Fear of Childbirth/Giving } \\
\text { Birth } \\
\text { Anxiety - Phobia } \\
\text { Anxiety - Obsessive-compulsive } \\
\text { Fear of Pain } \\
\text { Depression } \\
\text { General Pathological Symptoms } \\
\text { Intolerance of Uncertainty } \\
\text { Issues with Pregnancy and } \\
\text { Childbirth } \\
\text { Childbirth-related Self-efficacy } \\
\text { Fear of bearing a handicapped child } \\
\text { Concern about one's appearance }\end{array}$ & $\mathrm{X}$ & $\begin{array}{l}X \\
X\end{array}$ & $\begin{array}{l}X \\
X \\
X\end{array}$ & $\begin{array}{l}X \\
X\end{array}$ & $\begin{array}{l}X \\
X\end{array}$ & $\begin{array}{l}X \\
X\end{array}$ \\
\hline
\end{tabular}


Table 2

Expected cluster groupings

\begin{tabular}{ccccccccc} 
& \multicolumn{2}{c}{ Anxiety Sensitivity } & \multicolumn{2}{c}{ Fear of Pain } & \multicolumn{2}{c}{ Depression } & \multicolumn{2}{c}{ Childbirth } \\
Cluster & High & Low & High & Low & High & Low & $\begin{array}{c}\text { Self-efficacy } \\
\text { Better }\end{array}$ & $\begin{array}{c}\text { Poorer } \\
\text { (High) }\end{array}$ \\
& & & & & & & & Xow) \\
\hline 1 & $\mathrm{X}$ & & $\mathrm{X}$ & & $\mathrm{X}$ & & $\mathrm{X}$ & \\
\hline 2 & & $\mathrm{X}$ & & $\mathrm{X}$ & & $\mathrm{X}$ & $\mathrm{X}$ \\
\hline 3 & $\mathrm{X}$ & & $\mathrm{X}$ & & $\mathrm{X}$ & & & $\mathrm{X}$ \\
\hline
\end{tabular}


Table 3

Variables and method of computation

\begin{tabular}{|c|c|c|}
\hline Subject & Name & Calculation \\
\hline Anxiety sensitivity & ASI-3 & ASI-3 total score \\
\hline Anxiety/fear, childbirth & W-DEQ & W-DEQ total score \\
\hline Catastrophizing & PSWQ & PSWQ total score \\
\hline Depression & CES-D & CES-D total score \\
\hline Fear of pain & FPQ-III & Fear of Pain Questionnaire-III total score \\
\hline Health concerns, baby & $\begin{array}{l}\text { Health- } \\
\text { Child }\end{array}$ & $\begin{array}{l}\text { A }+\mathrm{B}+\mathrm{C}+\mathrm{D}+\mathrm{E}=\mathrm{Score} \\
\text { A) Do you have concerns about the health of your baby? }(\text { no }=1 \text {, yes }=2) \\
\text { B) Has a doctor said that there is a problem with your baby? }(\text { no }=1, \text { yes }=2) \\
\text { C) Has your doctor said that your pregnancy if "high risk"? (no }=1 \text {, yes }=2) \\
\text { D) Do you think about the concerns every day? (no }=1 \text {, yes }=2) \\
\text { E) Does thinking about the concerns interfere with your daily life? }(\text { no }=1 \text {, yes }=2)\end{array}$ \\
\hline Health concerns, self & HAQ & HAQ total score minus Health-Fetus (22) and Health-Child (23) questions \\
\hline Self-efficacy, childbirth & CB-SE & $\begin{array}{l}\text { Right now, rate your ability to handle labor pain? }(1=\text { I feel that I can handle labor } \\
\text { pain, } 5 \text { = I feel that I cannot handle labor pain). }\end{array}$ \\
\hline Self-efficacy, parenting & Parent-SE & $\begin{array}{l}\text { A } \mathrm{A}+\mathrm{B}+\mathrm{C}=\text { Score } \\
\text { A) Do you have concerns about your ability to be a good mother your baby? (no = } \\
1 \text {, yes }=2 \text { ) } \\
\text { B) If yes: Do you think about the concerns every day? }(\text { no }=1 \text {, yes }=2) \\
\text { C) Does thinking about the concerns interfere with your daily life? }(\text { no }=1 \text {, yes }=2)\end{array}$ \\
\hline \multirow[t]{2}{*}{ Social support concerns } & Soc-Birth & $\begin{array}{l}\text { Do you have a spouse or significant other like a boyfriend or a friend or a family } \\
\text { member who is planning to help you during the birth? }(\mathrm{Yes}=1, \mathrm{No}=2)\end{array}$ \\
\hline & Soc-PP & $\begin{array}{l}\text { Do you have a spouse or significant other like a boyfriend or a friend or a family } \\
\text { member who is planning to help you care for your baby after you bring your baby } \\
\text { home? } \mathrm{PP}=\text { postpartum (Yes }=1, \text { No }=2 \text { ) }\end{array}$ \\
\hline
\end{tabular}




\begin{tabular}{|c|c|c|}
\hline Demographics & & \\
\hline & Age & as input \\
\hline & $\begin{array}{l}\text { Annual } \\
\text { Income }\end{array}$ & $\begin{array}{l}1=\$ 0-10,000,2=\$ 10,001-20,000,3=\$ 20,001-35,000,4=\$ 35,001-50,000, \\
5=\$ 50,001-75,000,6=\$ 75,001-100,000,7=\$ 100,001+\end{array}$ \\
\hline & $\begin{array}{l}\text { Annual } \\
\text { Household } \\
\text { Income }\end{array}$ & $\begin{array}{l}1=\$ 0-10,000,2=\$ 10,001-20,000,3=\$ 20,001-35,000,4=\$ 35,001-50,000, \\
5=\$ 50,001-75,000,6=\$ 75,001-100,000,7=\$ 100,001+\end{array}$ \\
\hline & Education & $\begin{array}{l}1=\text { Grades } 1 \text { through grade } 12 \text { (did not graduate) }, 2=\text { Graduated high school, } 3= \\
\text { GED, } 4=\text { Some college, } 5=\text { Graduated college, } 6=\text { Post graduate years, } 7= \\
\text { Master's Degree, } 8=\text { Doctoral Degree }\end{array}$ \\
\hline & Trimester & $1=$ First, $2=$ Second, $3=$ Third \\
\hline & $\begin{array}{l}\text { Previous } \\
\text { Births }\end{array}$ & Have you had other births? $($ Yes $=1$, No $=2)$ \\
\hline & $\begin{array}{l}\text { Traumatic } \\
\text { Birth }\end{array}$ & Have you experienced a traumatic birth? $(\mathrm{Yes}=1$, No $=2)$ \\
\hline & $\begin{array}{l}\text { C-Section } \\
\text { Scheduled }\end{array}$ & Are you scheduled to have a cesarean section? $($ Yes $=1$, No $=2)$ \\
\hline
\end{tabular}

Note: Unless a specific assessment measure (e.g., ASI-3) is indicated, questions were from the Demographic Questionnaire

Note: Step 1 - Cluster Analyses variables (indicated in gray): ASI-3, FPQ-III, CES-D, CB-SE

Note: Step 2 - Analyses of variance variables: W-DEQ, PSWQ, Health-Child, HAQ, Parent-SE, Soc-Birth, Soc-PP 
Table 4

\section{Participant Demographics}

\begin{tabular}{|c|c|c|c|c|c|c|c|c|}
\hline Number of participants: & \multicolumn{8}{|l|}{102} \\
\hline Age - Mean/SD: & \multicolumn{8}{|c|}{$27.59 / 5.4$ (Range - 18 to 45$)$} \\
\hline \multicolumn{9}{|l|}{$n(\%)$} \\
\hline \multirow[t]{2}{*}{ Race/Ethnicity } & $\begin{array}{l}\text { American } \\
\text { Indian }\end{array}$ & Asian & $\begin{array}{c}\text { African } \\
\text { American }\end{array}$ & $\begin{array}{l}\text { Hispanic/ } \\
\text { Latino }\end{array}$ & White & \multicolumn{2}{|l|}{ Other } & \\
\hline & $0(0.0)$ & $2(2.0)$ & $0(0.0)$ & $1(1.0)$ & $97(95.0)$ & \multicolumn{2}{|c|}{$\begin{array}{c}2 \text { (2.0) (Middle Eastern, } \\
\text { American) }\end{array}$} & \\
\hline \multirow[t]{2}{*}{ Employed } & Yes & No & & & & & & \\
\hline & $49(48.0)$ & $53(52.0)$ & & & & & & \\
\hline \multirow[t]{2}{*}{ Income level, participant } & $\$ 0-10,000$ & $\begin{array}{c}\$ 10,001- \\
20,000\end{array}$ & $\begin{array}{c}\$ 20,001- \\
35,000 .\end{array}$ & $\begin{array}{c}\$ 35,001- \\
50,000 .\end{array}$ & $\begin{array}{c}\$ 50,001- \\
75,000 .\end{array}$ & $\begin{array}{l}\$ 75,001- \\
100,000 .\end{array}$ & $\$ 100,001+$ & \\
\hline & $35(34.3)$ & $19(18.6)$ & $21(20.6)$ & $15(14.8)$ & $9(8.7)$ & $2(2.0)$ & $1(1.0)$ & \\
\hline \multirow[t]{2}{*}{ Income level, household } & $\$ 0-10,000$ & $\begin{array}{c}\$ 10,001- \\
20,000\end{array}$ & $\begin{array}{c}\$ 20,001- \\
35,000 .\end{array}$ & $\begin{array}{c}\$ 35,001 \text { - } \\
50,000 \text {. }\end{array}$ & $\begin{array}{c}\$ 50,001 \text { - } \\
75,000 .\end{array}$ & $\begin{array}{l}75,001- \\
100,000 .\end{array}$ & $\$ 100,001+$ & \\
\hline & $18(17.7)$ & $13(12.7)$ & $16(15.7)$ & $20(19.6)$ & $10(9.8)$ & $19(18.6)$ & $6(5.9)$ & \\
\hline \multirow[t]{2}{*}{ Education } & $\begin{array}{c}\text { Grades } 1- \\
12\end{array}$ & $\begin{array}{c}\text { Graduated } \\
\text { high } \\
\text { school }\end{array}$ & GED & Some college & $\begin{array}{l}\text { Graduated } \\
\text { college }\end{array}$ & $\begin{array}{l}\text { Post graduate } \\
\text { year }\end{array}$ & $\begin{array}{l}\text { Master's } \\
\text { degree }\end{array}$ & $\begin{array}{c}\text { Doctoral } \\
\text { degree }\end{array}$ \\
\hline & $8(7.8)$ & $28(27.5)$ & $8(7.8)$ & $24(23.5)$ & $22(21.6)$ & $5(5.0)$ & $0(0.0)$ & $7(6.8)$ \\
\hline
\end{tabular}




\begin{tabular}{lccc}
\hline $\begin{array}{l}\text { Current trimester of } \\
\text { pregnancy }\end{array}$ & $1^{\text {st }}$ & $2^{\text {nd }}$ & $3^{\text {rd }}$ \\
\hline & $7(6.8)$ & $40(39.3)$ & $55(53.9)$ \\
& Yes & No & \\
$\begin{array}{l}\text { Number (percentage) of } \\
\text { participants who had } \\
\text { previous births }\end{array}$ & $53(52.0)$ & $49(48.0)$ &
\end{tabular}

\begin{tabular}{lccccc}
\hline $\begin{array}{l}\text { Number (percentage) of } \\
\text { births for the 48 } \\
\text { participants who had } \\
\text { previous births: }\end{array}$ & 1 birth & 2 births & 3 births & 4 births & 5 births \\
\hline & $29(28.4)$ & $68(66.7)$ & $2(2.0)$ & $2(2.0)$ & $1(1.0)$ \\
\hline $\begin{array}{l}\text { Number (percentage) of } \\
\text { participants who had a } \\
\text { history of traumatic birth }\end{array}$ & Yes & No & & \\
\hline & $17(17)$ & $85(85)$ & & \\
\hline $\begin{array}{l}\text { Anticipated delivery } \\
\text { method for current birth: }\end{array}$ & Cesarean & Vaginal & \\
\hline & $11(10.7)$ & $91(89.2)$
\end{tabular}


Table 5

Pearson Product Moment Correlations for Variables

\begin{tabular}{|c|c|c|c|c|c|c|c|c|c|c|}
\hline & ASI-3 & FPQ-III & CES-D & CB-SE & Age & $\begin{array}{c}\text { Ann } \\
\text { Income }^{\mathrm{a}}\end{array}$ & $\begin{array}{c}\text { House } \\
\text { Income }^{\mathrm{a}}\end{array}$ & Educ $^{\mathrm{a}}$ & $\operatorname{Tri}^{\mathrm{a}}$ & $\begin{array}{c}\text { Prev } \\
\text { Birth }^{\mathrm{a}}\end{array}$ \\
\hline ASI-3 & --- & --- & --- & --- & --- & --- & --- & --- & --- & --- \\
\hline FPQ-III & $.47 * *$ & --- & --- & --- & --- & --- & --- & --- & --- & --- \\
\hline CES-D & $.67 * *$ & $.29 * *$ & --- & --- & --- & --- & --- & --- & --- & --- \\
\hline CB-SE & .19 & .18 & .07 & --- & --- & --- & --- & --- & --- & --- \\
\hline Age & -.16 & $-.21 *$ & -.16 & -.06 & --- & --- & --- & --- & --- & --- \\
\hline $\begin{array}{l}\text { Annual } \\
\text { Income }\end{array}$ & -.07 & .07 & .01 &.- .01 & .01 & --- & --- & --- & --- & --- \\
\hline $\begin{array}{l}\text { Household } \\
\text { Income }\end{array}$ & -.09 & -.09 & .01 & $-.05 * *$ & -.02 & $.66 * *$ & --- & --- & --- & --- \\
\hline Education & -.02 & -.11 & -.05 & -.01 & .12 & $.39 * *$ & $.46 * *$ & --- & --- & --- \\
\hline Trimester & .01 & -.15 & .16 & -.12 & -.07 & -.19 & -.01 & .08 & --- & --- \\
\hline $\begin{array}{l}\text { Previous } \\
\text { Births }\end{array}$ & .10 & .08 & .14 & $.23 *$ & $-.31 * *$ & .09 & $.21 *$ & .10 & .00 & --- \\
\hline $\begin{array}{l}\text { Traumatic } \\
\text { Births }\end{array}$ & .05 & -.04 & .02 & $.20 *$ & -.12 & .16 & $.28 * *$ & .15 & -.08 & $.51 * *$ \\
\hline C-Section & .17 & .13 & $.25 *$ & .13 & $-.27 * *$ & .10 & .17 & .03 & .14 & $.20 *$ \\
\hline W-DEQ & $.47 * *$ & $.23 *$ & $.58 * *$ & $.38 * *$ & -.09 & -.03 & -.06 & -.08 & .05 & .17 \\
\hline PSWQ & $.50 * *$ & $.27 * *$ & $.63 * *$ & .18 & $-.20 *$ & $-.26 * *$ & -.04 & -.10 & $.28 * *$ & .15 \\
\hline $\begin{array}{l}\text { Health- } \\
\text { Child }\end{array}$ & $-.35 * *$ & $-.28 * *$ & $-.36 * *$ & $-.23 *$ & .07 & .06 & .02 & .06 & -.02 & -.18 \\
\hline $\mathrm{HAQ}$ & $.62 * *$ & $.45 * *$ & $.59 * *$ & $.21 *$ & $-.21 *$ & -.04 & -.03 & -.01 & .08 & .08 \\
\hline Parent- SE & -.12 & -.12 & -.04 & $-.20 *$ & $.20 *$ & -.05 & -.07 & -.11 & .09 & .02 \\
\hline Soc-Birth & .15 & .12 & .10 & -.02 & .02 & .17 & .03 & -.10 & -.03 & -.05 \\
\hline Soc-PP & .09 & .03 & .16 & -.06 & -.06 & .16 & -.02 & -.09 & -.02 & -.12 \\
\hline
\end{tabular}




\begin{tabular}{|c|c|c|c|c|c|c|c|c|c|}
\hline & $\begin{array}{l}\text { Traum } \\
\text { Birth }^{\mathrm{a}}\end{array}$ & C-Section & W-DEQ & PSWQ & $\begin{array}{l}\text { Health- } \\
\text { Child }\end{array}$ & HAQ & $\begin{array}{l}\text { Parent- } \\
\text { SE }\end{array}$ & $\begin{array}{l}\text { Soc- } \\
\text { Birth }\end{array}$ & Soc- PP \\
\hline ASI-3 & --- & --- & --- & --- & --- & --- & --- & --- & --- \\
\hline FPQ-III & --- & --- & --- & --- & --- & --- & --- & --- & --- \\
\hline CES-D & --- & --- & --- & --- & --- & --- & --- & --- & --- \\
\hline CB-SE & --- & --- & --- & --- & --- & --- & --- & --- & --- \\
\hline Age & --- & --- & --- & --- & --- & --- & --- & --- & --- \\
\hline $\begin{array}{l}\text { Annual } \\
\text { Income }\end{array}$ & --- & --- & --- & --- & --- & --- & --- & --- & --- \\
\hline $\begin{array}{l}\text { Household } \\
\text { Income }\end{array}$ & --- & --- & --- & --- & --- & --- & --- & --- & --- \\
\hline Education & --- & --- & --- & --- & --- & --- & --- & --- & --- \\
\hline Trimester & --- & --- & --- & --- & --- & --- & --- & --- & --- \\
\hline $\begin{array}{l}\text { Previous } \\
\text { Births }\end{array}$ & --- & --- & --- & --- & --- & --- & --- & --- & --- \\
\hline $\begin{array}{l}\text { Traumatic } \\
\text { Births }\end{array}$ & --- & --- & --- & --- & --- & --- & --- & --- & --- \\
\hline C-Section & .07 & --- & --- & --- & --- & --- & --- & --- & --- \\
\hline W-DEQ & -.11 & .19 & --- & --- & --- & --- & --- & --- & --- \\
\hline PSWQ & .04 & .13 & $.45 * *$ & --- & --- & --- & --- & --- & --- \\
\hline $\begin{array}{l}\text { Health- } \\
\text { Child }\end{array}$ & -.00 & -.05 & $-.35 * *$ & $-.30 * *$ & --- & --- & --- & --- & --- \\
\hline HAQ & -.03 & .18 & $.35 * *$ & $.50 * *$ & $-.43 * *$ & --- & --- & --- & --- \\
\hline Parent- SE & .01 & .02 & -.15 & .05 & .18 & -.01 & --- & --- & --- \\
\hline Soc-Birth & .08 & .06 & .18 & -.00 & .02 & -.02 & .03 & --- & --- \\
\hline Soc-PP & .10 & .08 & .13 & .08 & .01 & -.05 & -.03 & $.77 * *$ & --- \\
\hline
\end{tabular}

${ }^{\mathrm{a}}$ Ann Income $=$ Annual Income, House Income $=$ Household Income, Educ $=$ Education, Tri $=$ Trimester, Prev Birth $=$ Previous Births, Traum Birth $=$ Traumatic Births 


\begin{tabular}{|l|c|}
\hline & $\begin{array}{c}\text { Z } \\
\text { Skewness }\end{array}$ \\
\hline ASI-3 & $7.6^{* * *}$ \\
\hline FPQ-III & $3.7^{* * *}$ \\
\hline CES-D & $4.3^{* * *}$ \\
\hline CB-SE & 1.4 \\
\hline Age & $3.1^{* * *}$ \\
\hline $\begin{array}{l}\text { Annual } \\
\text { Income }\end{array}$ & $5.4^{* * *}$ \\
\hline $\begin{array}{l}\text { Household } \\
\text { Income }\end{array}$ & 1.5 \\
\hline Education & $2.5^{*}$ \\
\hline Trimester & $-5.3^{* * *}$ \\
\hline $\begin{array}{l}\text { Previous } \\
\text { Births }\end{array}$ & 0.2 \\
\hline $\begin{array}{l}\text { Traumatic } \\
\text { Births }\end{array}$ & $-7.6^{* * *}$ \\
\hline C-Section & $-10.7^{* * *}$ \\
\hline W-DEQ & 0.2 \\
\hline PSWQ & 1.1 \\
\hline Health-Child & $-2.3^{*}$ \\
\hline HAQ & $6.4^{* * *}$ \\
\hline Parent- SE & $33.8^{* * *}$ \\
\hline Soc-Birth & $23.7^{* * *}$ \\
\hline Soc-PP & $17.7^{* * *}$ \\
\hline
\end{tabular}

$$
\begin{aligned}
& * p<.05 \\
& * * p<.01 \\
& * * * p<.001
\end{aligned}
$$


Table 6

Characteristics of the Ward's Method Three- and Four-Cluster Solutions

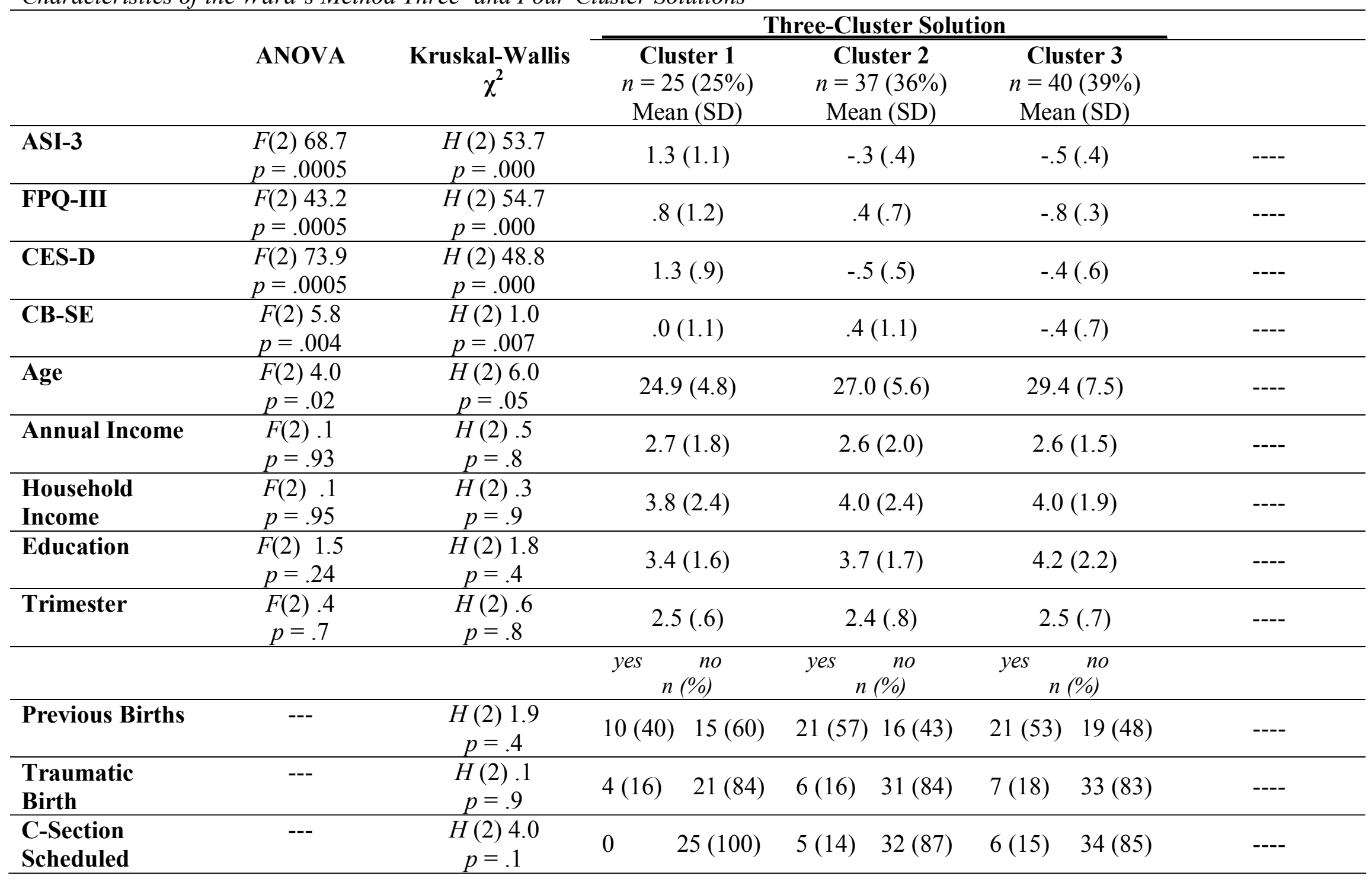




\begin{tabular}{|c|c|c|c|c|c|c|c|c|}
\hline & \multirow[b]{2}{*}{ ANOVA } & \multirow[b]{2}{*}{$\begin{array}{c}\text { Kruskal-Wallis } \\
\chi^{2}\end{array}$} & \multicolumn{6}{|c|}{ Four-Cluster Solution } \\
\hline & & & $\begin{array}{c}\text { Cluster 1 } \\
n=13 \\
13 \%\end{array}$ & $\begin{array}{c}\text { Cluster } 2 \\
n=37 \\
36 \% \\
\end{array}$ & \multicolumn{2}{|c|}{$\begin{array}{c}\text { Cluster } 3 \\
n=40 \\
39 \%\end{array}$} & \multicolumn{2}{|c|}{$\begin{array}{c}\text { Cluster } 4 \\
n=12 \\
12 \% \\
\end{array}$} \\
\hline ASI-3 & $\begin{array}{l}F(3) 52.1 \\
p=.0005\end{array}$ & $\begin{array}{c}H(3) 54.2 \\
p=.000\end{array}$ & $1.7(1.1)$ & $-.3(.4)$ & \multicolumn{2}{|c|}{$-.5(.4)$} & \multicolumn{2}{|c|}{$.9(1.1)$} \\
\hline FPQ-III & $\begin{array}{l}F(3) 57.7 \\
p=.0005\end{array}$ & $\begin{array}{c}H(3) 64.6 \\
p=.000\end{array}$ & $1.6(.9)$ & $.4(.7)$ & \multicolumn{2}{|c|}{$-.8(.3)$} & \multicolumn{2}{|c|}{$-.1(.7)$} \\
\hline CES-D & $\begin{array}{l}F(3) 50.6 \\
p=.0005\end{array}$ & $\begin{array}{c}H(3) 49.1 \\
p=.000\end{array}$ & $1.2(.9)$ & $-.5(.5)$ & \multicolumn{2}{|c|}{$-.4(.6)$} & \multicolumn{2}{|c|}{$1.5(.8)$} \\
\hline CB-SE & $\begin{array}{l}F(3) 9.7 \\
p=.0005\end{array}$ & $\begin{array}{c}H(3) 22.8 \\
p=.000\end{array}$ & $.7(.9)$ & $.4(.1)$ & \multicolumn{2}{|c|}{$-.4(.8)$} & \multicolumn{2}{|c|}{$-.7(.7)$} \\
\hline Age & $\begin{array}{l}F(3) 2.7 \\
p=.05\end{array}$ & $\begin{array}{c}H(3) 6.2 \\
p=.1\end{array}$ & $5.4(1.5)$ & $5.6(.9)$ & \multicolumn{2}{|c|}{$7.5(1.2)$} & \multicolumn{2}{|c|}{$4.1(1.2)$} \\
\hline Annual Income & $\begin{array}{c}F(3) 1.0 \\
p=.39\end{array}$ & $\begin{array}{c}H(3) 3.0 \\
p=.4\end{array}$ & $1.3(.4)$ & $2.0(.3)$ & \multicolumn{2}{|c|}{$1.5(.2)$} & \multicolumn{2}{|c|}{$2.1(.6)$} \\
\hline $\begin{array}{l}\text { Household } \\
\text { Income }\end{array}$ & $\begin{array}{l}F(3) 1.3 \\
p=.27\end{array}$ & $\begin{array}{c}H(3) 3.6 \\
p=.31\end{array}$ & $2.1(.6)$ & $2.4(.4)$ & \multicolumn{2}{|c|}{$1.9(.3)$} & \multicolumn{2}{|c|}{$2.5(.7)$} \\
\hline Education & $\begin{array}{c}F(3) 1.0 \\
p=.4\end{array}$ & $\begin{array}{c}H(3) 1.9 \\
p=.6\end{array}$ & $1.3(.4)$ & $1.7(.3)$ & 2.2 & (.4) & & $(.5)$ \\
\hline Trimester & $\begin{array}{c}F(3) .6 \\
p=.6\end{array}$ & $\begin{array}{l}H(3) 1.7 \\
p=.63\end{array}$ & $.7(.2)$ & $.8(.1)$ & & $(.1)$ & & $(.1)$ \\
\hline & & & $\begin{array}{c}\text { yes } \\
n(\%)\end{array}$ & $\begin{array}{c}\text { yes } \\
n(\%)\end{array}$ & $\begin{array}{l}\text { yes } \\
n\end{array}$ & $\begin{array}{l}n o \\
\%)\end{array}$ & $\begin{array}{r}\text { yes } \\
n\end{array}$ & $\begin{array}{l}n o \\
\%)\end{array}$ \\
\hline $\begin{array}{l}\text { Previous Births } \\
0=1\end{array}$ & --- & $\begin{array}{c}H(3) 2.8 \\
p=.42\end{array}$ & $4(31) \quad 9(69)$ & $21(57) \quad 16(43)$ & $21(53)$ & $19(48)$ & $6(50)$ & $6(50)$ \\
\hline $\begin{array}{l}\text { Traumatic } \\
\text { Birth } 0=1\end{array}$ & --- & $\begin{array}{l}H(3) .13 \\
p=1.0\end{array}$ & $2(15) \quad 11(85)$ & $6(16) \quad 31(84)$ & $7(18)$ & $33(83)$ & $2(17)$ & $10(83)$ \\
\hline $\begin{array}{l}\text { C-Section } \\
\text { Scheduled }\end{array}$ & --- & $\begin{array}{c}H(3) 4.0 \\
p=.26\end{array}$ & $13(100)$ & $5(14) \quad 32(87)$ & $6(15)$ & $34(85)$ & 0 & $12(100)$ \\
\hline
\end{tabular}

Note. ANOVA and Kruskal-Wallis Tests: alpha $=.05$. 
Note. Annual Income, Annual Household Income, and Education are the means of the responses for those questions on the demographic questionnaire. Example: Education $=.42$ is between "Some college" response 4 and "Graduated college" response 5. See Table 3. 
Table 7

Characteristics of the K-Means Clusters

\begin{tabular}{|c|c|c|c|c|c|c|}
\hline & & & $\begin{array}{c}\text { Cluster } 1 \\
n=9 \\
8 \% \\
\end{array}$ & $\begin{array}{c}\text { Cluster } 2 \\
n=24 \\
24 \% \\
\end{array}$ & $\begin{array}{c}\text { Cluster } 3 \\
n=56 \\
55 \%\end{array}$ & $\begin{array}{c}\text { Cluster } 4 \\
n=13 \\
13 \% \\
\end{array}$ \\
\hline & $\begin{array}{c}\text { Kruskal- } \\
\text { Wallis } \\
\chi^{2}\end{array}$ & ANOVA & Mean (SD) & Mean (SD) & Mean (SD) & Mean (SD) \\
\hline ASI-3 & $H(3) 48.6$ & $F(3) 56.1$ & & & & \\
\hline$Z$-score & $p=.000$ & $\begin{array}{c}p=.000 \\
\eta^{2}=.6\end{array}$ & $2.1(1.0)$ & $-.1(.6)^{\mathrm{a}}$ & $-.5(.4)^{\mathrm{a}}$ & $.9(1.0)$ \\
\hline $\begin{array}{r}\text { Clinical } \\
\text { Score }\end{array}$ & & & $49.7(10.7)$ & $26.7(6.0)$ & $23.1(4.1)$ & $37.5(10.5)$ \\
\hline FPQ-III & $H(3) 61.0$ & $F(3) 54.3$ & & & & \\
\hline$Z$-score & $p=.000$ & $\begin{array}{c}p=.000 \\
\eta^{2}=.4\end{array}$ & $1.5(.9)^{\mathrm{a}}$ & $.9(.7)^{\mathrm{a}}$ & $-.6(.5)$ & $-.0(.7)$ \\
\hline $\begin{array}{r}\text { Clinical } \\
\text { Score }\end{array}$ & & & $93.6(21.0)$ & $79.6(16.2)$ & $44.4(11.4)$ & $58.2(16.1)$ \\
\hline $\begin{array}{c}\text { CES-D } \\
Z \text {-score }\end{array}$ & $\begin{array}{c}H(3) 47.1 \\
p=.000\end{array}$ & $\begin{array}{c}F(3) 54.1 \\
p=.000 \\
\eta^{2}=.6\end{array}$ & $1.5(.8)^{\mathrm{a}}$ & $-.4(.6)^{b}$ & $-.4(.6)^{b}$ & $1.5(.8)^{\mathrm{a}}$ \\
\hline $\begin{array}{r}\text { Clinical } \\
\text { Score } \\
\end{array}$ & & & $31.6(9.7)$ & $9.9(6.6)$ & $9.7(6.6)$ & $32.2(9.0)$ \\
\hline $\begin{array}{c}\text { CB-SE } \\
\text { Z-score }\end{array}$ & $\begin{array}{c}H(3) 21.4 \\
p=.000\end{array}$ & $\begin{array}{c}F(3) 9.0 \\
p=.000 \\
\eta^{2}=.6\end{array}$ & $1.1(.8)^{\mathrm{a}}$ & $.4(.9)^{\mathrm{a}}$ & $-.2(.9)^{b}$ &.$-6(.7)^{b}$ \\
\hline $\begin{array}{r}\text { Clinical } \\
\text { Score }\end{array}$ & & & $3.4(.9)$ & $3.0(1.0)$ & $2.3(1.0)$ & $1.9(.8)$ \\
\hline
\end{tabular}




\begin{tabular}{|c|c|c|c|c|c|c|}
\hline \multicolumn{7}{|c|}{ Demographics } \\
\hline Age & $\begin{array}{c}H(3) 5.4 \\
p=.1\end{array}$ & $\begin{array}{c}F(3) 2.1 \\
p=.1\end{array}$ & $26.4(6.7)$ & $29.3(6.1)$ & $28.8(5.6)$ & $24.7(6.1)$ \\
\hline $\begin{array}{l}\text { Annual } \\
\text { Income }^{\text {a }}\end{array}$ & $\begin{array}{c}H(3) 1.6 \\
p=.7\end{array}$ & $\begin{array}{c}F(3) .6 \\
p=.6\end{array}$ & $2.5(1.6)$ & $3.2(2.0$ & $2.3(1.5)$ & $1.7(.7)$ \\
\hline $\begin{array}{l}\text { Household } \\
\text { Income }\end{array}$ & $\begin{array}{c}H(3) 2.6 \\
p=.5\end{array}$ & $\begin{array}{c}F(3) .9 \\
p=.4\end{array}$ & $3.8(2.3)$ & $4.6(2.3)$ & $4.0(2.0)$ & $3.3(1.5)$ \\
\hline $\begin{array}{l}\text { Education } \\
\text { Level }^{\text {a }}\end{array}$ & $\begin{array}{c}H(3) 1.4 \\
p=.7\end{array}$ & $\begin{array}{l}F(3) .5 \\
p=.7\end{array}$ & 3.7 (1.9) & $4.1(1.9)$ & 3.9 (2.2.) & $3.0(1.4)$ \\
\hline Trimester & $\begin{array}{c}H(3) 3.0 \\
p=.4\end{array}$ & $\begin{array}{c}F(3) .9 \\
p=.4\end{array}$ & $2.4(.7)$ & $2.5(.6)$ & $2.7(.5)$ & $2.4(.6)$ \\
\hline
\end{tabular}

\begin{tabular}{lccccccccc} 
& $\begin{array}{c}\text { Kruskal- } \\
\text { Wallis } \\
\chi^{2}\end{array}$ & $Y e s \%$ & No $\%$ & $Y e s \%$ & No $\%$ & $Y e s \%$ & No $\%$ & $Y e s \%$ & No $\%$ \\
\cline { 2 - 7 } & $n(\%)$ & $n(\%)$ & $n(\%)$ & $n(\%)$ & $n(\%)$ & $n(\%)$ & $n(\%)$ & $n(\%)$ \\
\hline $\begin{array}{l}\text { Previous } \\
\text { Births }\end{array}$ & $\begin{array}{c}H(3) 3.6 \\
p=.3\end{array}$ & $2(22)$ & $7(78)$ & $13(54)$ & $11(56)$ & $31(55)$ & $25(45)$ & $6(46)$ & $7(54)$ \\
\hline $\begin{array}{l}\text { H/O } \\
\text { Traumatic } \\
\text { Birth }\end{array}$ & $\begin{array}{c}H(3) 1.1 \\
p=.8\end{array}$ & $1(11)$ & $8(89)$ & $2(8)$ & $22(92)$ & $12(21)$ & $44(79)$ & $2(15)$ & $11(85)$ \\
\hline $\begin{array}{l}\text { C-Section } \\
\text { Scheduled }\end{array}$ & $\begin{array}{c}H(3) 3.4 \\
p=.3\end{array}$ & $9(100)$ & 0 & $23(96)$ & $1(4)$ & $56(100)$ & 0 & $11(85)$ & $2(15)$ \\
\hline
\end{tabular}

Note. ANOVA and Kruskal-Wallis Tests: alpha $=.05$.

Note. Means across rows that share a common superscript are not significantly different from each other (Tukey's HSD, $\mathrm{p}<0.05$ ).

a Annual Income, Annual Household Income, and Education are the means of the responses for those questions on the demographic questionnaire. Example: Education $=4.2$ is between "Some college" response 4 and "Graduated college" response 5 . See Table 3. 
Table 8

Stage 2 Anxiety Variables and their Association with the K-means Clusters

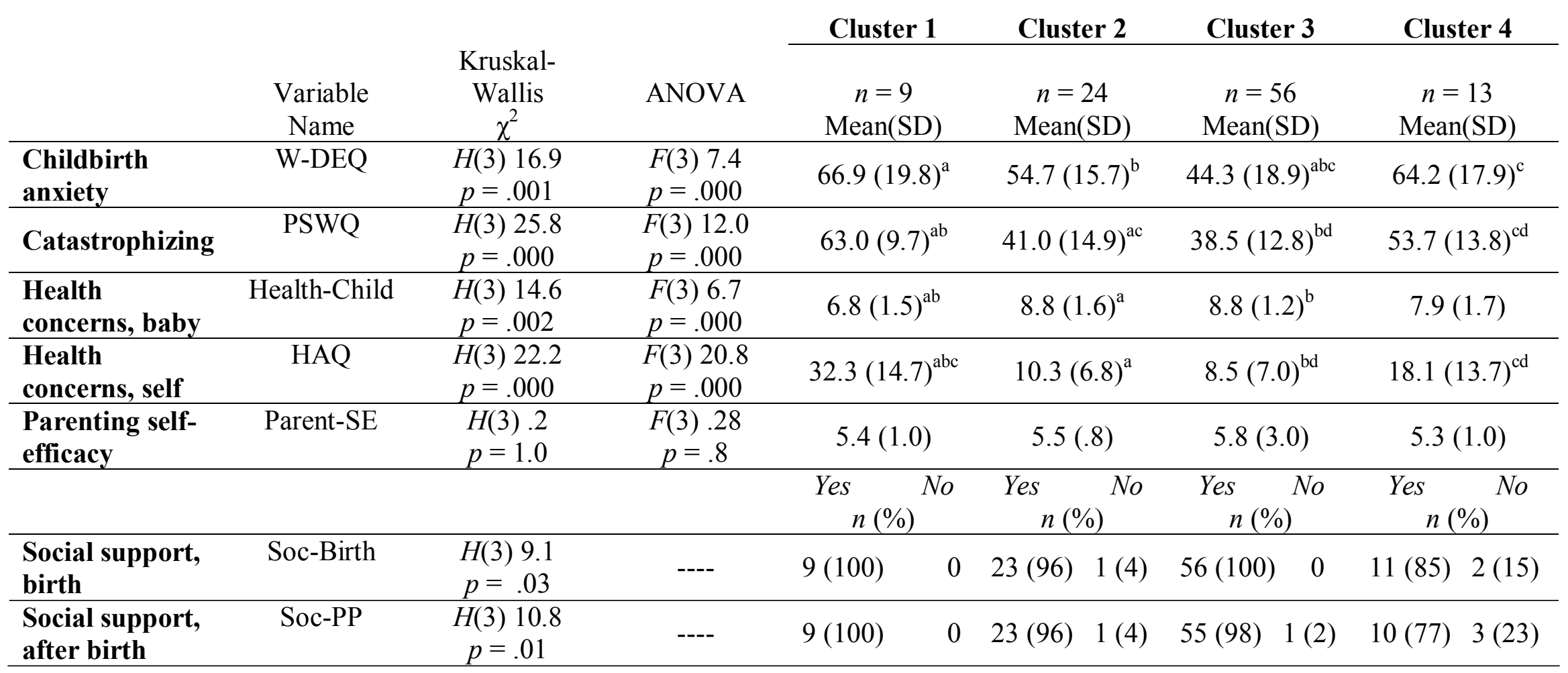

Note. ANOVA and Kruskal-Wallis Tests: alpha $=.05$.

Note. Means across rows that share a common superscript differ significantly at $p<.05$, using a Tukey's test. 
Table 9

K-means Four Clusters and Associated Significant Variables

\begin{tabular}{|c|c|c|c|c|c|c|}
\hline & Range & $\begin{array}{l}\text { Clinical } \\
\text { Cutoffs }\end{array}$ & $\begin{array}{c}\text { Cluster } 1 \\
\mathrm{n}=9 \\
\text { Mean }\end{array}$ & $\begin{array}{c}\text { Cluster } 2 \\
\mathrm{n}=23 \\
\text { Mean }\end{array}$ & $\begin{array}{c}\text { Cluster } 3 \\
\mathrm{n}=56 \\
\text { Mean } \\
\end{array}$ & $\begin{array}{c}\text { Cluster } 4 \\
n=13 \\
\text { Mean }\end{array}$ \\
\hline $\mathrm{ASI}^{\mathrm{a}}$ & $18-90$ & Higher levels ${ }^{b}$ & 50 & 27 & 23 & 38 \\
\hline FPQ-III $^{\mathrm{a}}$ & $30-150$ & Higher levels ${ }^{b}$ & 94 & 80 & 44 & 58 \\
\hline CES-D ${ }^{\mathrm{a}}$ & $0-60$ & $\begin{array}{l}\text { Mild 16-27 } \\
\text { Major }>27\end{array}$ & 32 & 10 & 10 & 32 \\
\hline CB-SE ${ }^{a}$ & $1-5$ & Higher levels $^{\mathrm{b}}$ & 3 & 3 & 2 & 2 \\
\hline W-DEQ & $33-165$ & $\begin{array}{c}\text { High }<85 \\
\text { Intense }<100\end{array}$ & 67 & 55 & 44 & 64 \\
\hline PSWQ & $16-80$ & Cut score $=57$ & 63 & 41 & 39 & 54 \\
\hline Health-Child & $5-10$ & Higher levels $^{\mathrm{b}}$ & 7 & 9 & 9 & 8 \\
\hline \multirow[t]{3}{*}{ HAQ } & $0-63$ & Higher levels ${ }^{\mathrm{b}}$ & 32 & 10 & 9 & 18 \\
\hline & & & yes & yes & yes & yes \\
\hline & & & $\%$ & $\%$ & $\%$ & $\%$ \\
\hline Soc-Birth & yes/no & & 100 & 96 & 100 & 85 \\
\hline Soc-PP & yes/no & & 100 & 96 & 98 & 77 \\
\hline
\end{tabular}

Highest

$\square 3^{\text {rd }}$

$\square 2^{\text {nd }}$

$\square$ Lowest

a The clinical measure scores, not the $z$-scores, are shown for these assessments.

${ }^{\mathrm{b}}$ Higher levels indicate more problems or psychological pathologies.

Note. All means were rounded to the nearest integer.

Note. The relationships (i.e., Highest, $2^{\text {nd }}$ ) were determined by comparing the individual cluster means. The shades are in numerical order of the scores for the individual variables. Clusters with means common with other clusters are graded in relation to the Lowest mean for the variable, except when the common means were the Highest means. 
Figure 1

K-Means Clusters of Prenatal Anxiety Related Components

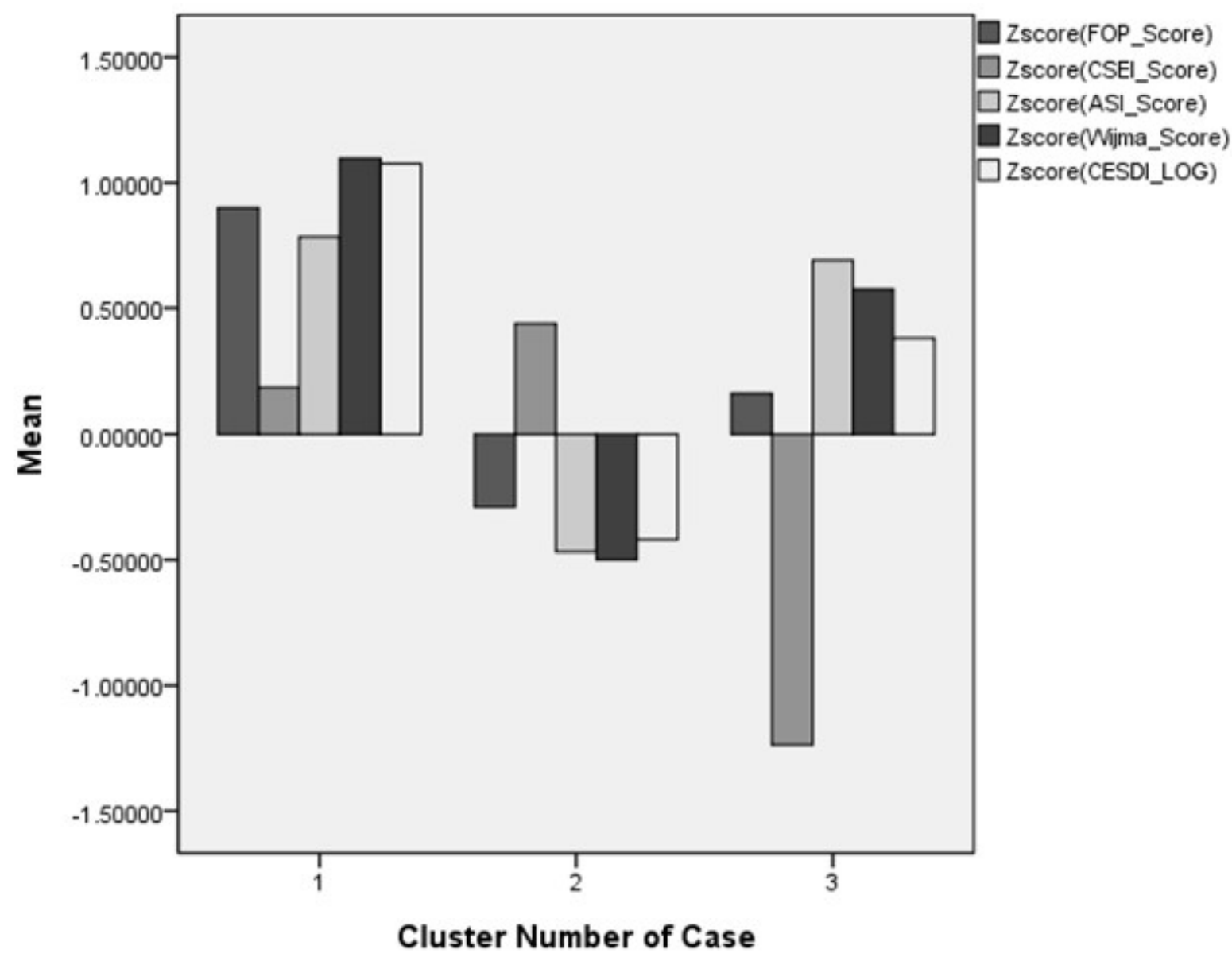

Note: Fear of Pain (FOP_Score), Childbirth Self-efficacy Index (CSEI_Score), Anxiety

Sensitivity Index (ASI_Score), Wijma Delivery and Expectancy Questionnaire A

(Wijma_Score), Center for Epidemiological Studies Depression Scale (CESDI_LOG)

Note: Higher scores on the FOP_Score, ASI_Score, Wijma_Score, and CESDI_LOG indicate higher symptom elevations. A higher score on CSEI_Score indicates better self-efficacy. 
Figure 2

\section{Participation Flow Chart}

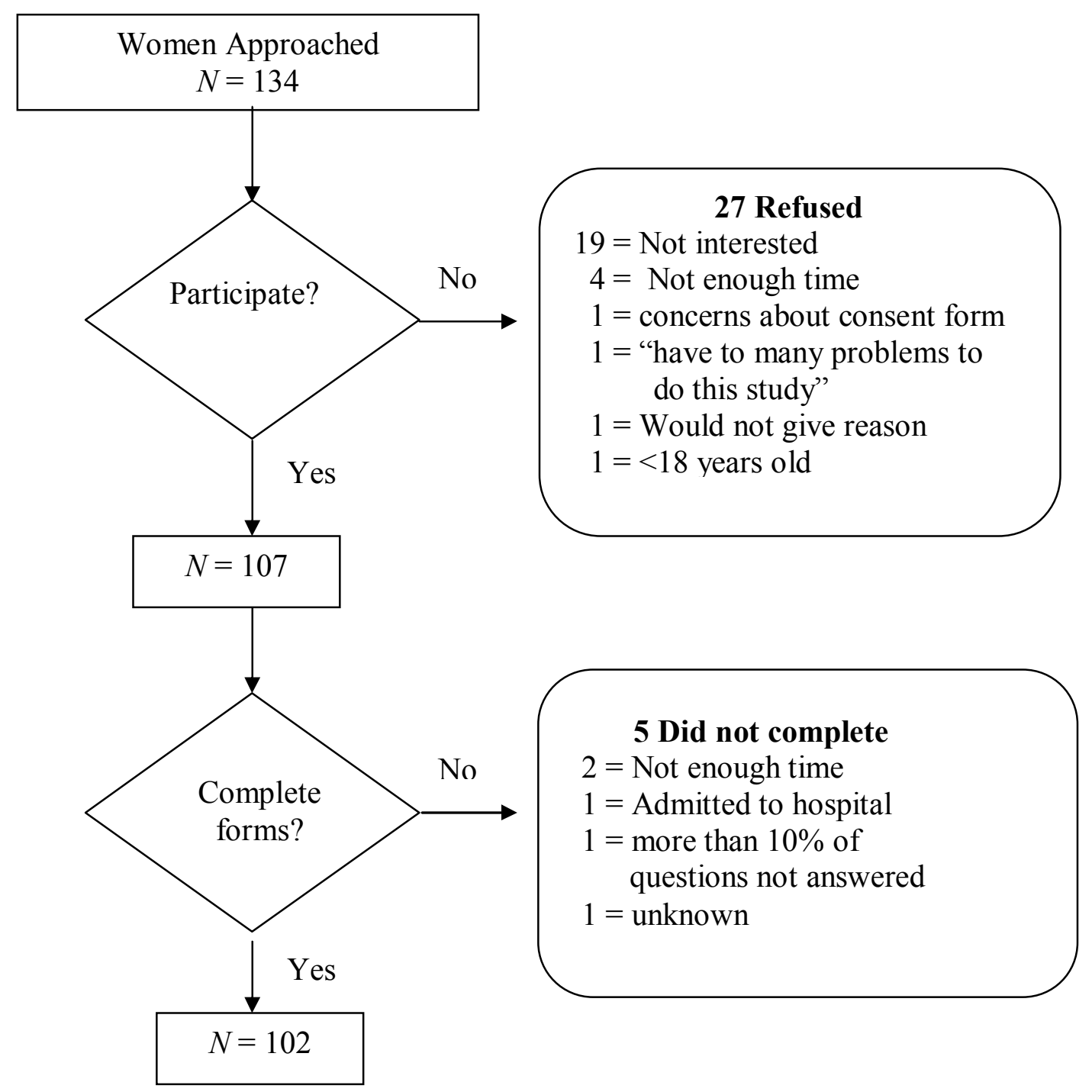


Figure 3

Ward's Method Cluster Analysis: Dendrogram and Scree Plot

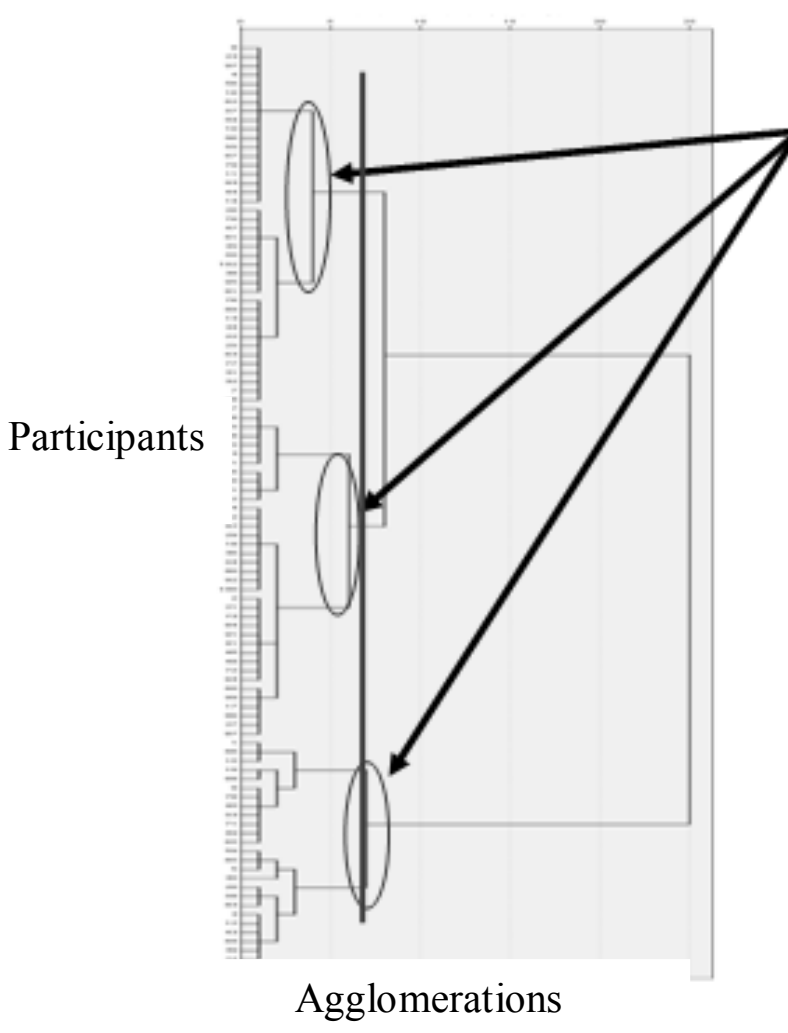

3-Cluster

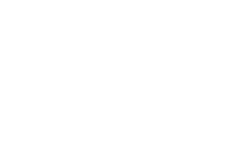

4-Cluster

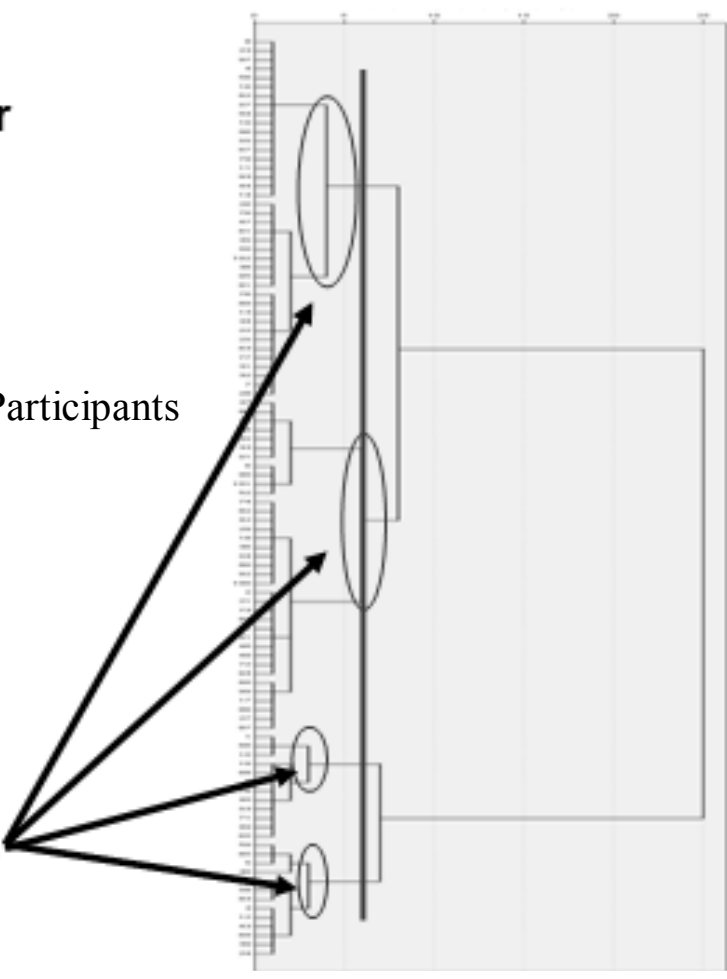

Agglomerations

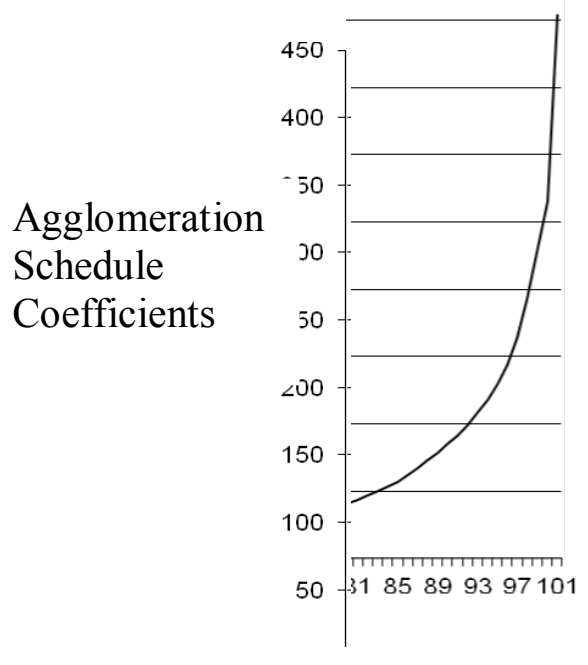

Participants

(Last 20) 
Figure 4

Graphs of the Ward's Method Three-and Four-Cluster Solutions
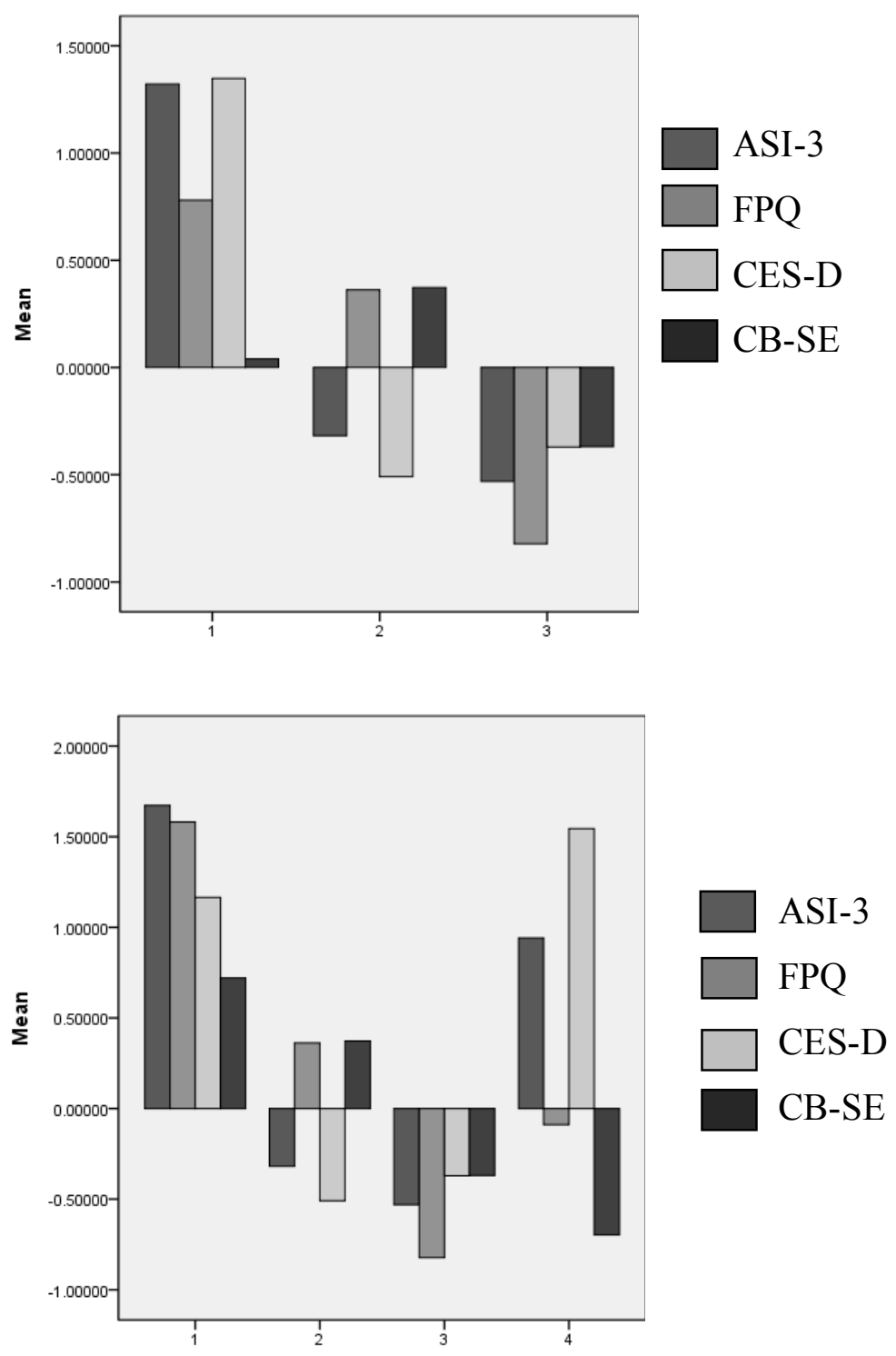

Note. Higher levels, above the median, indicate more problems or psychological pathologies. 
Figure 5

$K$-means Four-Cluster Solution

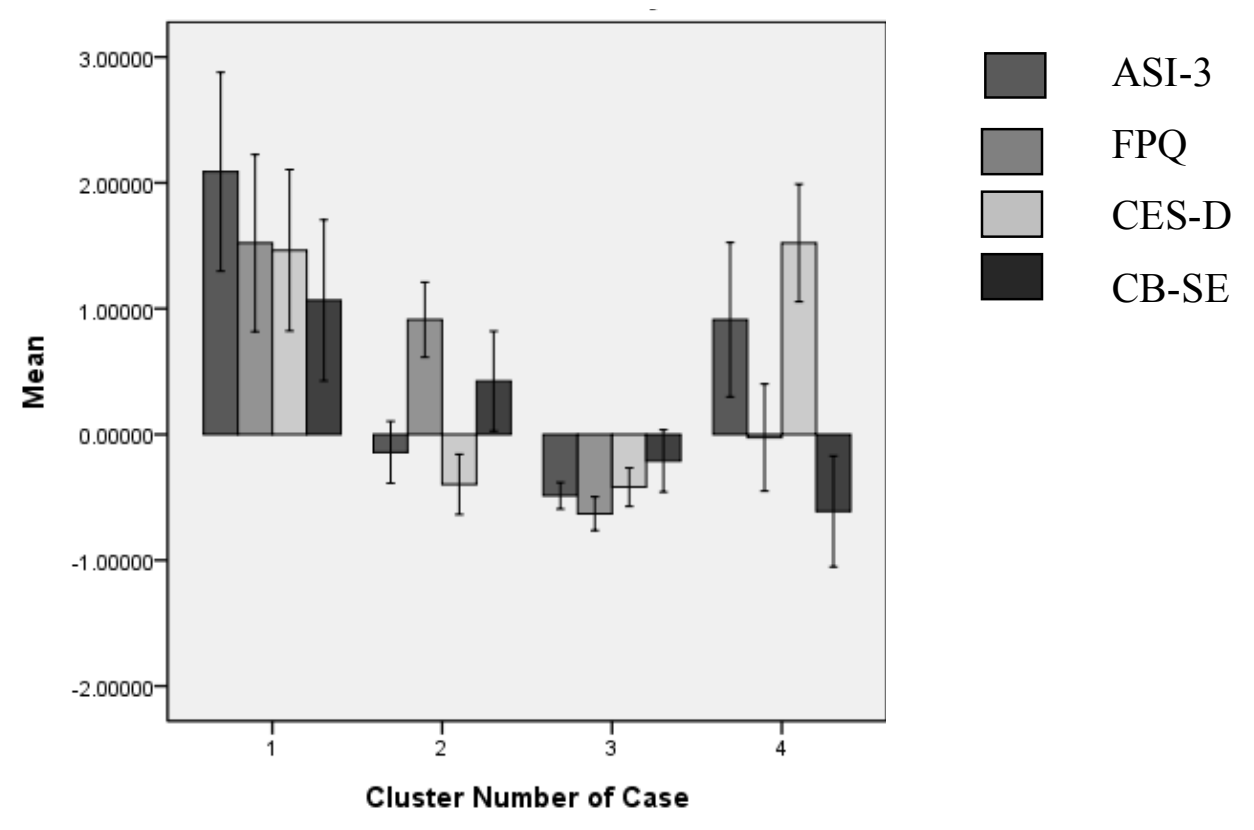

Note. Higher levels, above the median, indicate more problems or psychological pathologies. 
This document was created with Win2PDF available at http://www.win2pdf.com. The unregistered version of Win2PDF is for evaluation or non-commercial use only. This page will not be added after purchasing Win2PDF. 